\title{
Advanced generation NIOSH automatically deployable rollover protective structure (AutoROPS)
}

Khaled Ali Alkhaledi

West Virginia University

Follow this and additional works at: https://researchrepository.wvu.edu/etd

\section{Recommended Citation}

Alkhaledi, Khaled Ali, "Advanced generation NIOSH automatically deployable rollover protective structure (AutoROPS)" (2002). Graduate Theses, Dissertations, and Problem Reports. 1248.

https://researchrepository.wvu.edu/etd/1248

This Thesis is protected by copyright and/or related rights. It has been brought to you by the The Research Repository @ WVU with permission from the rights-holder(s). You are free to use this Thesis in any way that is permitted by the copyright and related rights legislation that applies to your use. For other uses you must obtain permission from the rights-holder(s) directly, unless additional rights are indicated by a Creative Commons license in the record and/ or on the work itself. This Thesis has been accepted for inclusion in WVU Graduate Theses, Dissertations, and Problem Reports collection by an authorized administrator of The Research Repository @ WVU. For more information, please contact researchrepository@mail.wvu.edu. 
Advanced Generation NIOSH Automatically deployable Rollover Protective Structure (AutoROPS)

Khaled Alkhaledi

\begin{abstract}
A Thesis Submitted to the
College of Engineering and Mineral Resources

at West Virginia University

In Partial fulfillment of the Requirement

for the degree of

Masters of Science

In

Mechanical Engineering
\end{abstract}

Kenneth H. Means, Ph.D., Chair

E.A. McKenzie, Jr., Ph.D

James Smith, Ph.D

Morgantown, West Virginia

2002

Keywords: Rollover protective Structure

Copyright 2002 Khaled Alkhaledi 


\section{ABSTRACT \\ Advanced Generation NIOSH Automatically deployable Rollover Protective Structure (AutoROPS)}

\section{Khaled Alkhaledi}

Safety is one of the most important aspects in every society. It is a major issue in the agricultural industry. Agriculture continues today as one of the most hazardous industries in the U.S. with comparatively high fatality rates. Despite the fact that a highly effective safe guard is available in the form of a rollover protective structure (ROPS), hundreds of farmers die each year due to tractor rollovers. The use of ROPS on farm tractors has attributed to saving numerous lives, and has prevented many human injuries over the years.

Many tractors come with the ROPS factory installed; however, many ROPS were apparently removed by the tractor's owners due to the lack of the ROPS having a proper housing area on the tractor. For example, while working in an orchard, an improper housing area may cause the ROPS to damage produce located on low hanging tree branches. The prominence of tractor rollover incidents resulting in farm work related deaths, and the effectiveness of the ROPS in reducing such events, has resulted in the collaboration between The National Institute for Occupational Safety and Health (NIOSH) and West Virginia University's Mechanical and Aerospace Engineering Department. The goal of this collaboration is to increase the level of ROPS safety and effectiveness.

Engineering studies and tests have been done on The NIOSH AutoROPS based of SAE J-2194 Static Load Standard. The first purpose of this work is to study the base model for the second generation NIOSH AutoROPS based on J-2194 standard tests to insure that the base will absorb the impact loads during farm tractor's roll over. The second purpose is to design a new generation of the AutoROPS that is smaller in size and more cost effective. Using a computer-aided design program (ANSYS - professional version), the tests and simulations were completed. The $\mathrm{NIOSH}$ AutoROPS designs were structurally analyzed the to insure that they comply with the SAE J2194 standard. The results proved that those generations did absorb all loads applied in sequence on the AutoROPS and thus satisfied the SAE J-2194 standard requirements. 


\section{ACKNOWLEDGMENTS}

I would like to take this opportunity to thank the many people whom have made this thesis' work possible. First, I would like to thank my whole family for their help, caring, and support throughout my entire masters degree program. Also I would like to show my gratitude and my thanks to my advisor and Chairperson, Dr. Kenneth Means. Thank you for your guidance, help, wisdom, and never ending patience throughout all of the hard and difficult times of this research. I would also like to thank Dr. James Smith for his assistance in sharing his ideas with me about this research.

Secondly, I would like to thank the following people from the National Institute of Occupational Safety and Health $(\mathrm{NIOSH})$, located in Morgantown, WV: Dr. Tony McKenzie, thank you for your support and input during the difficult time of this research, and for all the life listens that you tough me. Dr. John Etherton, thank you for your help and support during this masters studies and for your help in allowing me to use the professional version of ANSYS available at $\mathrm{NIOSH}$. James Harris, thank you for all the great help you offered during the 
difficult time of this research, and for your valuable advice and great direction in solving a lot of experimental problems in this thesis, and for helping me with ANSYS. Captain James Spahr, thank you for your help with all of the administration needs and especially for allowing me to have access to the $\mathrm{NIOSH}$ building to run some experimental test during the weekend. Finally, I would like to thank Thomas Bobich for staying late after 6 o'clock and giving me extra time to work on my thesis everyday.

Last but not least, my thanks also go to Eric Saunders for helping me to use the computer aided design program (ANSYS). Your great knowledge in the use of this program was very important in making this study possible. I would also like to thank Dr. Gary Morris for all of your help and support during my Masters program period. 


\section{TABLE OF CONTENTS}

Abstract

Acknowledgments

Table of Contents

List of Figures

List of Tables

Chapter 1: Introduction and Literature.

1.1: Introductory Remarks and Background 1

1.2: Review of Relevant Literature 5

1.3: Thesis Objective 9

Chapter 2: Society of Automotive Engineering (SAE) Standard

for ROPS J-2194.

2.1: Introduction

2.2 Energy Criteria 10

2.3 Static Tests 11

2.3.1 First Longitudinal Loading 13

2.3.2 Side Transverse Loading 14

2.3.3 Second Longitudinal Loading 15

2.3.4 Vertical Loadings $\quad 15$

Chapter 3: Introduction to Finite Element Procedures

3.1 Introduction

3.2 The Principle of Virtual Displacements

3.3 Materials Properties

3.4 Material Nonlinearities and the Hardening Rules

3.5 Temperature Effect on Materials Under Impact

Test

3.6 Yield Criteria

3.7 Finite Element Mesh

25

3.8 Boundary Conditions

29

3.9 Solution Control

Chapter 4: Geometry for the NIOSH Second and Third Generation AutoROPS

4.1: NISOH Second Generation AutoROPS Base Analysis

4.2: NIOSH Third Generation AutoROPS 
Chapter 5: Second Generation Auto ROPS Base Analysis

5.1: Introduction

5.2: First Longitudinal Test

5.3: Vertical Crush Test

Chapter 6: Analytical Results for the NIOSH Third Generation AutoROPS.

6.1: Introduction

6.2: First Longitudinal Test

6.3: Vertical Crush test

6.4: Side Transverse Test

6.5: Second Longitudinal Test

Chapter 7: Redesigned Model for the NIOSH Third Generation AutoROPS

7.1: Introduction

55

7.2: Selecting Post Dimensions

7.3: First Longitudinal Test Results

7.4: Vertical Crush Test

7.5: Side Transverse Test

61

7.6: Second Longitudinal Test

Chapter 8: Comparable Experimental Results

8.1: Introduction

8.2: Data Comparison Between Analytical Studies Conducted on NIOSH Third Generation AutoROPS and Prototype One and Two Experimental Data 77

Chapter 9: Conclusion and Recommendations

9.1: Conclusion

9.1.1 General Safety Tips

82

9.2: Recommendation For Future Work

Appendix A: Stresses on the Base Bolts for Third Generation AutoROPS

Appendix B: Dimensions and Experimental Results for the First Generation AutoROPS 


\section{List of Figures:}

Figure 1.1: Factory ROPS Mounted on the Tractor 2

Figure 1.2: NIOSH First Generation Deployable AutoROPS 4

Figure 2.1: Typical Rear (Front) Load Application 14

Figure 2.2: Typical Side Load Application 14

Figure 2.3: Vertical Crush Application 16

Figure 2.4: Clearance Zone Occupancy 17

Figure 3.1: The Process of Finite Element Analysis $\quad 19$

Figure 3.2: HR 1018 Steel Stress-Strain Curve 21

Figure 3.3: The Fracture Appearance of Impact Specimens, Broken at Different Test Temperatures, of Steel

That undergoes a Ductile-to-Brittle Transition 23

Figure 3.4: Von Mises Yield Surface 24

Figure 3.5: Boundary Conditions for the Cantilever Beam 26

Figure 3.6: Free Mesh for the 62" (2X3) Post 26

Figure 3.7: Mapped Mesh for the Cantilever Beam Specimen (Finer Mesh) 27

Figure 3.8: Deflection for Free Mesh Post 28

Figure 3.9: Deflection for Finer Mapped Mesh Post 28

Figure 3.10: Mesh and Boundary Conditions for the Original $3^{\text {rd }}$ Gneration AutoROPS

Figure 4.1: General Sketch for the Second Generation Base 33 Figure 4.2: Top View for Bolts Numbers of Second Generation AutoROPS Base 33

Figure 4.3: Dimensions for the Second Generation Base $\quad 34$

Figure 4.4: General Overview of the Third Generation AutoROPS

36

Figure 4.5: Dimensions for the Third Generation AutoROPS (Main Model)

Figure 4.6: Dimensions for Third Generation Base

Figure 4.7: Base and Base Bolts Numbers for the Third Generation AutoROPS

Figure 4.8: Operator Clearance Zone Dimension Layout $\quad 40$

Figure 5.1: Prestress on the Base Bolts 43

Figure 5.2: The Maximum Stress in the Bolts for First Longitudinal Test

Figure 5.3: Side Transverse Test for the Second Generation AutoROPS 
Figure 5.4: Maximum Stress Found in Bolts 1 and 2 in the

Transverse test

Figure 6.1: Top View for the Maximum Deflection for First Longitudinal Test

Figure 6.2: Force vs. Deflection for the First Longitudinal Test

Figure 6.3: Vertical Crush Test Stress Results

Figure 6.4: Back View for Side Transverse Test

Figure 6.5: Force Deflection Curve for the Side Transverse Test

Figure 6.6: Top View of AutoROPS Deflection for the Second Longitudinal Test

Figure 6.7: Energy Under Force Deflection Curve for the Second Longitudinal Test

Figure 6.8: Maximum Stress in Bolt Number 3 for the First Longitudinal Test

Figure 6.9: Maximum Stress on Bolts Number 5 for Side Transverse Test

Figure 7.1: Dimensions for the Redesigned Third Generation AutoROPS

Figure 7.2: Overlap Dimensions for the Redesigned Third Generation AutoROPS

Figure 7.3: Tops View for the Redesigned First Longitudinal Test

Figure 7.4: Force Deflection Curve for the First Longitudinal Test

Figure 7.5: Deflection for the Vertical Crush test

Figure 7.6: Rear View for the Side Transverse Test

Figure 7.7: Force Deflection Curve for the Second Longitudinal Test

Figure 7.8: Top View of the Deflection for the Second Longitudinal Test

Figure 7.9: Force Deflection Curve for Second Longitudinal Test

Figure 8.1: Prototype 1, Rectangular Tubing Similar to the Third Generation AutoROPS Used to Build the CROPS 66

Figure 8.2: Longitudinal Load test, Force vs. Deflection Curve for Prototype 1

Figure 8.3: Energy Curve for First Longitudinal Test 
Figure 8.4: First Longitudinal Test, force vs. Deflection Curve for Prototype 2

Figure 8.5: First Longitudinal Test, Energy vs. Deflection Curve of Prototype 2

Figure 8.6: First Longitudinal Test Set Up for Prototype 270 Figure 8.7: The Deformed Shape for Prototype 2 After the First Longitudinal Load

Figure 8.8: Vertical Crush Test Set Up Prototype $2 \quad 72$

Figure 8.9: Transverse Test Set Up Prototype $2 \quad 74$

Figure 8.10: Transverse Load Test, Force vs. Deflection Curve for Prototype 2

75

Figure 8.11: Transverse Load Test, Energy vs. Deflection Curve for Prototype 2

75

Figure 8.12: Prototype 2 After Transverse Loading

76 


\section{List of Tables}

Table 2.1: Structural Testing Requirements for any ROPS Model

Table 4.1: Geometry and Identity of the Operator Clearance Zone

Table 8.1: Energy and Load Comparison Table for Experimental Prototypes and Third Generation AutoROPS 


\section{Chapter 1}

\section{$\underline{\text { Introduction and Literature }}$}

\subsection{Introductory Remarks and Background}

The agriculture Industry remains among one of the most hazardous occupational industries in the United States. Tractor rollover accidents are the largest cause of tractor related deaths. Each year more than 320 American farmers are killed in agricultural tractor rollover accidents. Those statistics show that the "it can't happen to me" syndrome doesn't hold water. Statistics for past 15 years showed that the number of people killed or injured in rollover accidents did grow. These deaths continue to occur despite the fact that ROPS has been commercially available on most tractors manufactured during the past 16 years. (See figure 1.1). The purpose of a ROPS is to provide the best protection for the tractor's operator in the event of an upset or rollover.

There are numerous tractors without a ROPS still in use. These tractors were either built before Oct. 25, 1976, the date that all tractors with more than 20 PTO horsepower were required to be equipped with a ROPS, or have had the protective structures removed. 


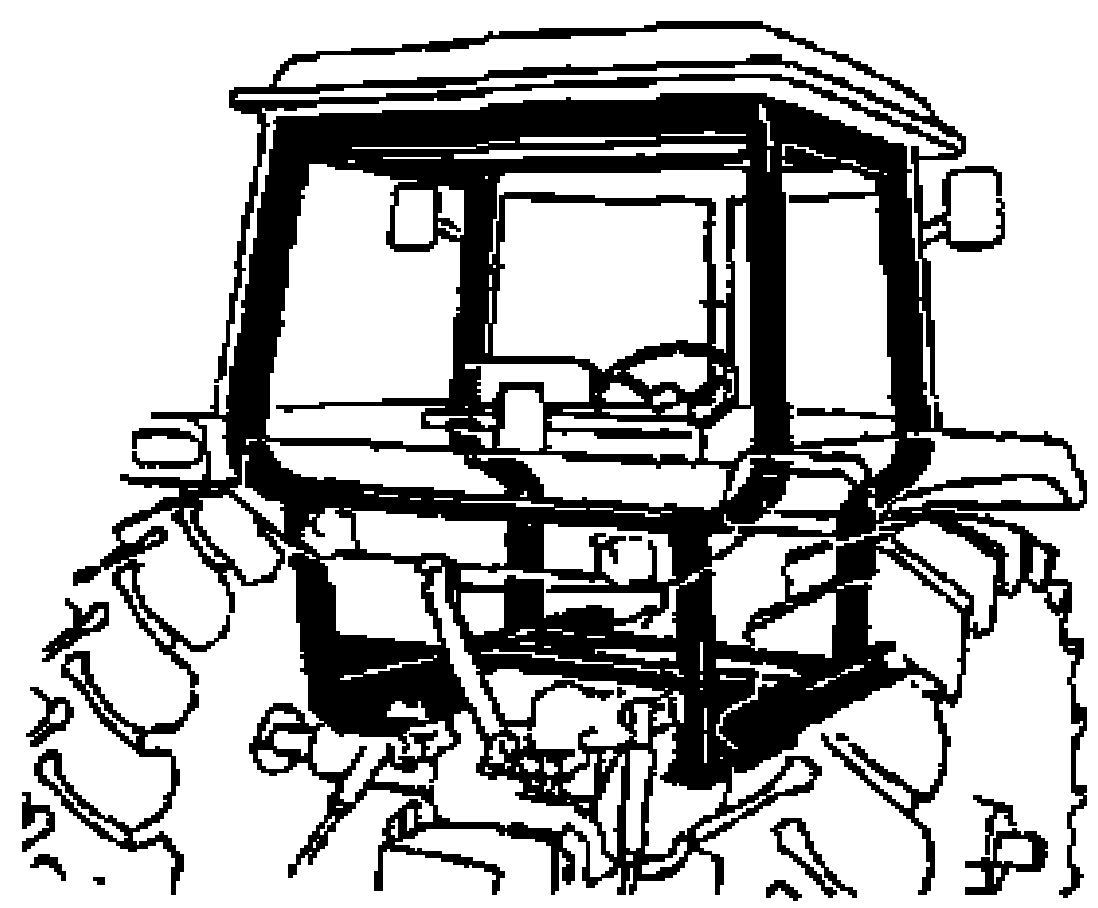

Figure 1.1: Factory ROPS Mounted on the Tractor.

These life saving structures are also available as retrofits for virtually every tractor manufactured. A ROPS retrofit for a tractor in the 20 to 30 PTO horsepower range can cost as little as $\$ 500$. All agricultural tractors built after Oct 25, 1976 must have a rollover protective structure if it is to be driven by an employee other than an immediate family member.

These deaths have continued to occur despite the implementation of ROPS in all new tractors being sold in today's market. The ROPS is designed to work in conjunction with the use of a seat belt. Some of these deaths are due to the removal of the ROPS 
from the tractor, and/or from the driver not using a seat belt. In addition to having a certified ROPS, a seat belt is a necessity. Without a seat belt, the operator may not remain in the safety crush zone of the ROPS.

The question is why would someone remove the ROPS, which could save his life? One answer would be because the size of the ROPS housing area is too big for some farmers. These farmers want the convenience of driving their tractor conveniently below low hanging tree limbs without knocking some crops out of the trees. A need for a more convenient ROPS in order to fit the farmer's requirements becomes more important then ever. This is where the idea of the AutoROPS was born. The AutoROPS will perform the same task of a conventional ROPS, but instead of having the post as one solid part as with the ROPS, the AutoROPS will have the post as two telescoping parts, it has one part located inside of the other to meet the farmer's need of low clearance. The deployable part of the AutoROPS will only deploy in the event of tractor rollover to protect the operator from death or severe injury (See figures 1.2).

West Virginia University and NIOSH have been researching and testing ROPS since 1995. The present goal is to come up with a safe 
design, which can be marketable at the same time. The early tests on $\mathrm{NIOSH}$ first generation AutoROPS were conducted according to the SAE J-2194 ROPS Standard (from this point, NIOSH AutoROPS will be preferred as AutoROPS for simplicity and readability. Those deployable AutoROPS were designed and built for use on the Ford New Holland 4600 series Tractor. The tests at this point were aimed to see if the internal mechanisms such as the springs, pistons, and materials could withstand rollover forces. The tests were also used to determine if the rate of deployment was sufficiently fast, and finally to confirm that the clearance zone not compressed and would lead to increase the safety of the operator.
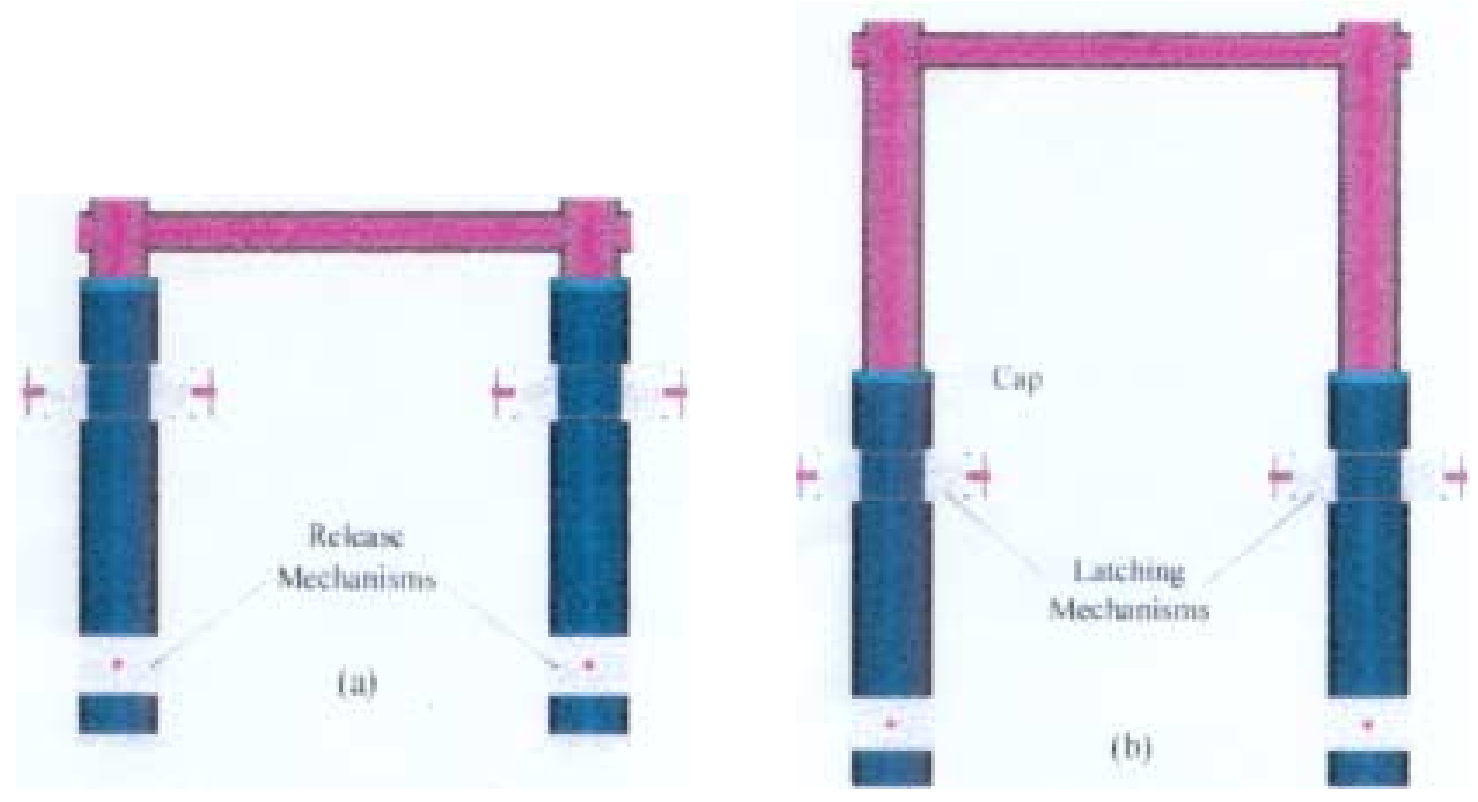

Figure 1.2: NIOSH First Generation Deployable AutoROPS
(a) Before Deployment.
(b) After Deployment. 
The results of those tests came out positive showing that the internal mechanisms and the deployment bars worked and the chosen material did withstand the applied load.

None of the tests were focused on the base of the second generation AutoROPS. The design of the base is considered to be one of the most important areas of study. The structure of the base of the AutoROPS is major concern. The failure of the base in a rollover accident can lead to injuries and even death; therefore, should take place to insure the safety of the whole device. The initial base design was very heavy and difficult to mount on the tractor axle. Making this design more acceptable by reducing the size and the cost is needed.

\subsection{Review of Relevant Literature}

A literature search was conducted to determine if any research has been done on the base of the second generation AutoROPS. No research was found during this search. Most of the research was related to designing other parts of ROPS and testing them. The National Swedish Testing Institute for Agricultural Machinery in 1954 had done some research on tractor safety. These studies focused on an anti-crush protection structure on a farm tractor. The tests conducted were actual rollover tests. The nature of these tests was 
fairly expensive, inaccurate and non-reproducible. This was due to variations in how the vehicles happen to impact the ground. There were no pre-set standards for the tests. One of the main goals of the tests was to determine the effect of the rollover on the ROPS (Staab, 1971).

Tractor safety studies in United States were also investigating tractor rollovers during the 60 's, 70 s and the 80 's and are currently still being conducted. The major concerns and focus is in rural areas. An answer is needed for the question of "what can be done to improve a tractor's safety?"

$\mathrm{NIOSH}$ and Department of Mechanical \& Aerospace Engineering at West Virginia University (WVU) have done much work toward the improvement of the Rollover Protection structure. They developed a deployable AutoROPS, which could remain in the retracted position to aid in housing space for the tractor and the ROPS. This AutoROPS was tested for rapid deployment and also against the SAE J-2194 Static load standard. The results of testing first generation AutoROPS were encouraging. The design did not fail due to any impact and the clearance zone remained untouched. That test; however, did not focus on the base attachment and did not include any model for it. 
Finite Element Analysis (FEA) for the load applied on the AutoROPS was conducted by Adam Gillispie of West Virginia University and focused on the second generations AutoROPS. The study focused on the stresses applied on the posts and the post deflection. Four directions of static loading were applied to the structure to satisfy SAE standard requirements. For the series static loading of tests, the raised structure was found to maintain a protective clearance zone after all loads were applied. In this finite element Model, spring elements were used to model the surface-to-surface contact in the sliding-fit joint. The analysis indicated that there was no plastic bending at the sliding-fit joint. The maximum bending stress in the structure was found to be in the lowest 10 " of the total height if the outside fixed post. The study also showed the structure is overly stiff and should be redesigned to increase its ability to absorb groundimpact energy.

The costly venture of actual overturn vehicles to validate ROPS performance has led to some researchers finding alternative methods of studying the impact tests on the factory ROPS. A study written by Harris (1995), used a Fortran code Program by Cobb (1976) to study the two-dimensional modeling effects of tractor mass on the force, and 
energy absorbed by the factory ROPS. Furthermore, an ANSYS ${ }^{\mathrm{TM}}$ Nonlinear FEM technique was used in this study to simulate both the static and dynamic loading tests. Steven Howard of West Virginia University conducted dynamic test on the performance of the mechanisms of the AutoROPS. That study was aimed at the latching mechanisms and rubber parts between the deployable posts to insure that they will handle any impacts. The device is a spring, telescoping structure that releases after a rollover signal is set to pyrotechnic squibs in an internal piston. The structure extends until the piston impacts elastometric rings and latches at the top position. In lab tests the two-post structure consistently deployed in less than 0.3 seconds and latched securely.

A study by Clay Brewer, of West Virginia University, was done on a factory version of the ROPS. The tests were aimed at the posts and the energy absorbed by the structure. The posts were made out of steel and were modeled by Finite Element Analysis. The study showed that the posts will meet the energy requirement and that the occupant clearance zone remained untouched by the deformed ROPS under the SAE J-2194 standard loads. 


\subsection{Thesis Objective}

Although extensive engineering studies have been done on several parts of the second generation AutoROPS, such as the posts, locking pins, rubber rings and deployment time, the base was not extensively studied using FEA. To complete the work on second generation AutoROPS, one part of this thesis will be focused on the base design and its criteria. The first objective in this study is to develop a finite element analysis for second generation AutoROPS base model. The second objective is to design a more acceptable deployable AutoROPS that has smaller size and yet the same efficiency as $\mathrm{NIOSH}$ first and second generations AutoROPS for energy absorption, and also to lower the cost and simplify construction so it will be easy to manufacture.

This study will provide analysis and details in what will happen during the rollover of the tractor in order to get enough data to calculate and evaluate the design criteria. It is important to include all aspects of the AutoROPS such as failure criteria, material type, weight, and cost (using computer-aided design ANSYS). The analysis will include running an efficient number of tests and simulations to develop a safe, light, and cost efficient design. 


\section{Chapter 2}

\section{Society of Automotive Engineering (SAE) Standard for ROPS J-2194}

\section{1: Introduction}

SAE sets the design standards and technical requirements for farm machinery to insure design safety. In this thesis SAE J-2194, is the static test standard, which has been applied to the AutoROPS (AutoROPS must come under the same standard as the ROPS). There are two standards sets for two different kinds of tests: static testing and dynamic testing. The major interest in this study is to meet the standard static test requirement. ROPS must follow the guideline for the static load testing in order to be approved for commercial use. This chapter will discuss and list the energy criteria and the guidelines for static testing standards.

\subsection{Energy Criteria}

The energy criterion is considered to be one of the most important requirements to be met during any static load testing on the ROPS. Energy absorbed by a ROPS during a rollover is related to the mass of the tractor. SAE J-2194 is the standard for a tractor reference 
mass of $8220 \mathrm{lb}$. This reference mass is the maximum mass listed for a Ford 4600 in the Nebraska tractor test (Gillispie).

Static test loads have four ways to be applied on the ROPS. ROPS must be able to withstand the four different series of loading, which are pointed in four different directions and magnitudes. And they must be applied in sequence. The ROPS must meet the requirement of $\mathrm{J}-2192$, and fulfill the performance requirement of this SAE standard.

The ROPS base shall be secured to the Tractor axle. This is to be done so that the member connecting the assembly and the lower plate do not deflect significantly in relation to the protective structure under load. The assembly shall not receive any support under load other than what is due to an initial attachment (ASAE standard). The loads are to be applied to the ROPS according to J-2194 in the following manner:

\subsection{Static Tests}

The four tests should be applied on the ROPS in sequence, and they must be properly applied to the structure. During the sequence of tests, the maximum and permanent deflection of ROPS shall be measured and recorded. The three horizontal loading tests are applied 
from the rear, front, and side. This is done in conjunction with the vertical load (see table 2.1).

Table 2.1: Structural Testing Requirements for any ROPS Model

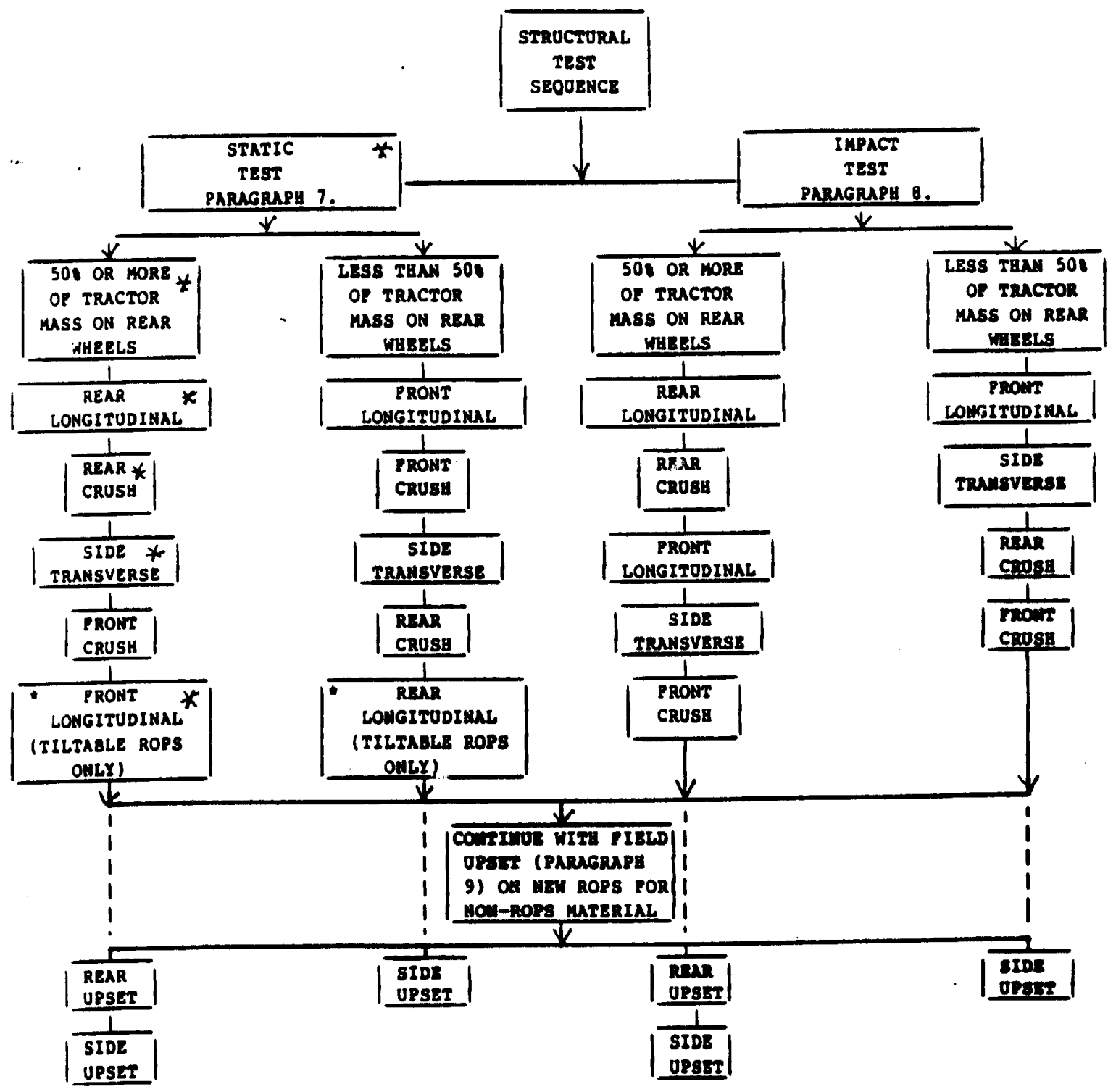

A stiff load application device, normal to the direction of load application, shall distribute the loads applied to the ROPS uniformly. 
The rate of deflection should not be any more than $5 \mathrm{~mm} / \mathrm{s}$ (ASAE standard 1997).

\subsubsection{First Longitudinal Loading}

The load shall be applied horizontally and parallel to the longitudinal median plane of the tractor. If the load is applied from the rear, the longitudinal load and the lateral load shall be applied to different sides of the ROPS. The load shall be applied to the upper most transverse structure that would touch the ground first in case of an overturn. It should also be stated that the loading location is at onesixth of the width along the top of the ROPS and inward from the outside corner (see figure 2.1). The required energy for this impact is:

$$
E=1.4 m_{t} \text { (Joules) }
$$

Where: $\mathbf{m}_{\mathbf{t}}$ is the mass of the tractor.

The mass for this case is $3,278 \mathrm{~kg}$ (according to Nebraska tractor test 1223), which results in $E=46,188$ in-lb ( 1 Joule $=8.851$ in-Lb). 


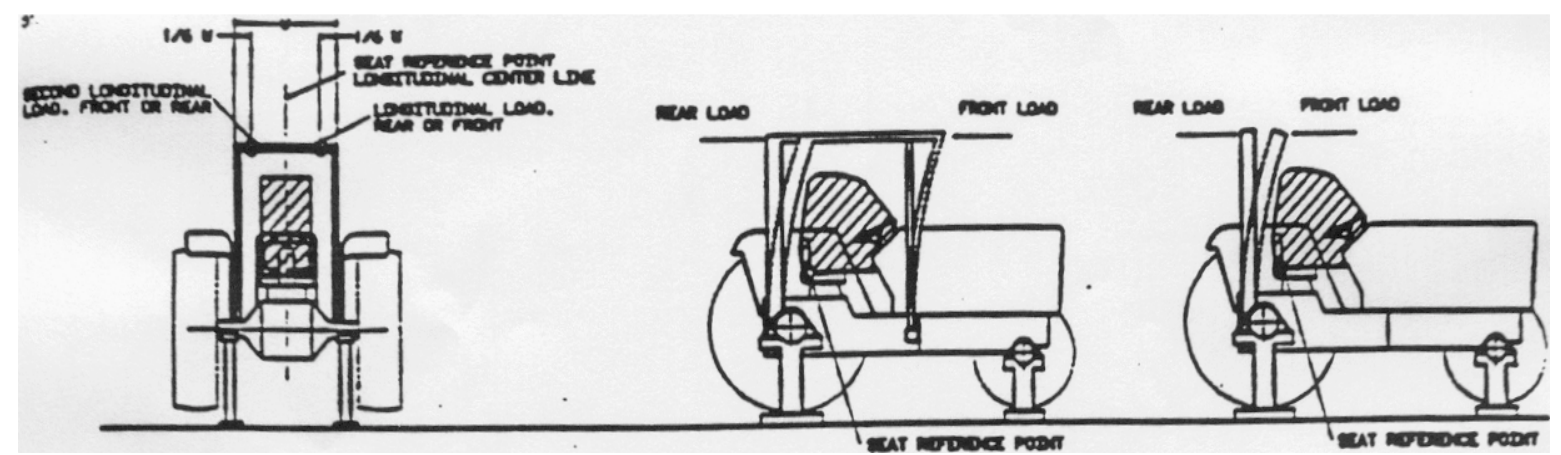

Figure 2.1: Typical Rear (Front) Load Application

\subsubsection{Side Transverse Loading}

The second load to be applied on the ROPS is the side transverse load. This is similar to the first longitudinal load but is applied from a different direction (see figure 2.2). The point of loading should be the one, which will touch the ground in case of sideways overturn. The load was applied until the required energy was met. The required energy was calculated as following:

$E=1.75 m_{t}$ (Joules)

Which for this case resulted in $\mathbf{5 7 , 7 3 5}$ in-lbs ( 1 Joule $=8.851$ in-Lb).



Figure2.2: Typical Side Load Application 


\subsubsection{Second Longitudinal Loading}

The load shall be applied in the opposite direction to, and at the corner furthest from the point of application of the first longitudinal load. The required energy for this test from:

$E=0.35 m_{t}$ (Joules)

Which resulted in E being 11,547 in-lbs ( 1 Joule $=8.851 \mathrm{in}-\mathrm{Lb}$ ).

\subsubsection{Vertical Loadings}

The beam shall be positioned across the rear uppermost structural member and the resultant crushing force shall be located in the vertical reference plane. The force $F_{f}=20 m_{t}(N)$ shall be applied. This will coincide with the plane joining the upper parts of the ROPS along with that part of the rear of the tractor that is capable of supporting the vehicle mass when overturned (see figure 2.3).

The force shall be applied over that point of the ROPS, which would support the rear of the tractor when completely overturned, and the full force is applied. The force of $16,700 \mathrm{lb}$ must be applied in this vertical crush test. 


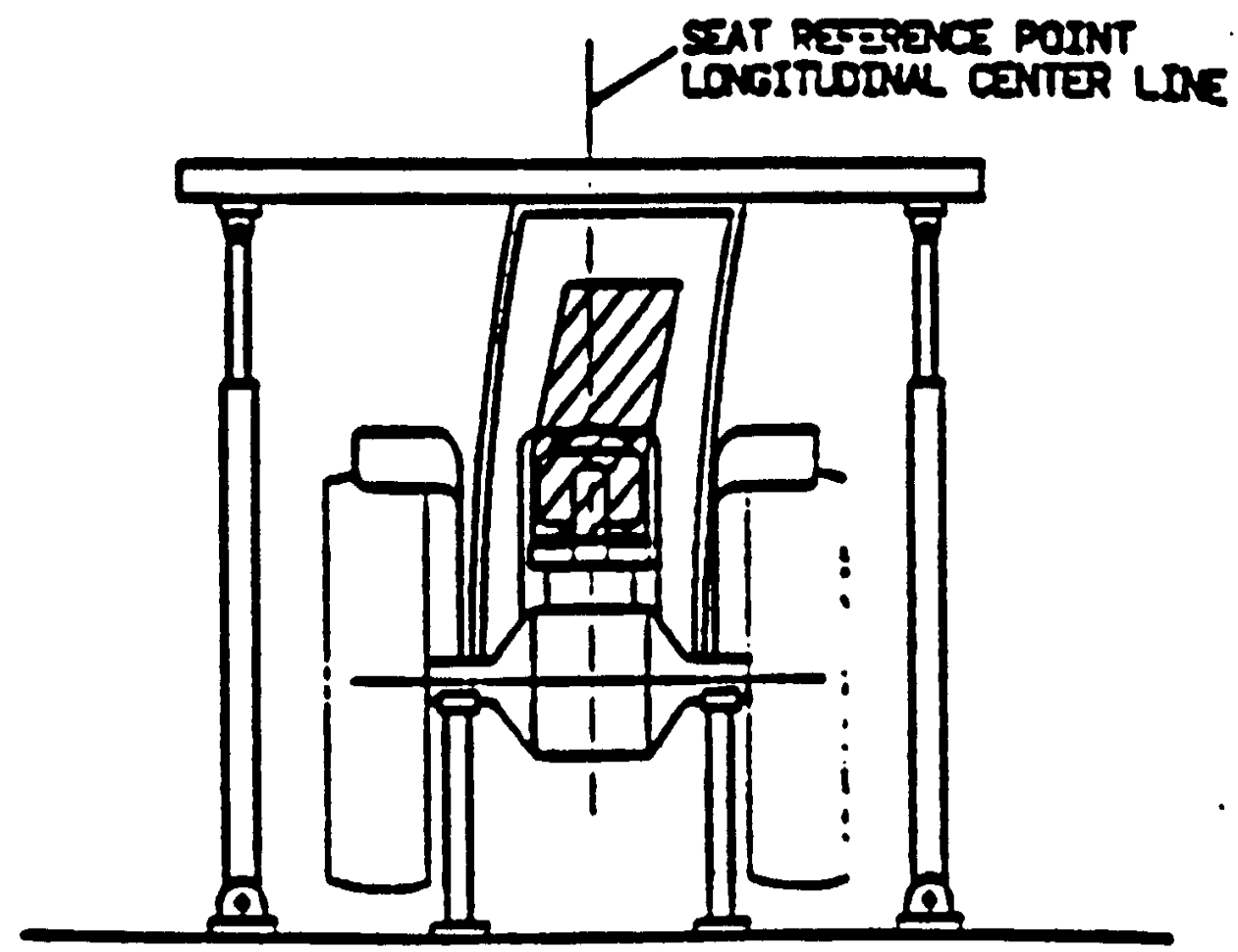

Figure 2.3: Vertical Crush Application

After applying the previous loads, failure can be measured by how the ROPS deformation intrudes into the occupant clearance zone. Success is measured by the ability of the ROPS to absorb the required amount of energy without intrusion in to the clearance zone. The determination of the occupant clearance zone is an important process. Each tractor has its own unique clearance zone, and each zone has its own reference point. This reference point can be determined by the ISO 3462 standard, which calls for the seat to be in the uppermost inclined position (see figure 2.4). Once the seat position is known, the clearance zone can be easily built and modeled. 

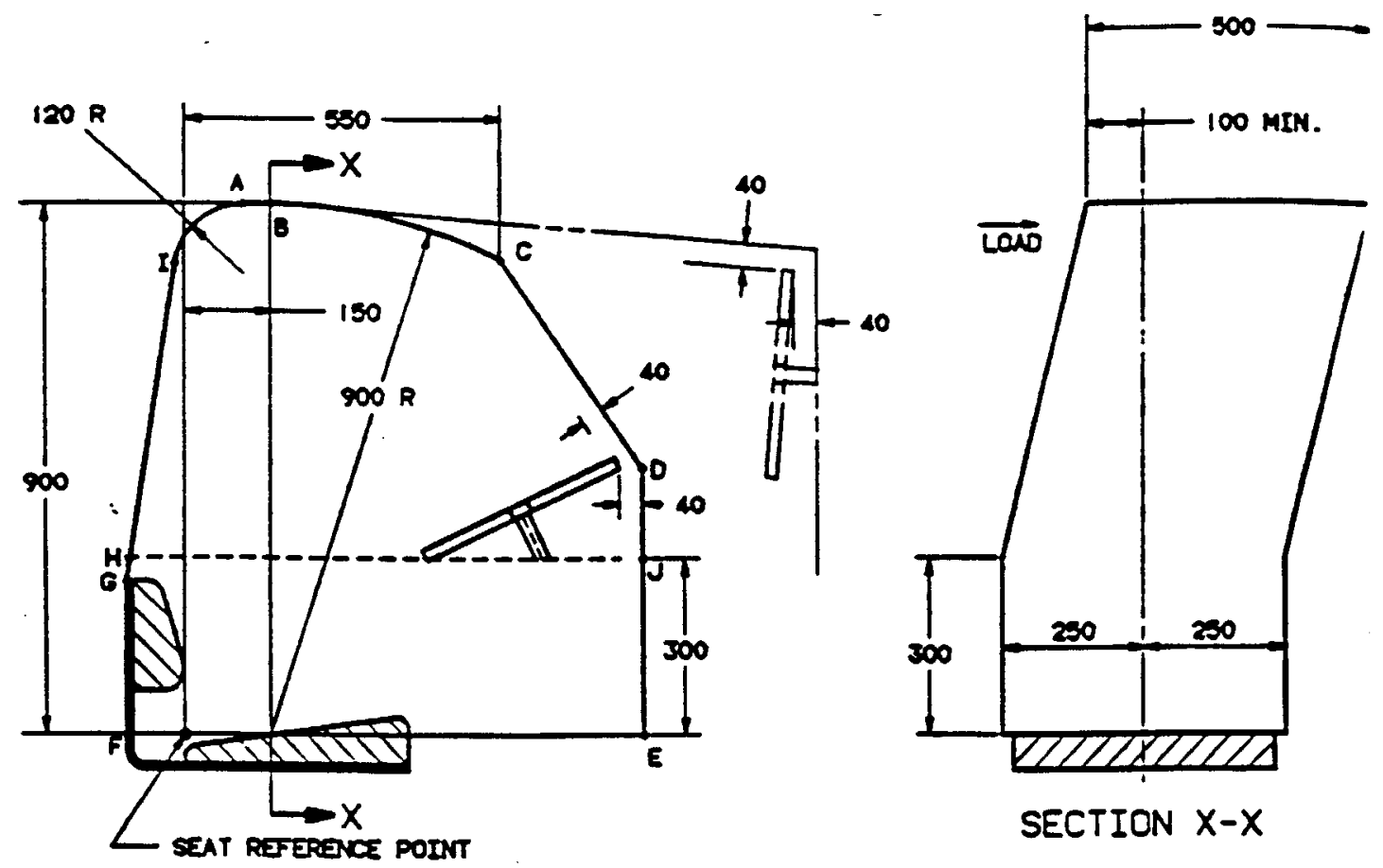

ODENSIONS ARE MILITETERS.


Figure 2.4: Clearance Zone Occupancy 


\section{Chapter 3}

\section{Introduction to Finite Element Procedures}

\subsection{Introduction}

Finite element procedures are at present very widely used in engineering analysis. The use of FEA is expected to increase significantly in the years to come. The procedures are employed extensively in the analysis of solid structures, heat transfer, and fluids. Finite element methods are indeed, useful in virtually every field of engineering analysis. The development of finite element for the solution of practical engineering problems began with the advent of the digital computer. The finite element method is used to solve physical problems in engineering analysis and design. Figure 3.1, summarizes the process of finite element analysis (Bathe, Klaus-Jurgen 1996). The physical problem typically involves the actual structure or structural component subjected to certain loads. The idealization of physical problems to a mathematical model requires a certain assumption that, together, leads to differential equations governing the mathematical model. There are four assumptions, which must be considered in any finite element based solution. The assumptions are: Geometry, Materials properties, Mesh and Boundary conditions. 


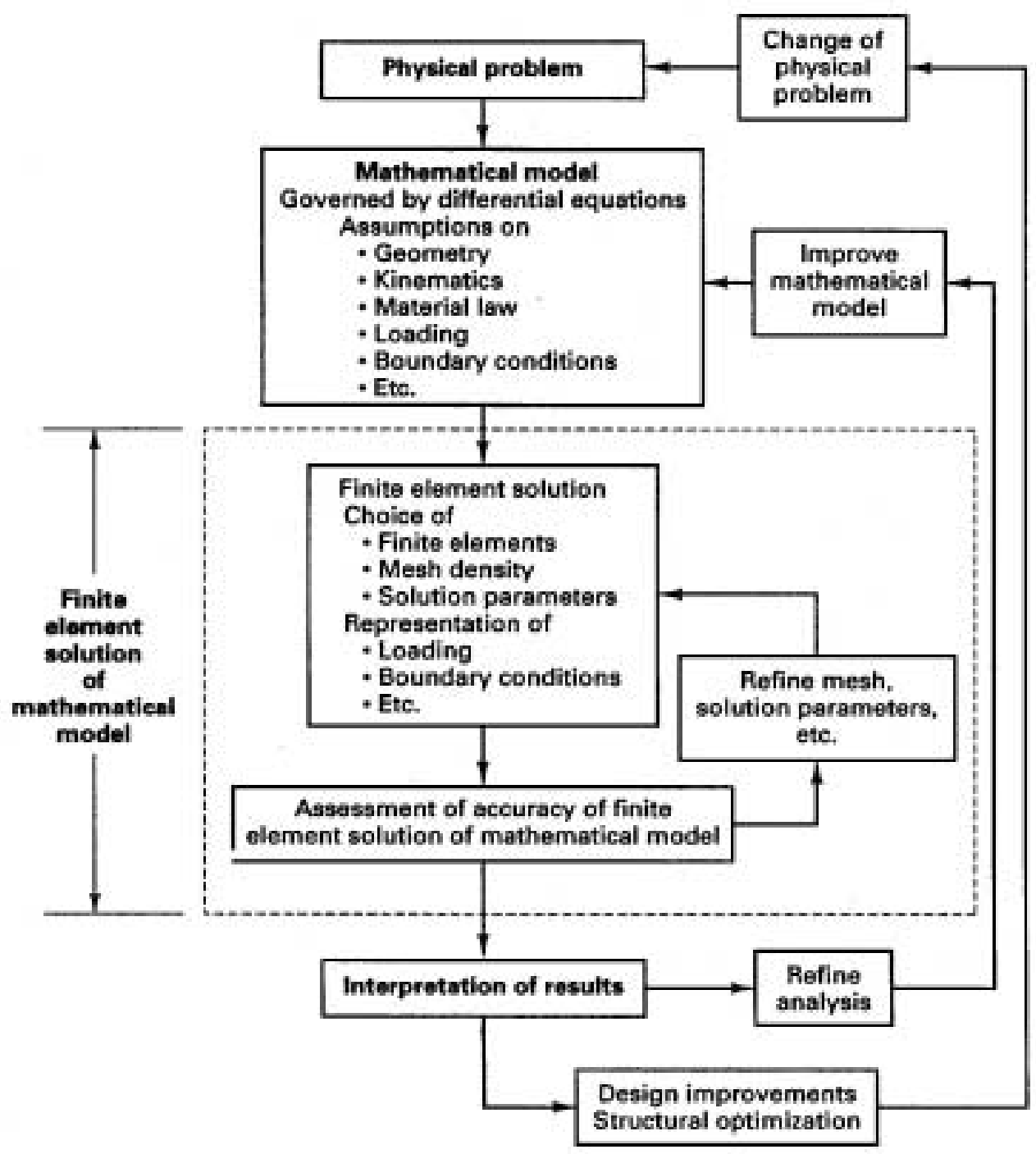

Figure 3.1: The Process of Finite Element Analysis

\subsection{The Principle of Virtual Displacements}

The basis of the displacement-based finite element solution is the principle of virtual displacement (which is also called the principle of virtual work). This principle stated that for any compatible small virtual displacements (which are zero corresponding to prescribe 
displacement) imposed on the body in its state of equilibrium, the total internal virtual work is equal to the total external virtual work.

$\int \epsilon^{\top} \tau d V=\int \mathbf{U}^{\top} \mathbf{f}^{B} d V+\int \mathbf{U}_{f}^{s} \mathbf{f}_{f}^{s} d s+\sum_{l} \mathbf{U}^{i \top} \mathbf{R}_{C}^{i}$

Left side is internal virtual work $=$ right side, external virtual work $\Re$

$\epsilon=$ Virtual strain corresponding to virtual displacement $\mathbf{U}$.

$\tau=\mathbf{f}^{B}=\mathbf{f}_{\mathrm{f}}^{\mathrm{s}}=\mathbf{R}_{\mathrm{C}}^{\mathrm{i}}$ are stresses in equilibrium with applied load.

The use of the principle of virtual displacements, assumes to have the exact solution displacement field of the body (Bathe, Klaus-Jurgen 1996).

\subsection{Materials Properties}

For the second generation AutoROPS, Adam Gillispie tested a sample of 1018 steel at the WVU research lab to verify the material properties. The uniaxial stress-strain plots for 1018 steel can be seen in (figure 3.2). The yield point for 1018 was found at 32,000 Psi, and the ultimate tensile strength was 58,000 Psi (Gillispie). 


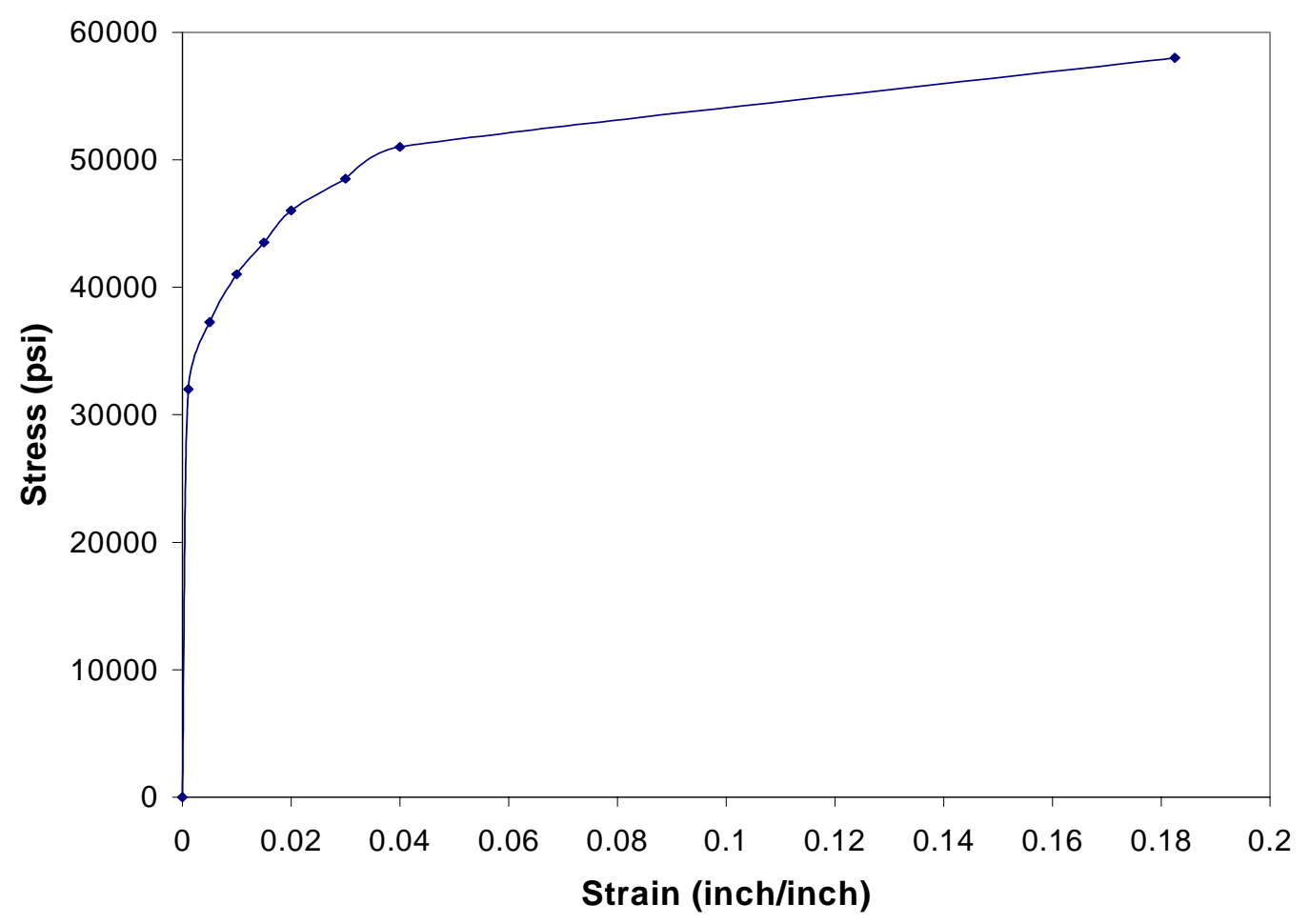

Figure 3.2: HR 1018 Steel Stress-Strain Curve

\subsection{Material Nonlinearities and the Hardening Rules}

All materials in this study are considered to be nonlinear to let the design yield and reach the plasticity range. Studying the hardening rule is also very critical in solving this finite element model, because it will show how the model behaves after yielding. This is with the assumption that the yield surface will expand uniformly due to plastic straining. 


\subsection{Temperature Effect on Materials Under Impact Test}

Temperature can be a major factor in determining the failure of materials. The temperature effect can be seen clearly on the fracture surface. The visual inspection of the impacted specimen's fracture surface can provide useful information. For metal, the surface may be fibrous (indicating ductile fracture), or shiny and "crystalline" (giving evidence of damage). Or, for those materials that undergo a change in fracture mode with temperature. The damaged portion is found in the central section of the specimen and is surrounded on its periphery by a region of fibrous failure (MAE 53 lab notes). The percentage of fibrous fracture increases with increasing test temperature. The materials become more brittle in low temperature environment, and that makes the material reach the failure point faster. (See figure 3.3) 

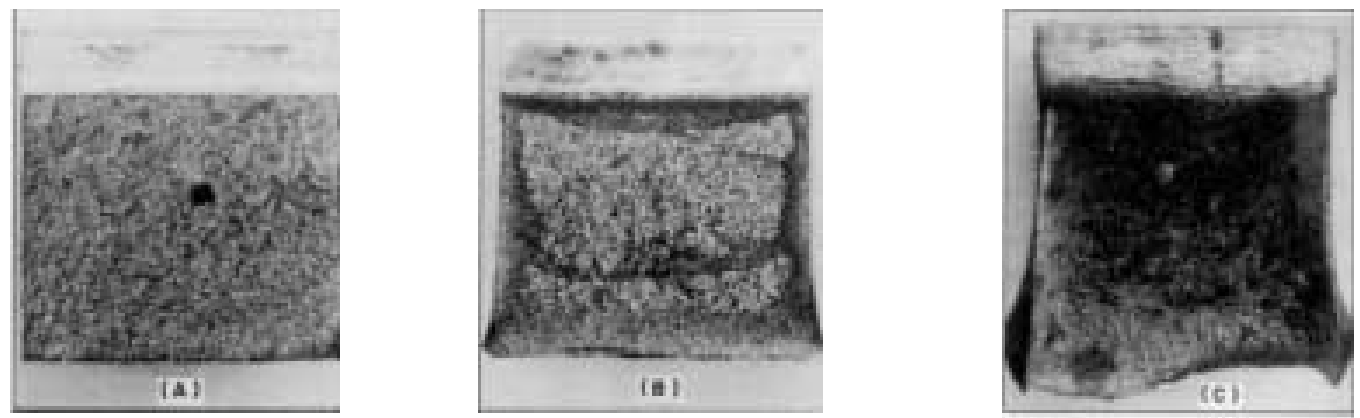

Figure 3.3:The Fracture Appearance of Impact Specimens, Broken at Different Test Temperatures, of Steel That Undergoes Ductile- to-Brittle Transition.

(A) Low Temperature Shows the Fracture Surface is Flat and Shiny;

(B) Intermediate Temperature Shows the Interior of The Specimen Still Manifests a Shiny "Crystalline" Appearance, but the Periphery is Dull; C) Higher Temperature Shows the Surface is Entirely Dull. 


\subsection{Yield Criteria}

Plastic deformation stresses can be calculated by using the Von Mises Yield Function (see figure 3.4).

$$
\sigma_{y}=\sqrt{\frac{1}{2}\left[\left(\sigma_{1}-\sigma_{2}\right)^{2}+\left(\sigma_{2}-\sigma_{3}\right)^{2}+\left(\sigma_{3}-\sigma_{1}\right)^{2}\right.}
$$

The yield function is a six dimensional space on the surface and makes a distinction between the elastic and inelastic zones. The points inside the yield surface are the elastic points while the points outside the stress surface are the inelastic points.

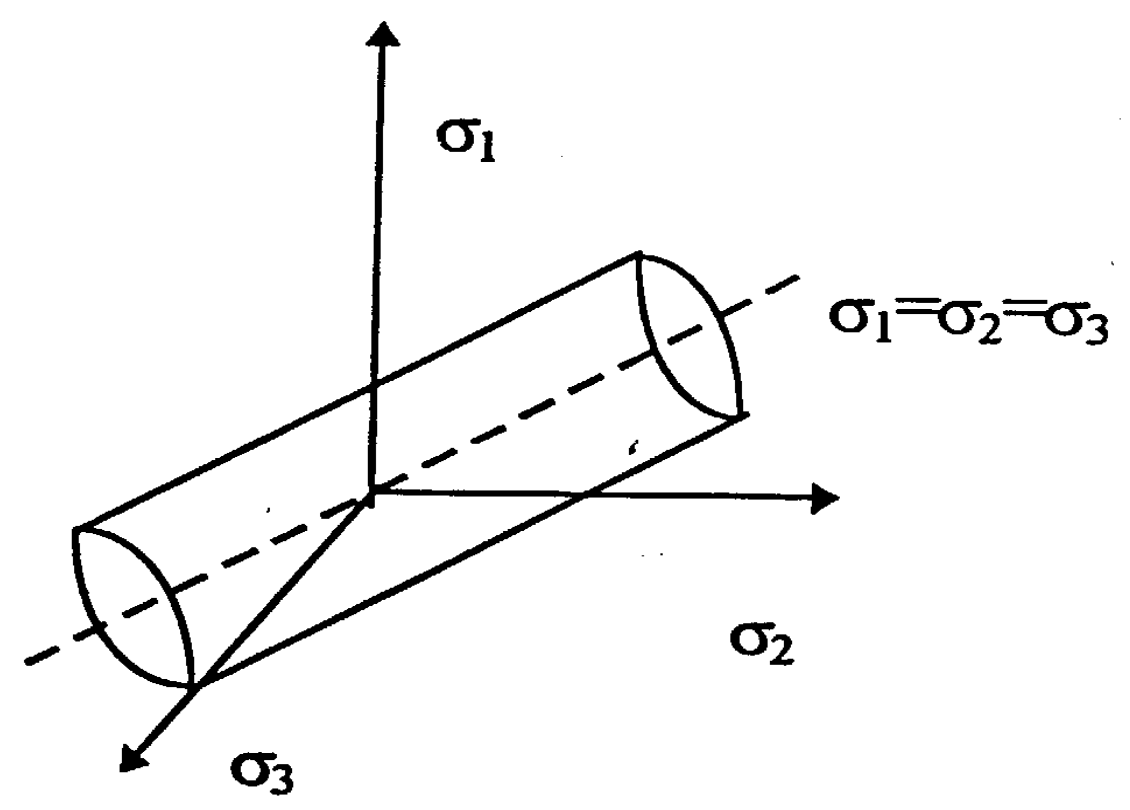

Figure 3.4: Von Mises Yield Surface. 


\subsection{Finite Element Mesh}

Finite element technique is a numerical procedure; Structural models are divided into smaller parts by meshing using a grid system. If the accuracy criteria are not met, the finite element solution must be repeated with refined solution parameters, such as finer mesh, until sufficient accuracy is reached (Kreyszing). Here is an example to show how a finer mesh can give you a more accurate solution.

A 2" $\times 3$ " post 62 inches high has been constrained at the base and exposed to $1,000 \mathrm{lb}$ of force at the upper part of post (see figure 3.5)

The first test was done after meshing the post with free mesh (see figure 3.6). The post on the second test was meshed with finer mesh (mapped meshing) (see figure 3.7).

$\mathrm{D}=\mathrm{FL}{ }^{3} / 3 \mathrm{EI}$

Where $\mathbf{F}$ is the force, $\mathbf{E}$ is modulus of elasticity, $\mathbf{I}$ is the moment of inertia and $\mathbf{D}$ is the deflection at the end.

Hand calculation for this test by using the equation 3.3, gave an estimated deflection of 1.0 inch at the end of the cantilever beam. 


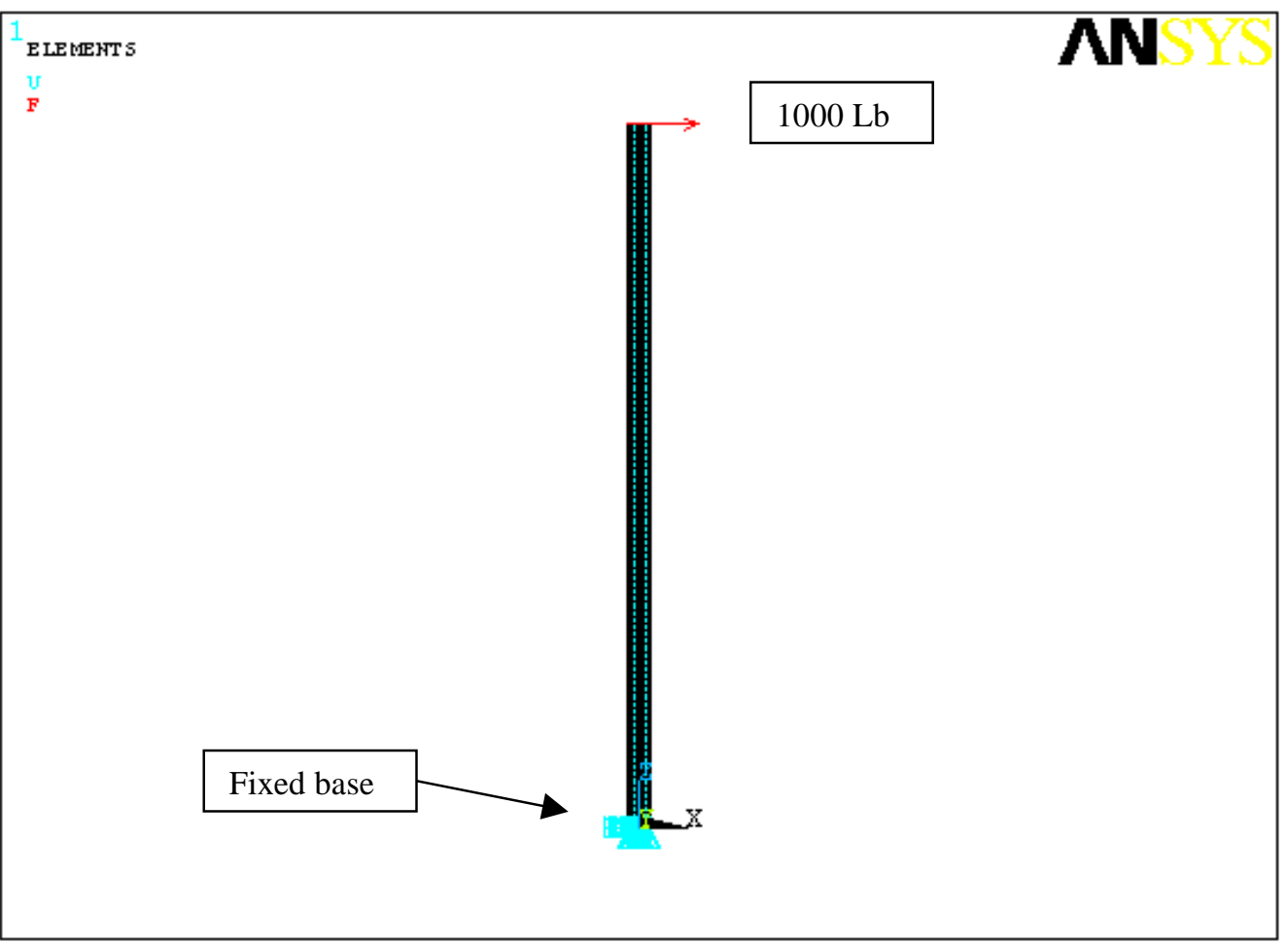

Figure 3.5: Boundary Conditions for the Cantilever Beam

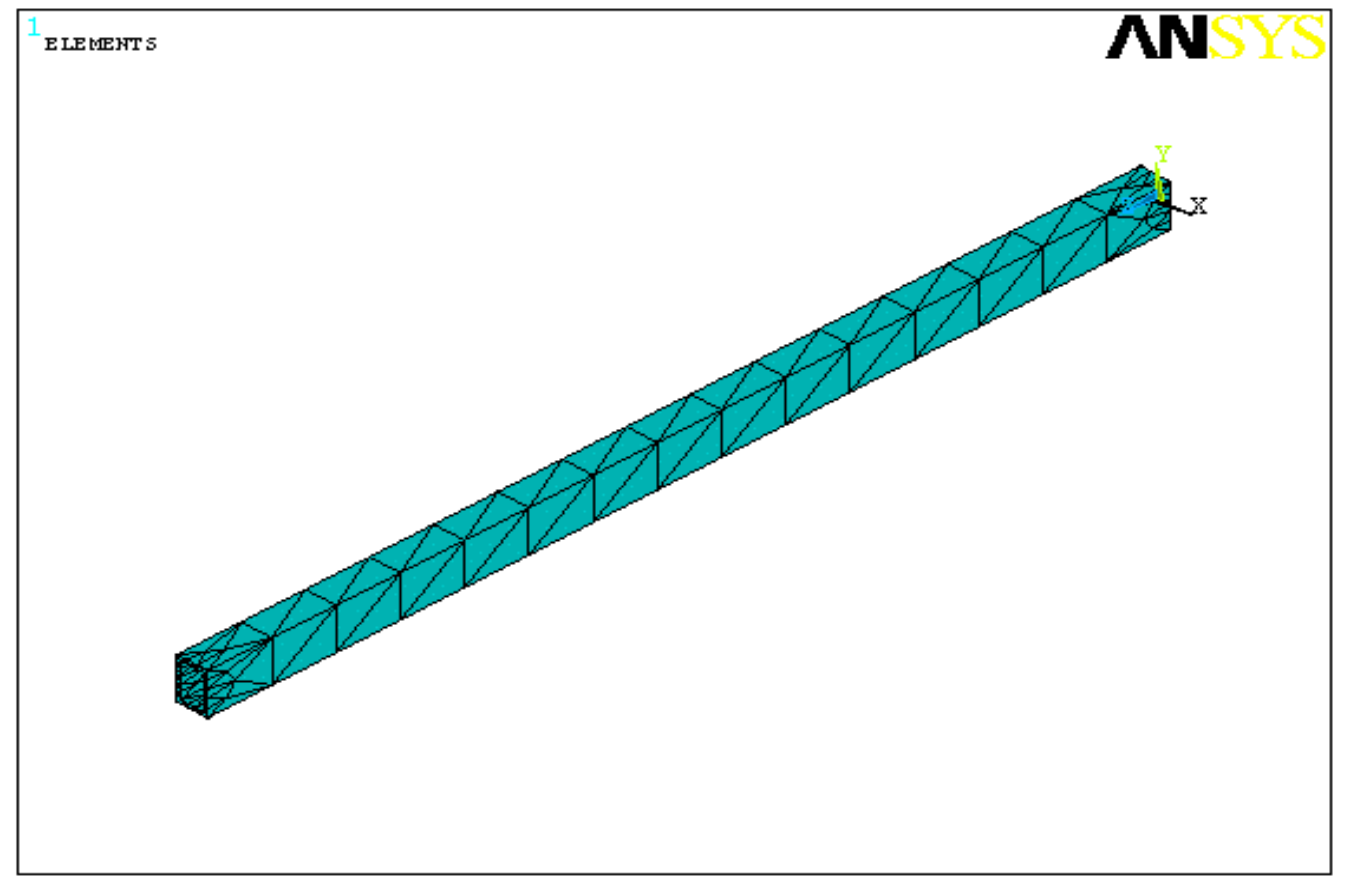

Figure 3.6: Free Mesh for the 62" (2X3) Post. 


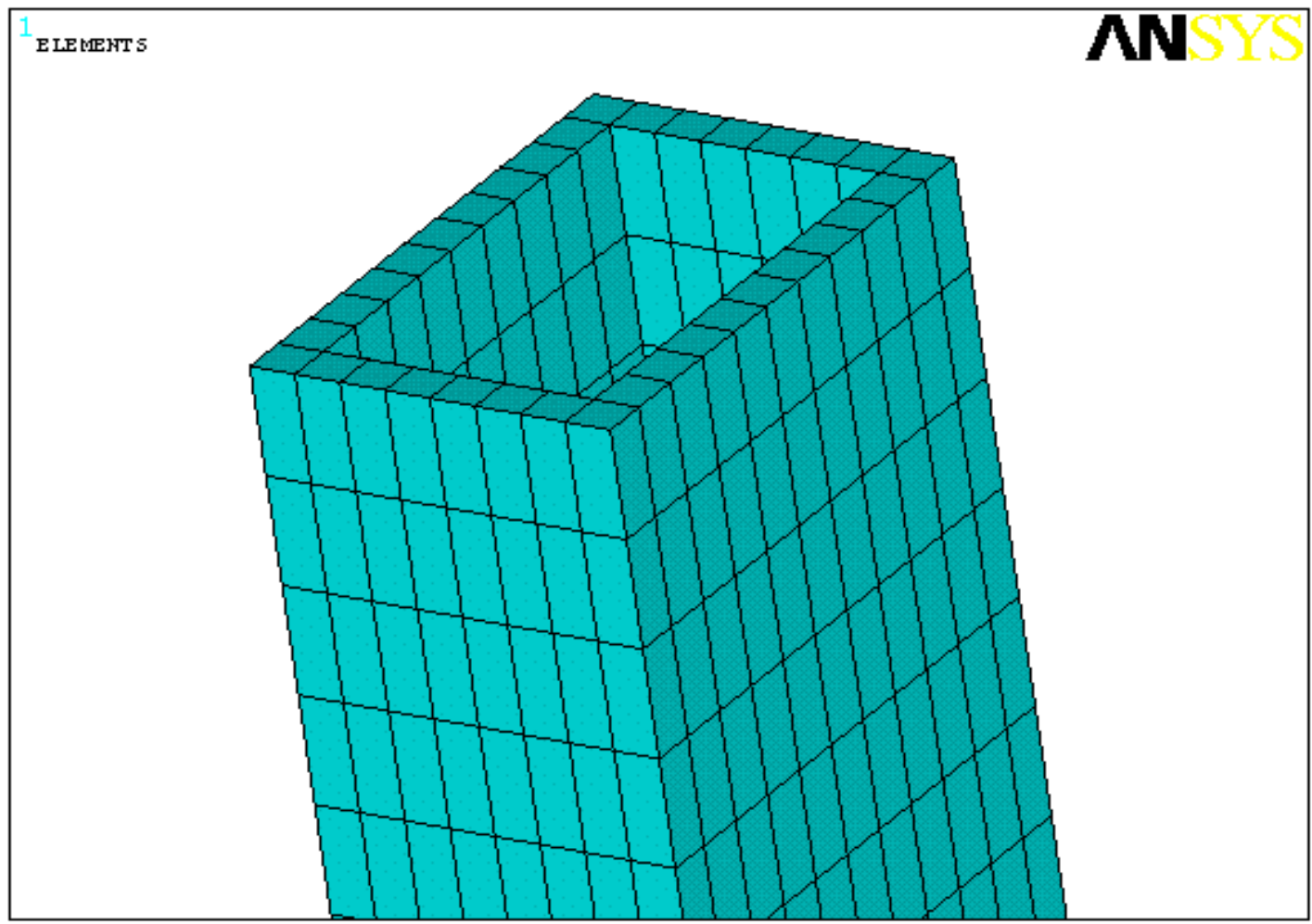

Figure 3.7: Mapped Mesh for the Cantilever Beam Specimen (Finer Mesh)

The deflection from the first test is 0.24 inches (see figure 3.8). The deflection from second test is 1.04 inches (see figure 3.9). The second test is closer to the calculated answer.

Those results prove that the finer the mesh yields more accurate results. The finer mesh gives more control over the object, and it gives the smaller elements a more realistic shape in order to achieve greater accuracy in solving any object. Sound engineering judgement must be used when determining how the model should be meshed. The disadvantage in the finer mesh is the increased computer time required for solution. 




Figure 3.8: Deflection for Free Mesh Post

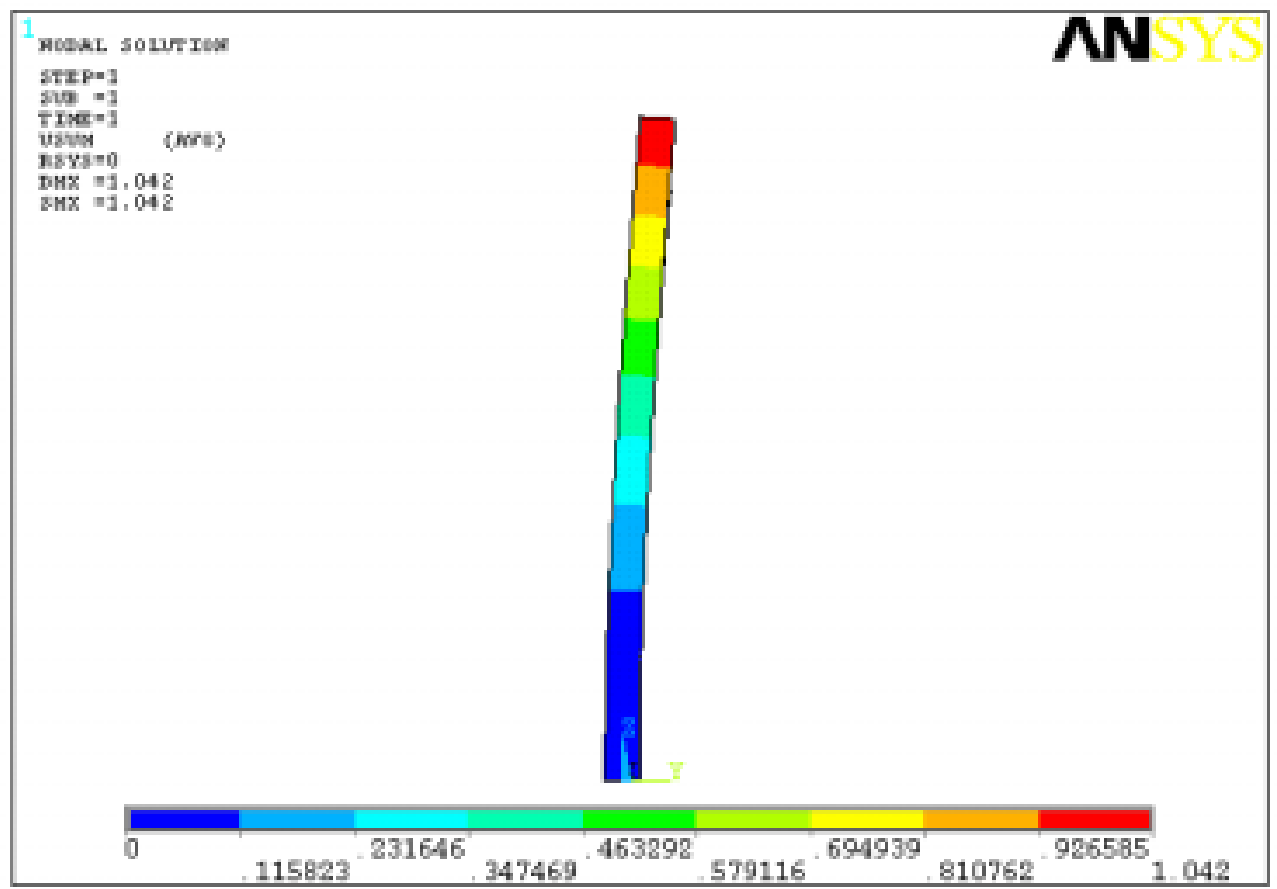

Figure 3.9: Deflection for Finer Mapped Mesh Post 


\subsection{Boundary Conditions}

A finite element solid model has to have boundary conditions in order to be solved. The boundary conditions can represent geometric shapes and loading conditions that are not or cannot be explicitly modeled. A boundary condition has to have at least two things. First, one is the restraining load set. Fixing targeted places like nodes and areas made up the restraining load set. For this study on the AutoROPS, we assumed the base is fixed (see figure 3.10).

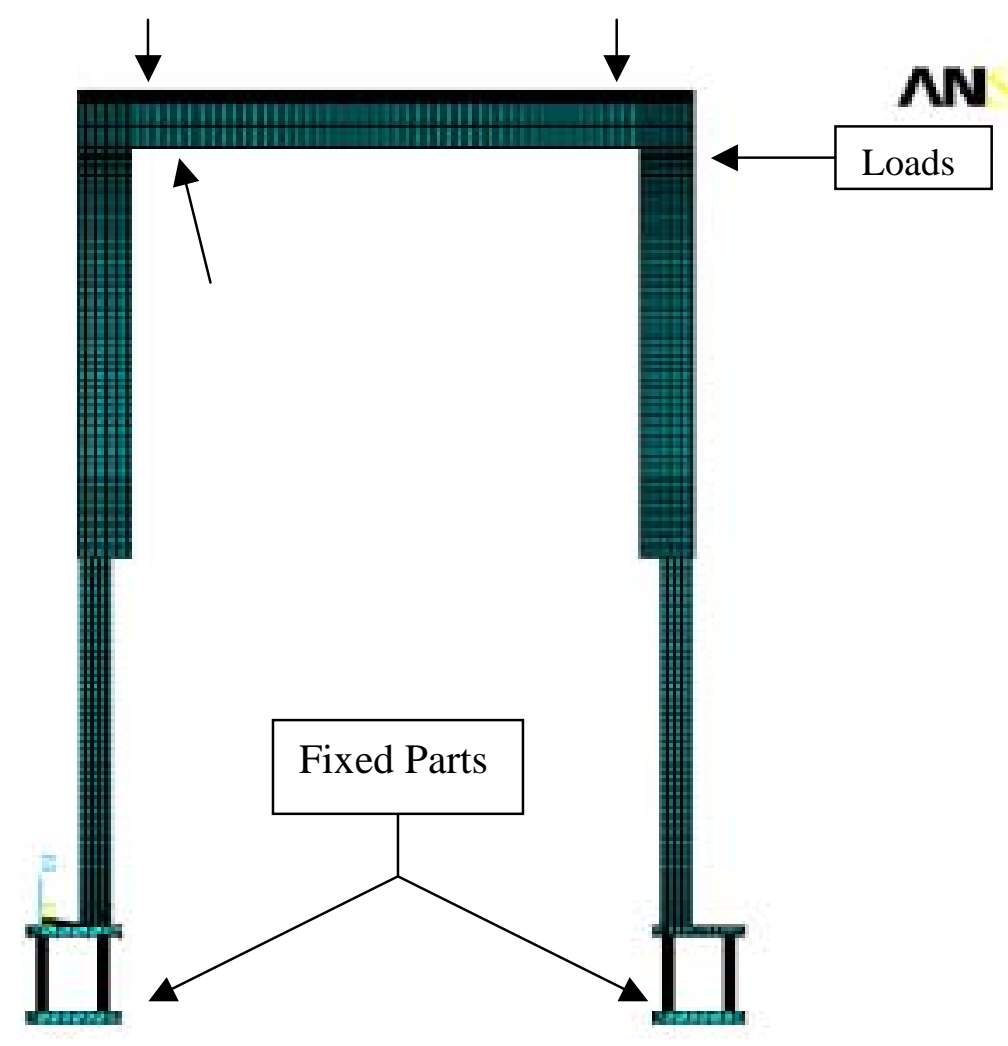

Figure 3.10: Mesh and Boundary Conditions for the $3^{\text {rd }}$ Generation AutoROPS. 
The second part of the boundary condition is the loads. Those loads can be applied directly on targeted places of the finite element model. The loads can be applied over nodes, areas, or as a pressure, or temperature.

The time variable curve allows for plotting of the load deflection curve, though different kinds of loading is required to find the right amount of force needed. Engineering assumptions are very important here in insure the right decisions for the right boundary conditions.

\subsection{Solution Control}

The loads steps and time variables can be controlled by the solution control. This can help the user determine the desired results at certain times of the loading. The desired results in this research for the AutoROPS are stress, strain, deflection, and strain energy.

The load steps can provide a small step or a large steps solution.

Pros and cons exist for each type of step. For a small step the load tends to converge but uses up a considerable amount of computer time. For a large step the load takes longer to converge but uses less time.

The load sets, corresponding to time history for each load, have no guidelines to determine the rate of load incrementing needed to 
attain a complete run. So, to find the required amount of load, the trial and error procedure was used. The results from solving the model were used to determine the force deflection curve. These results can also provide useful information to estimate the required loads in the linear and the plastic region. 


\section{Chapter 4}

\section{Geometry for NIOSH Second and Third Generation}

\section{AutoROPS}

Meeting the SAE J-2192 standard is the main goal to be considered when any AutoROPS being designed. Second generation AutoROPS looks similar to first generation AutoROPS in tube size and height. The main changes on second generation AutoROPS were done on the base and latching mechanisms. For the third generation AutoROPS, a new design is presented with major changes.

\section{1: NISOH Second Generation AutoROPS Base Analysis}

The second generation AutoROPS consisted of the two inside deployable tubes connected by a horizontal tube and two outside fixed tubes welded to the base. There are latching pins, and caps in the overlapping area between the tubes (see Appendix B for the NIOSH second generation AutoROPS dimensions and layout). The base has 2-plates, connected by 8 grade 8 bolts with 0.75 " diameter- around the axle housing. The second generation AutoROPS base geometry can be viewed in (figure 4.3). 




Figure 4.1: General Sketch for the Second Generation Base

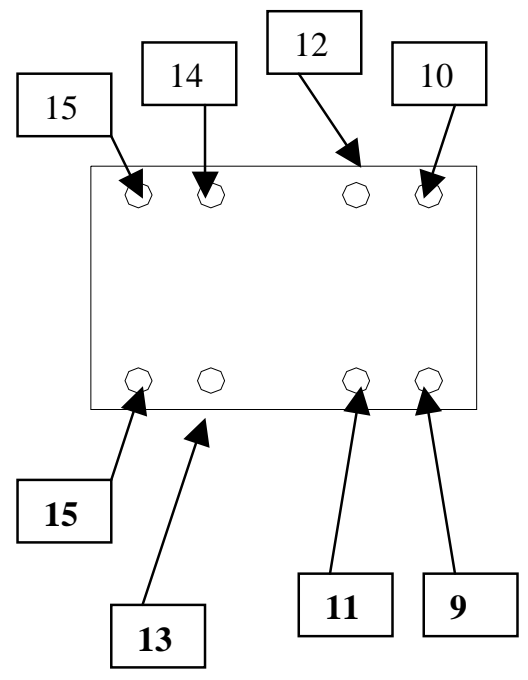

Tractor front side

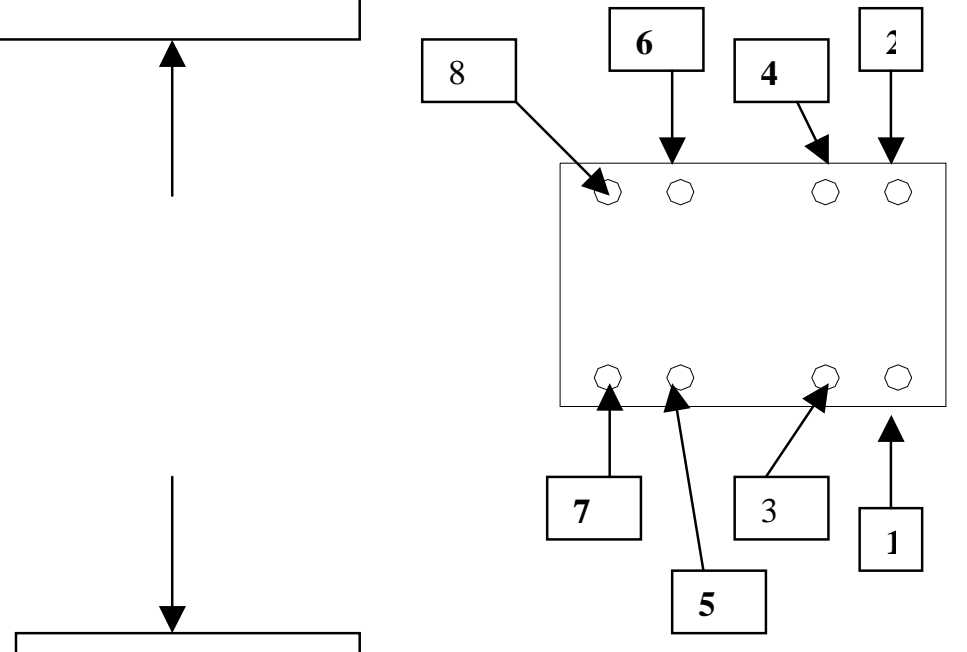

Tractor rear side

Figure 4.2: Top View for Bolts Numbers of Second Generation AutoROPS Base 


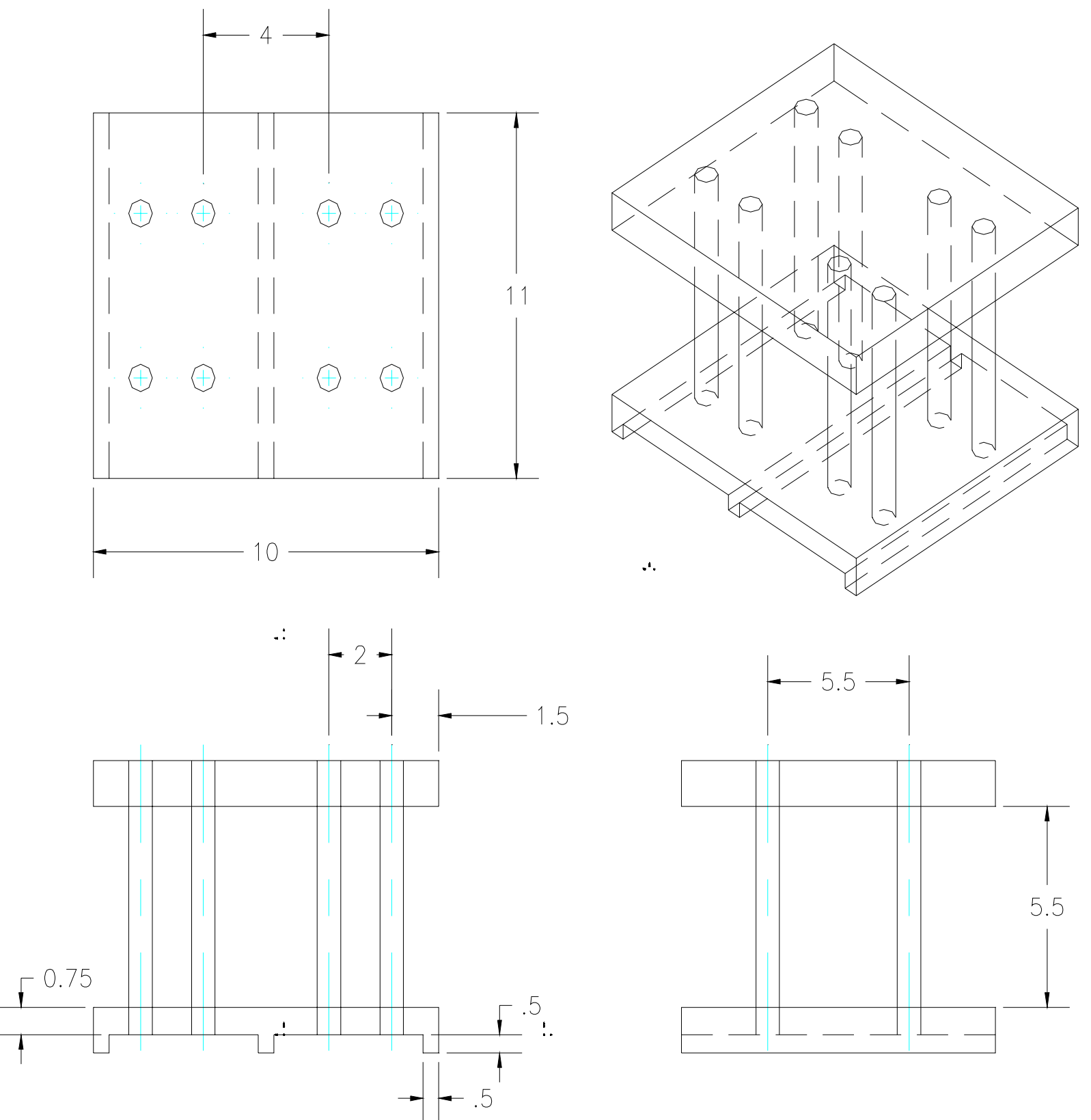

Figure 4.3: Dimensions for the Second Generation Base 


\section{2: NIOSH Third Generation AutoROPS}

The design for third generation AutoROPS consists of the outside deployable posts and inside fixed posts and an over-lapping area in between them. This area must connect the posts and be able to handle any deflection of the AutoROPS.

The top part of the AutoROPS consists of the two outside posts 3.5"X3.5" connected with the horizontal 3.5"X3.5" square post, and two 2"X3" inside posts welded to the base which has a 2 plate connected method around the axle housing by four grade 8 bolts (see figure 4.5 and 4.6 for geometry details).

Analyzing the third generation AutoROPS was one of the biggest challenges incurred during this research. There are many things that need to be considered in this design. For instance, the inside posts has to be 2"X3" while the deployable/outside post has to be 3.5 "X3.5" and that will causes the smaller inner post to carry more of the applied stresses and absorb more energy than the outer deployable post, which is bigger in size. Also, the spring size has to be sized to meet the deployment characteristics. The base also has to handle the stresses on it and to remain firmly attached. 


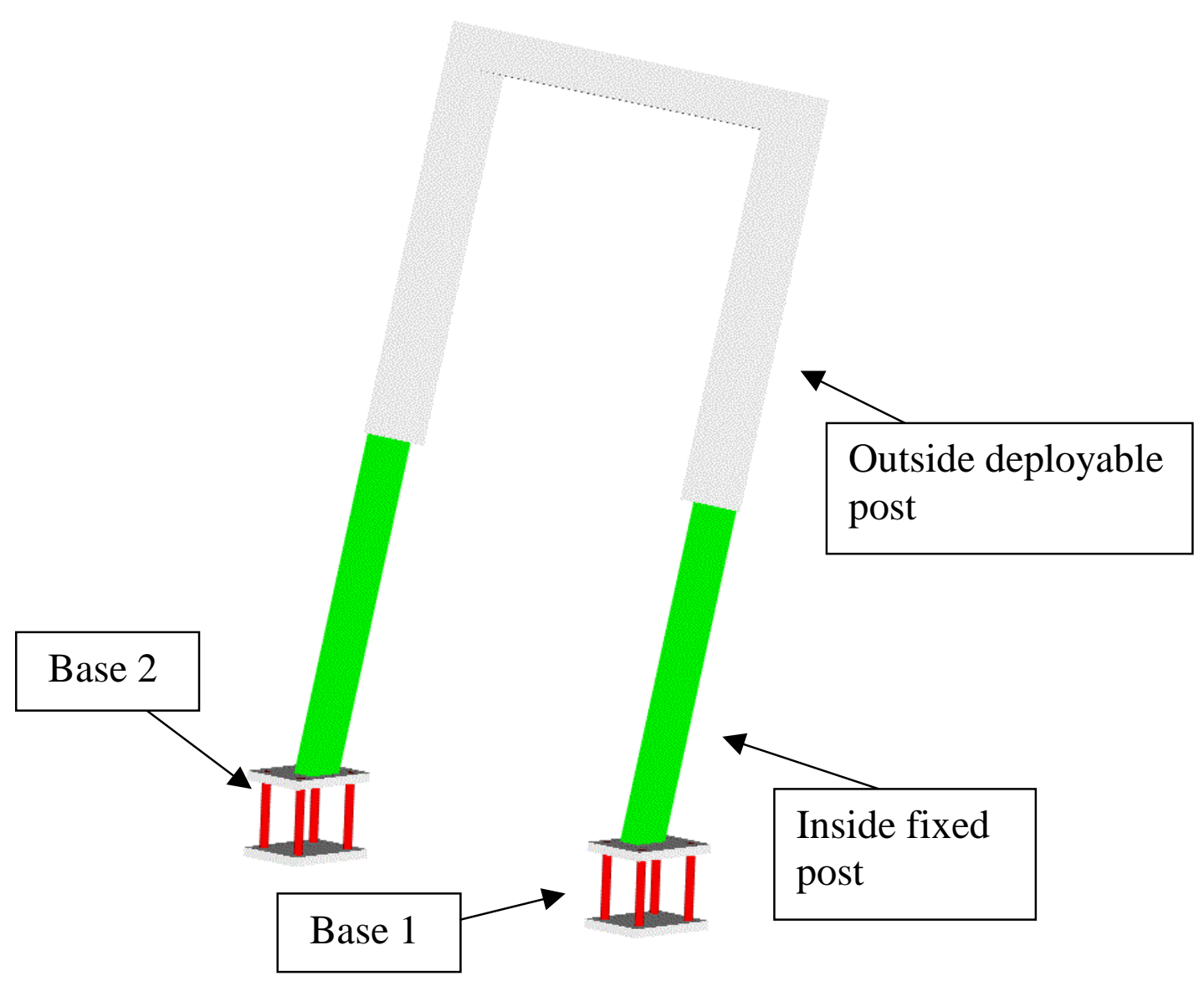

Figure 4.4: General Overview of the Third Generation AutoROPS.

The third generation AutoROPS should be less expensive and easier to build than the second generation AutoROPS. Weight plays a major factor in this design. Due to the fact that the third generation AutoROPS has to be lighter, that also will benefit the tractor operator by using less fuel. Manufacture of the AutoROPS with an acceptable price range is also necessary goal. 

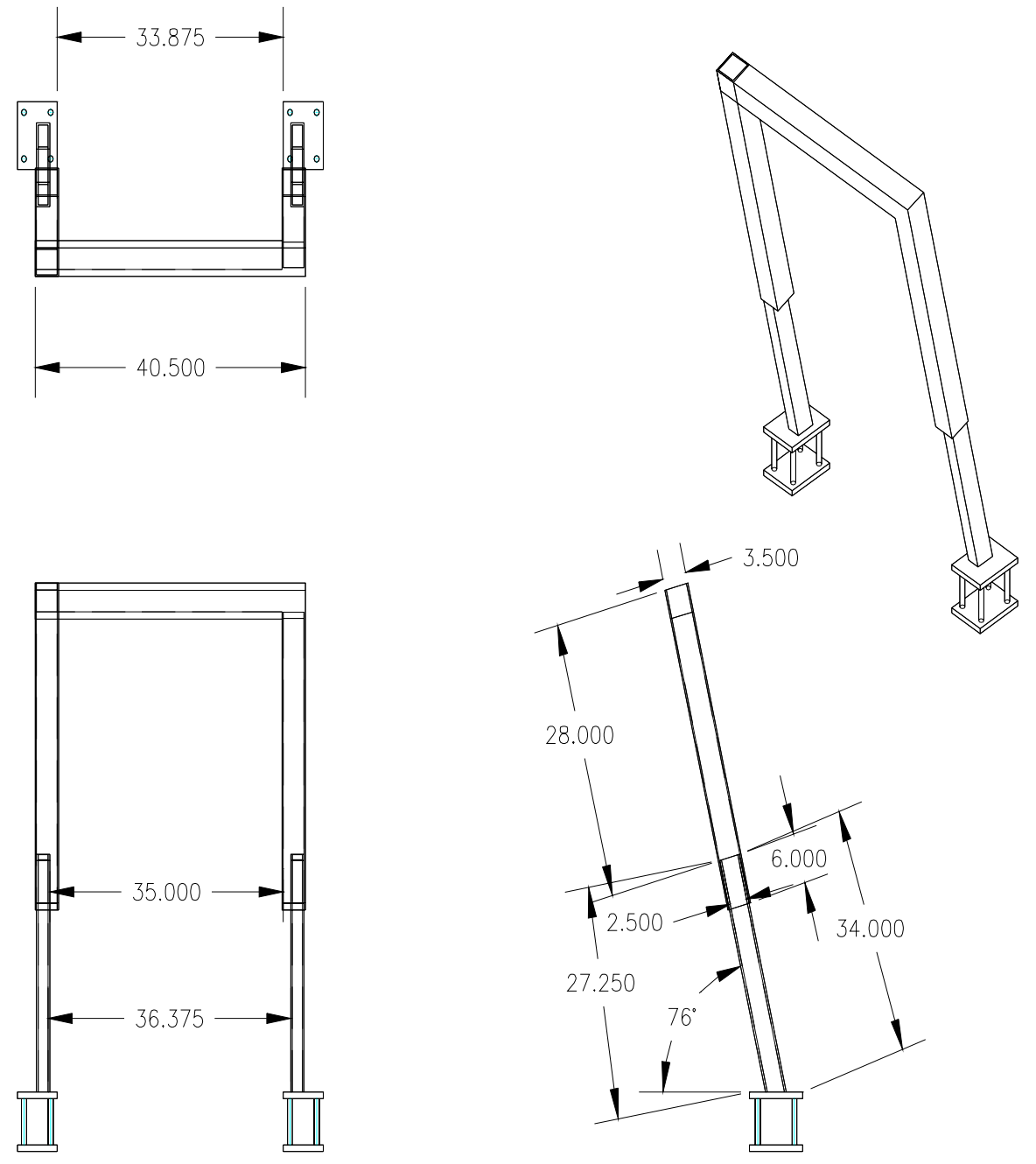

Figure 4.5: Dimensions for the Third Generation AutoROPS Main Model 

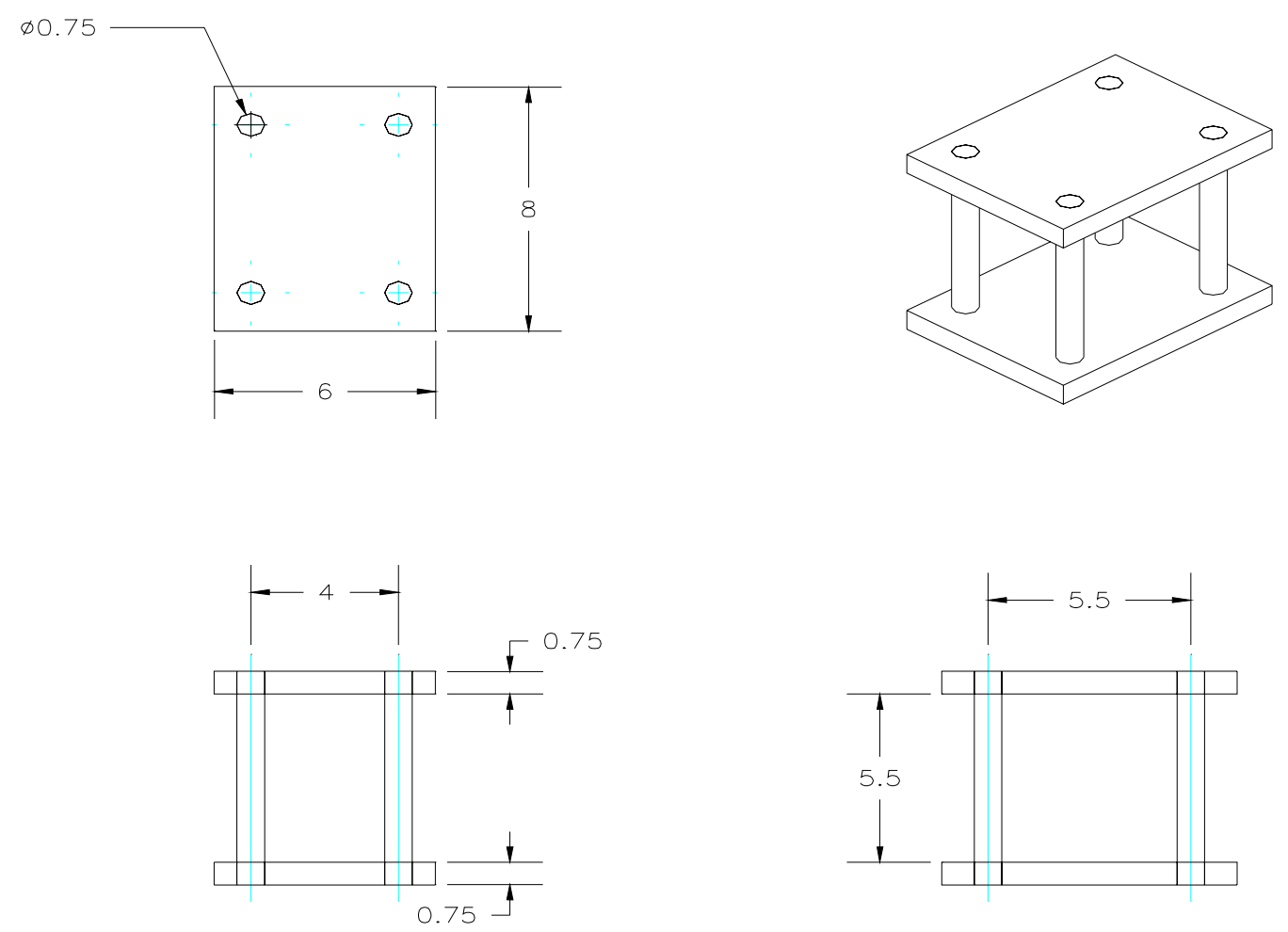

Figure 4.6: Dimensions for the Third Generation Base.

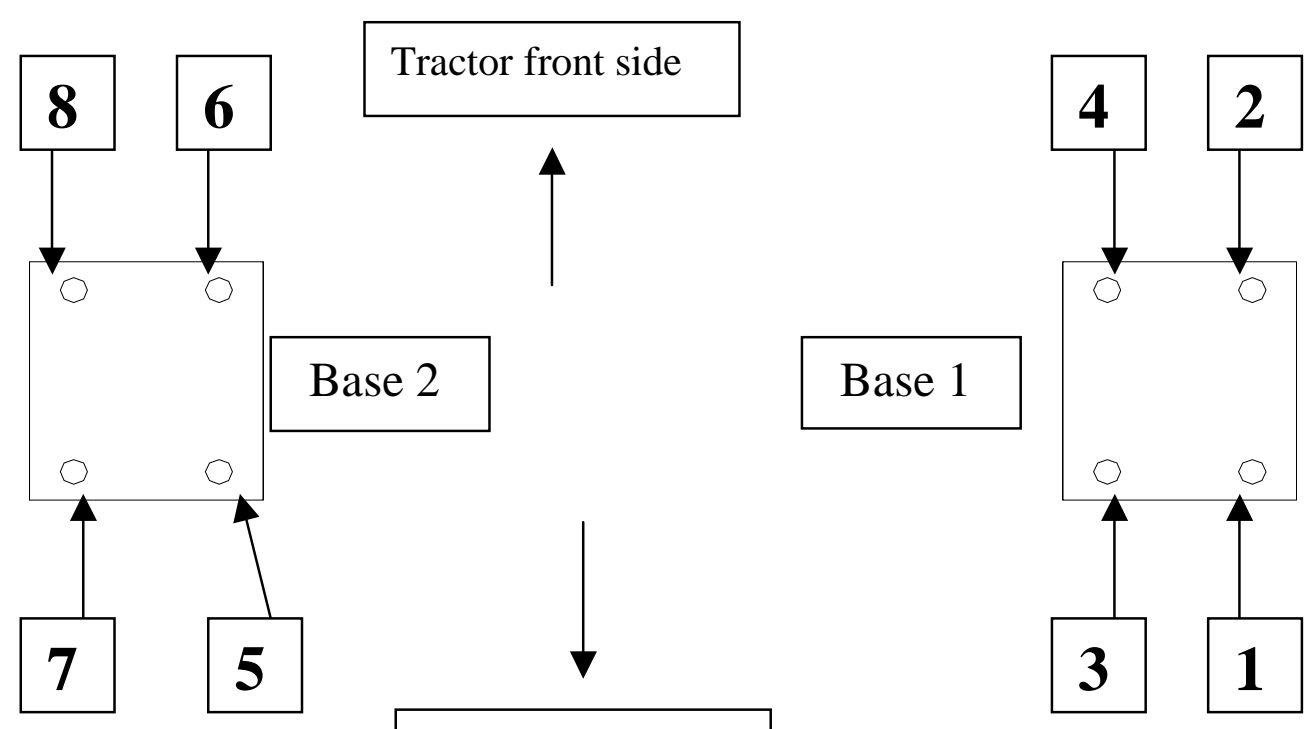

Tractor rear side

Figure 4.7: Base and Base Bolts Numbers for the Third Generation AutoROPS 


\section{3: The Operator Clearance Zone}

The Operator Clearance Zone was modeled in direct accordance with the SAE J-2194 standard. The standard gives mandatory dimensions as well as those, which are dependent upon the particular type of tractor. The key dimensions and their reference to the operator clearance zone can be seen in figure 4.8 , and further elaborated by Table 4.1.

Keeping the clearance zone away from any intrusion is one of the most important goals in this research. The solid model of the clearance zone was built out of wire frames, and then the frame was placed at the proper location in the tractor, taking the third generation AutoROPS into consideration. 


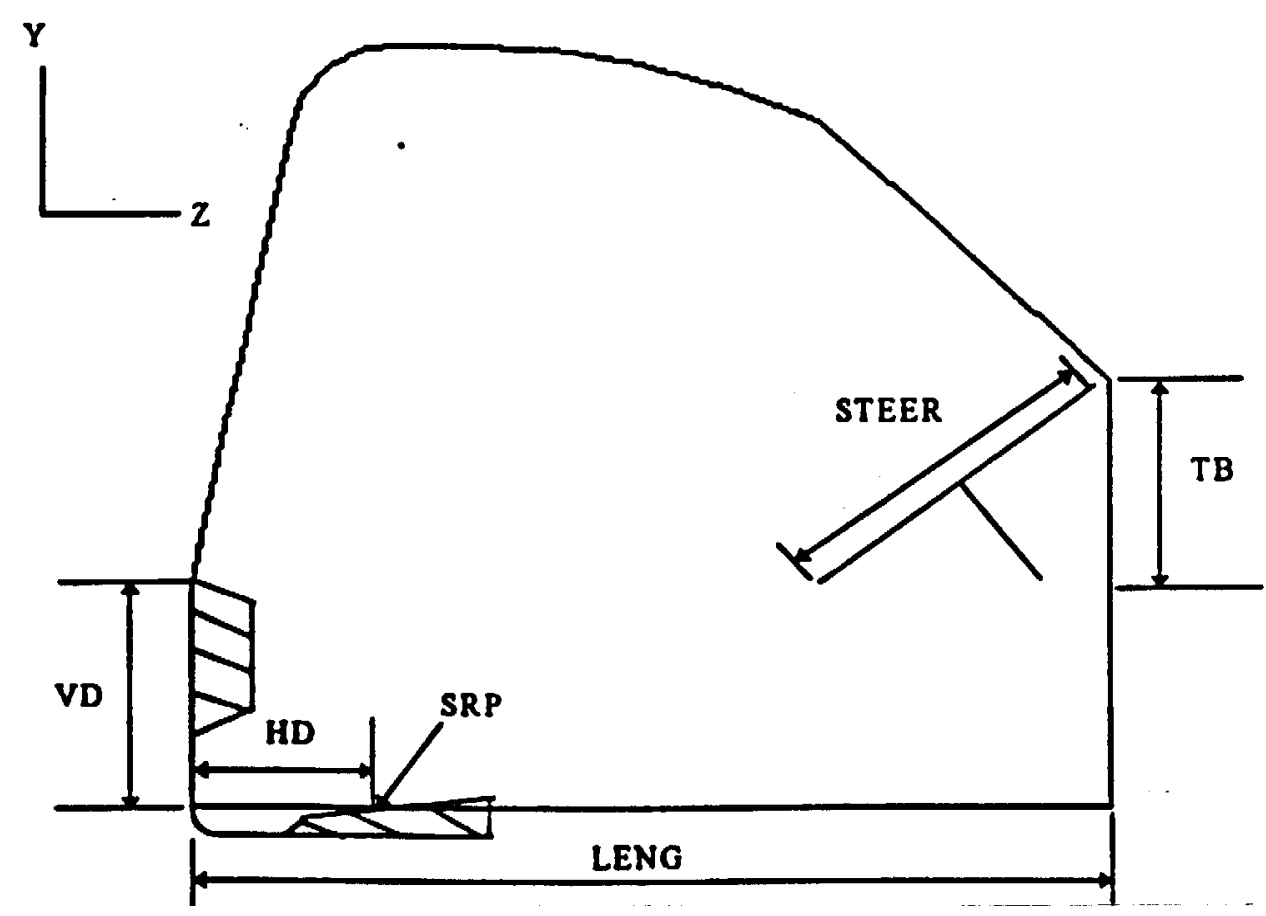

Figure 4.8: Operator Clearance Zone Dimension Layout

Table 4.1: Geometry and Identity of the Operator Clearance Zone

\begin{tabular}{|c|c|}
\hline Dimension & $\begin{array}{c}\text { Value } \\
\text { (Inches) }\end{array}$ \\
\hline $\begin{array}{l}\text { Horizontal Distance of SRP to } \\
\text { Rearmost of Backrest (HD) }\end{array}$ & 5 \\
\hline $\begin{array}{c}\text { Vertical Distance of SRP to Rearmost } \\
\text { of Backrest (VD) }\end{array}$ & 10.25 \\
\hline $\begin{array}{l}\text { Vertical Distance of Steering Wheel } \\
\text { Top to Bottom (TB) }\end{array}$ & 8 \\
\hline $\begin{array}{l}\text { * Horizontal Distance of Plane } \\
\text { E1F1F2E2 (LENG) }\end{array}$ & 38.95 \\
\hline $\begin{array}{l}\text { Extruded Distance of Zone } \\
\text { (OPDEPTH) }\end{array}$ & 18 \\
\hline Diameter of Steering Wheel (STEER) & 21.15 \\
\hline X-Axis Distance (Center of Mount-SRP) & 19 \\
\hline Y-Axis Distance (Center of Mount-SRP) & 17.375 \\
\hline Z-Axis Distance (Center of Mount-SRP) & 8 \\
\hline
\end{tabular}

*Denotes the Plane E1, F1, F2, E2, in Figure 2.3. 


\section{Chapter 5}

\section{Second Generation AutoROPS Base Analysis}

\section{1: Introduction}

An analysis of the second generation AutoROPS was completed by performing a nonlinear static analysis on the AutoROPS using ANSYS (Version 6.0) at NIOSH. There has been no documented analysis conducted on the second generation AutoROPS base prior to this work.

The crucial factor during meshing the AutoROPS model was the size of the mesh of the element. That's because the model with finer mesh densities, in the areas of concern, resulted in more accurate results.

The FEA Model used the maximum load from the first generation AutoROPS experimental testing to act as the cut off load that meets the AutoROPS Energy requirements. After applying each load during the load sequences, the load is allowed to return to zero in order for the AutoROPS to spring back before applying the next load sequence. This method was used in order to meet the SAE J-2194 standard. A list file was then created for stored reaction forces. 
The results for the second generation AutoROPS base due to the loads applied in sequence as required by SAE J2194 standard are as follows:

\section{2: First Longitudinal Test}

The part to be tested is the base. The bolts were prestressed based on NIOSH Experimental tests on the first generation AutoROPS to 27,327 psi (see figure 5.1). Then the load, which was applied on the posts gradually, increased until it reached the maximum required load of $9100 \mathrm{lb}$. The maximum stress found in the base, was 38,593 psi (See Figure 5.2). This was well within the allowable limits, because of two reasons: First, the base is over-designed by having 8 bolts of grade- 8 in each base. They have a minimum proof yield stress of 120,000 psi. Secondly, from figure 4.3 , which shows the lay out of the base dimensions, the upper plate is 1.25 inches thick and the lower plate is 0.75 Inches thick and supported by C-channels. This gives added support to the base and reduces the stresses on the bolts. (Figure 5.2 shows the maximum stresses on bolt number 9, 11, 13, 15). After reaching the maximum load, the clearance zone remained untouched by the AutoROPS, and that was major key for the 
AutoROPS to pass the test and be considered a successful test. The number of the elements in this prototype is 77,138 (see figure 4.8).

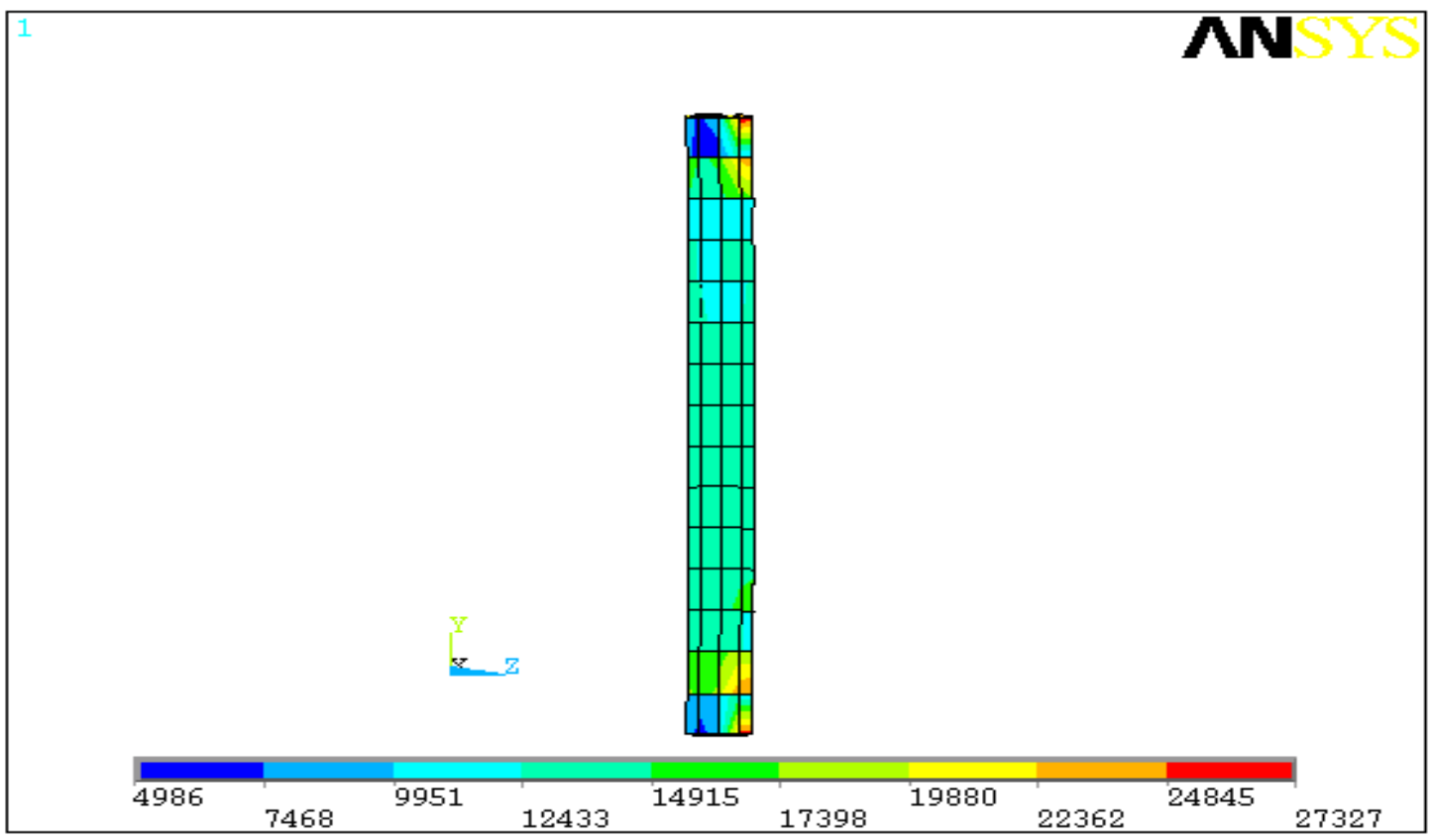

Figure 5.1: Prestress on the Base Bolts

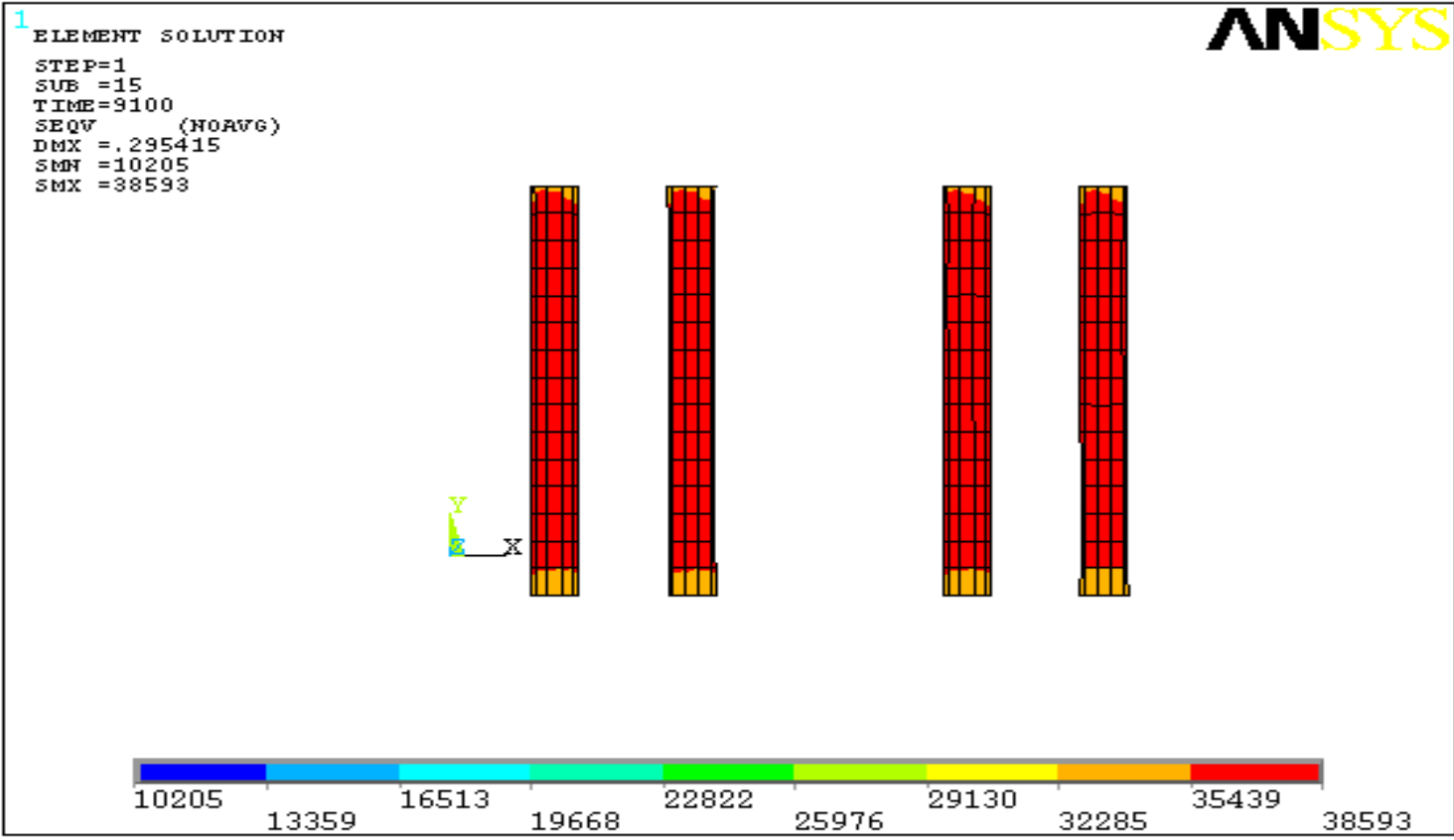

Figure 5.2: The Maximum Stress in the Bolts for First Longitudinal Test 


\section{$\underline{5.3 \text { Vertical Crush Test }}$}

The vertical load was the next load to be applied on the AutoROPS based on the SAE J-2194 sequence requirements. The force applied was $16,700 \mathrm{lb}$. There was no determinate effect to the base of the AutoROPS.

\section{$\underline{5.4 \text { Transverse Test }}$}

A load of $14,000 \mathrm{Lb}$ was applied on the side of the ROPS. The base is crucial part of this design because it has to absorb all of the loads and the stresses being applied on the AutoROPS. The maximum stress found in the base bolts was 37,790 psi (see figure 5.4).

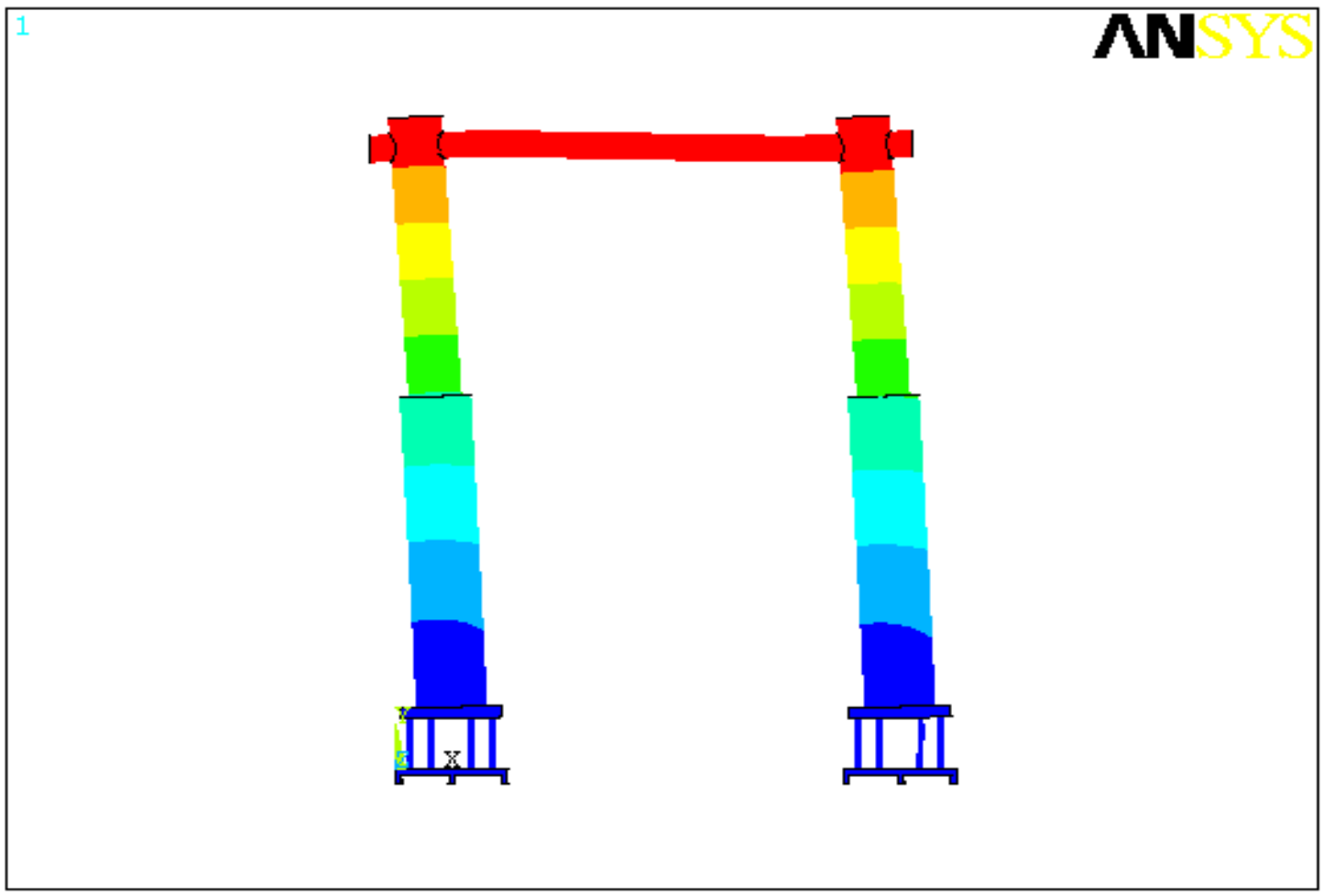

Figure 5.3: Side Transverse Test for the Second Generation AutoROPS 


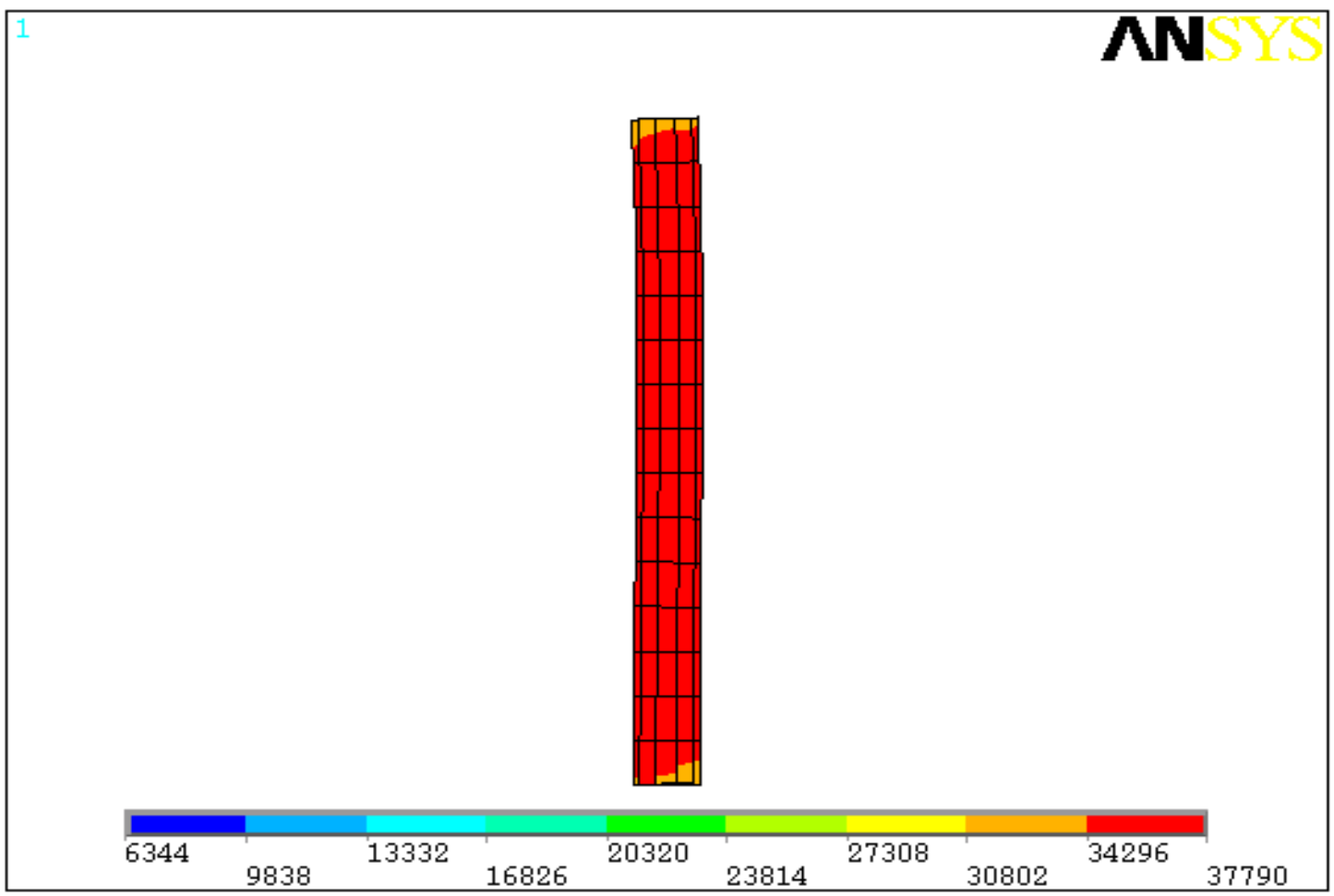

Figure 5.4: Maximum Stress Found in Bolts 1 and 2 in the Transverse Test

From the previous results it can be concluded that this base is robust and will survive all the loads applied on the posts. All of the loads were taken from the NIOSH experimental tests, which were conducted on the first generation AutoROPS. (See Appendix B for complete results of those tests of first generations AutoROPS).

This base is heavy and costly to build, since it is over-designed. This base can be redesigned to have less weight and therefore, become more cost effective while having the same strength. 


\section{Chapter 6}

\section{Analytical Results on the NIOSH Third Generation}

\section{AutoROPS}

\subsection{Introduction}

The overall purpose of the third generation AutoROPS design is to make a lightweight AutoROPS that will be able to protect the tractor operator in the event of rollover. Many design considerations are involved in to insure the structural integrity. The AutoROPS ultimate strength must meet the required energy absorption according to the $\mathrm{J}$ 2194 standard. Also, the design structure must sustain the failure loads with limited damage for a period of time. An AutoROPS computer model was developed to analyze performance. The key element of this new design is the minimum overlap dimension in the deployed state that is created between the deployable and fixed posts. The design must pass an energy absorption test in order to find the required overlap dimension between the two posts. All of the studies were theoretically conducted on the third generation AutoROPS main design model by using Ansys 6.0. A basic computer prototype design of the third generation AutoROPS was developed. The total number of elements used in this prototype was 23,456 . 


\section{$\underline{6.2 \text { First Longitudinal Test }}$}

The applied load on the first longitudinal test was gradually increased until it reached the maximum required load of $4,650 \mathrm{lb}$. The maximum deflection found to be 11.74 Inches. The AutoROPS complied with the standard, absorbing a total energy of 46, 266 in-lb. (see figure 6.1,6.2). The energy was calculated using trapezoidal rule, for details on how the energy is calculated see appendix $C$ table $C-1$ ).

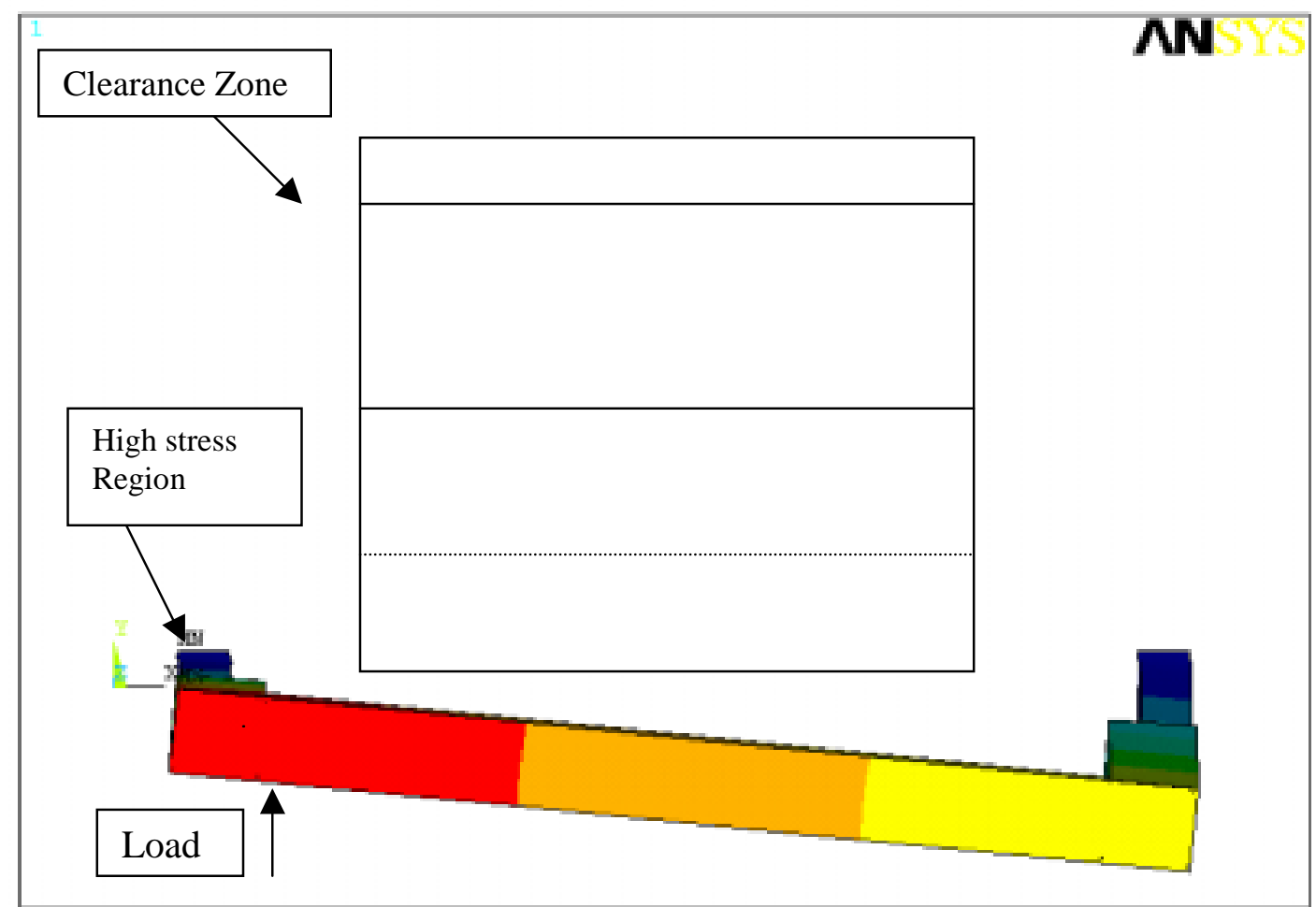

Figure 6.1: Top view for the maximum deflection for the first longitudinal test 


\section{Force vs. Deflection}

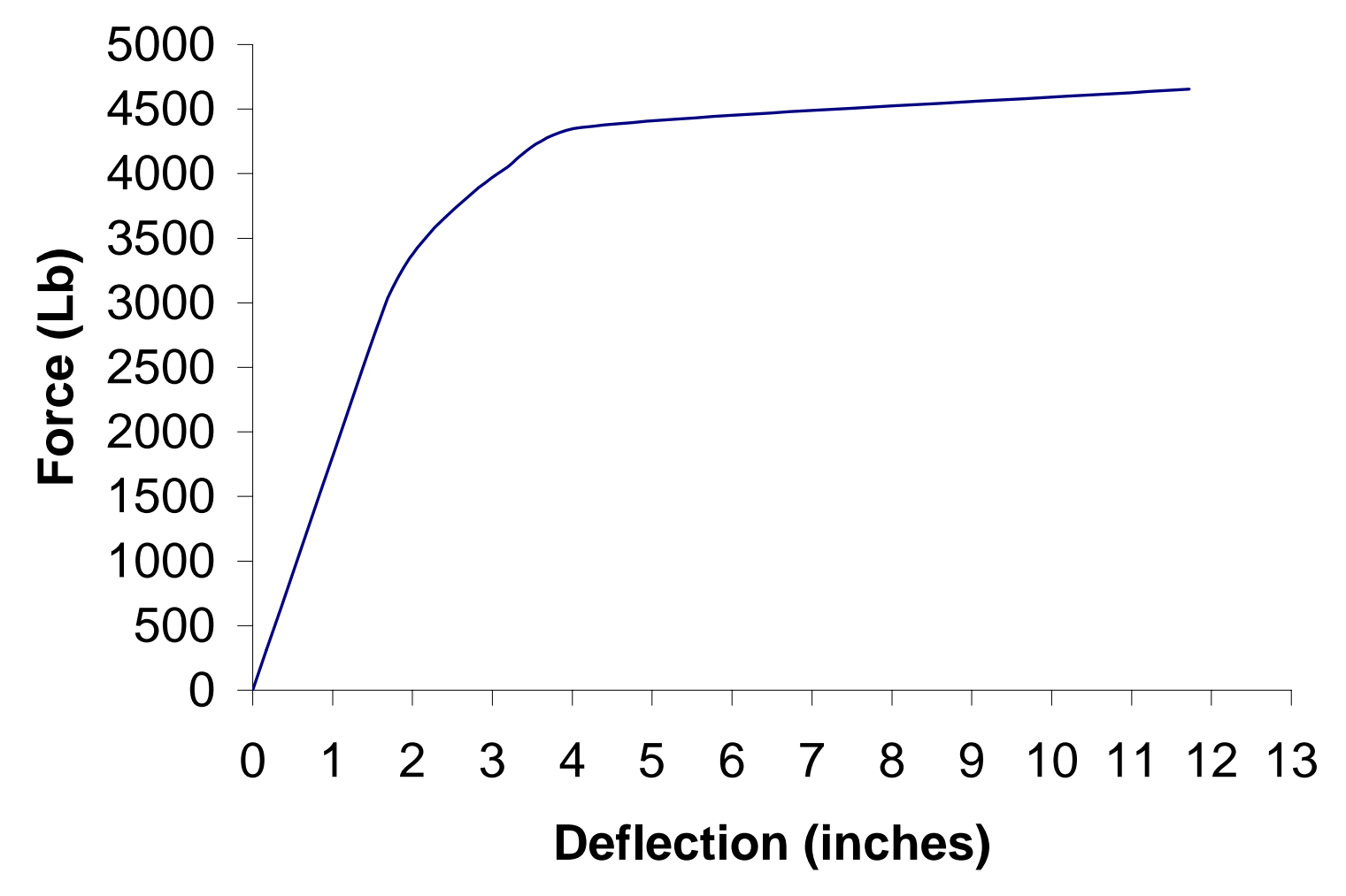

Figure 6.2: Force vs. Deflection for the First Longitudinal Test

Upon reaching the maximum applied load, the clearance zone remained untouched by the deformed AutoROPS. The maximum stress of 63,877 psi was found at the lower portion of the outside fixed tube. 


\section{$\underline{6.3 \text { Vertical Crush Test }}$}

The vertical load was applied on the AutoROPS according to the SAE J-2194 sequence requirements. The effects of the latching mechanisms were not included in this thesis; therefore, we assumed a perfect latch in the mechanisms and contact in the overlap area. An applied force of $16,700 \mathrm{lbs}$. resulted in a maximum difference of 0.809 in. and a maximum stress of $63,713 \mathrm{psi}$, located at the lower part of the outside fixed post of the AutoROPS (This is shown in figure 6.3).

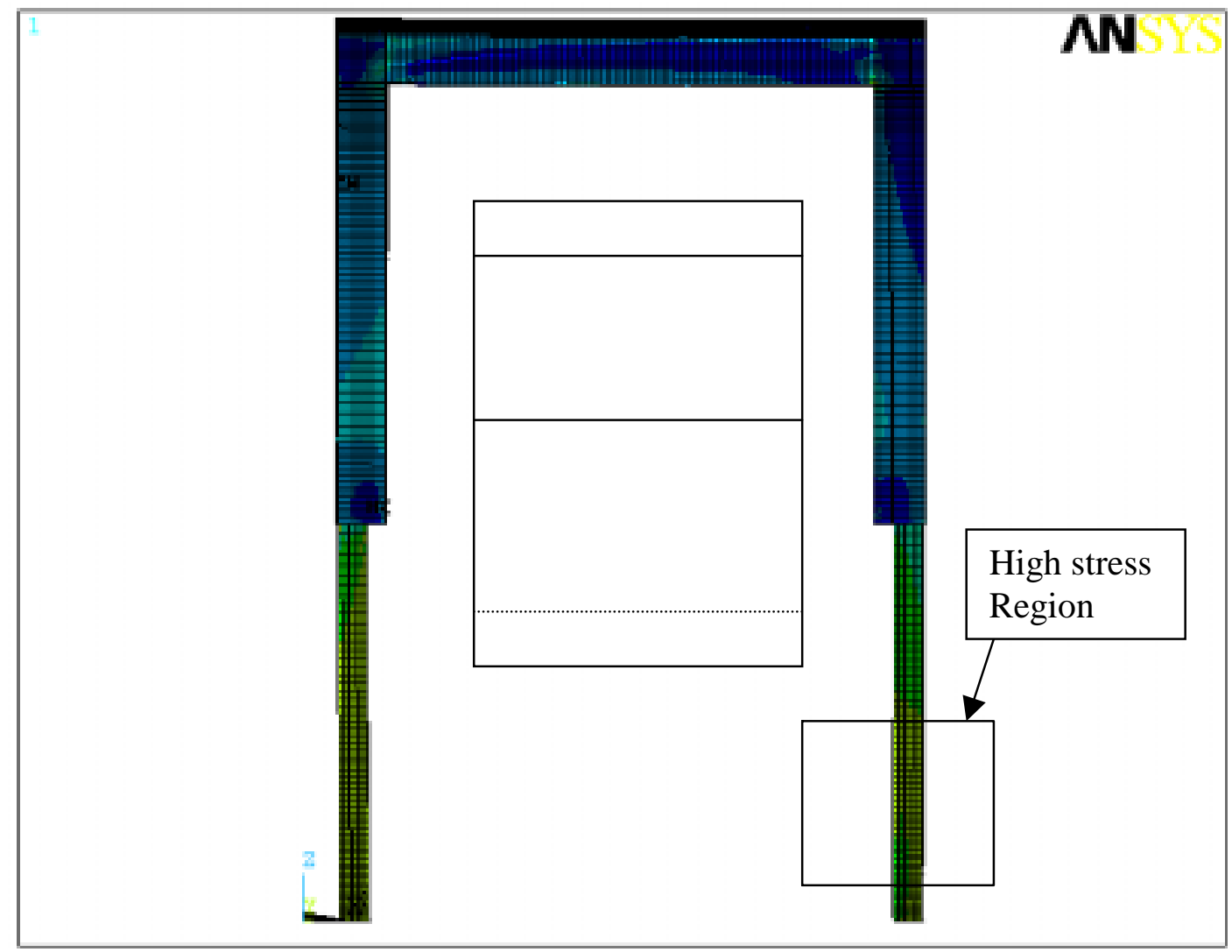

Figure 6.3: Vertical Crush Test Stress Results. 


\subsection{Side Transverse Test}

A load of $7,900 \mathrm{lb}$ was applied transversely on the AutoROPS. The AutoROPS deformed by 8.38 inches and the total energy absorbed by the AutoROPS in this test was 57, 847.8 in-lb. (See figure $6.4,6.5)$.

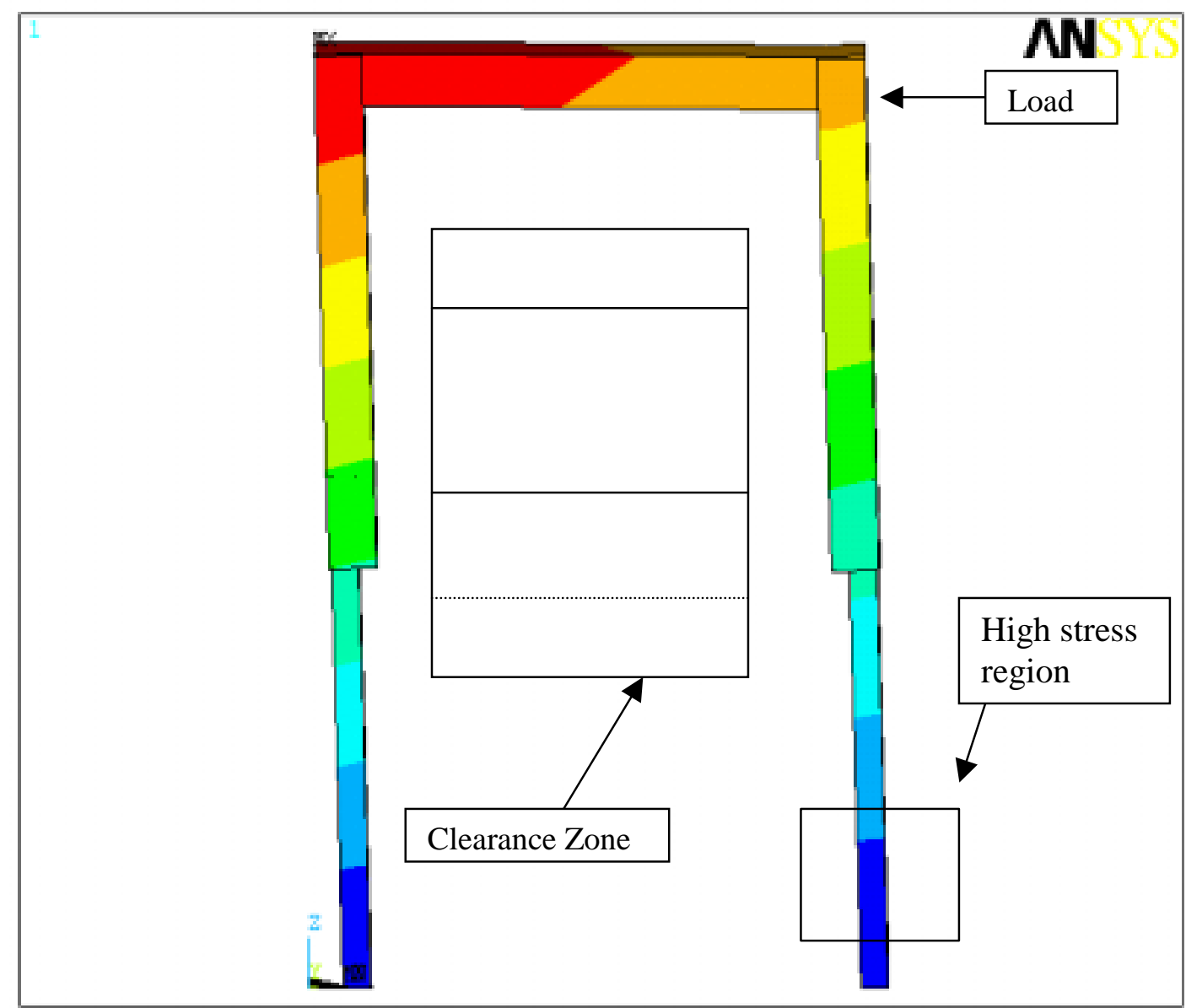

Figure 6.4: Back View for Side Transverse Test

The maximum stress of 64,850 psi was found at the lower part of the fixed post of the AutoROPS (see figure 6.4). 


\section{Force vs. Deflection}

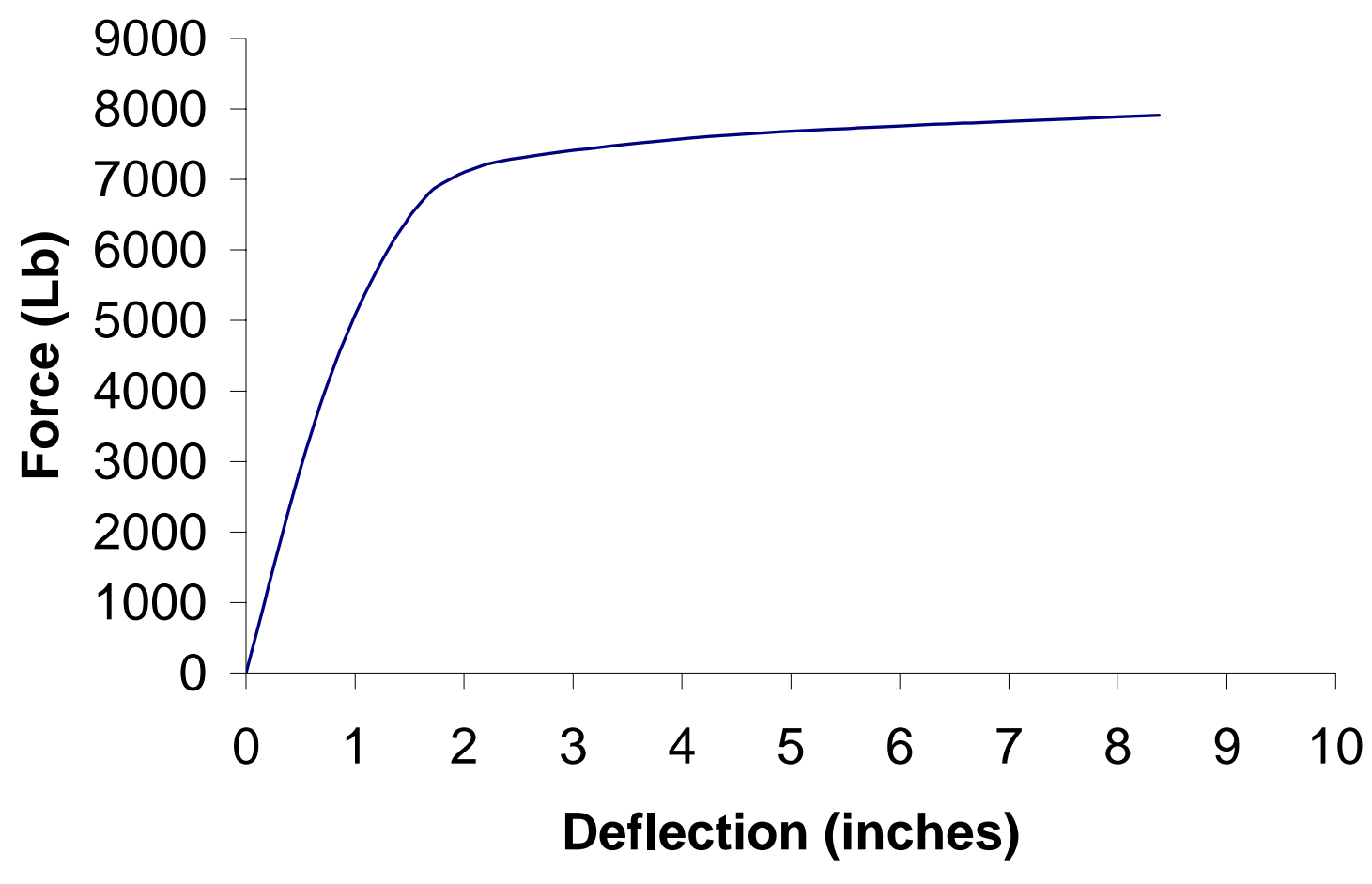

Figure 6.5: Force Deflection Curve for the Side Transverse Test

(For detailed energy calculation see appendix C Table C-2)

\subsection{Second Longitudinal Test}

The maximum force applied on the second longitudinal test reached 4,215 Lb., while the deformation of the AutoROPS was 4.15 inches and the AutoROPS absorbed energy of 11, 589 in-lb. The AutoROPS did not compromise the clearance zone. The maximum stress found during the test was 63,085 psi in the lower portion of the internal fixed post. (See figure 6.6, 6.7). 


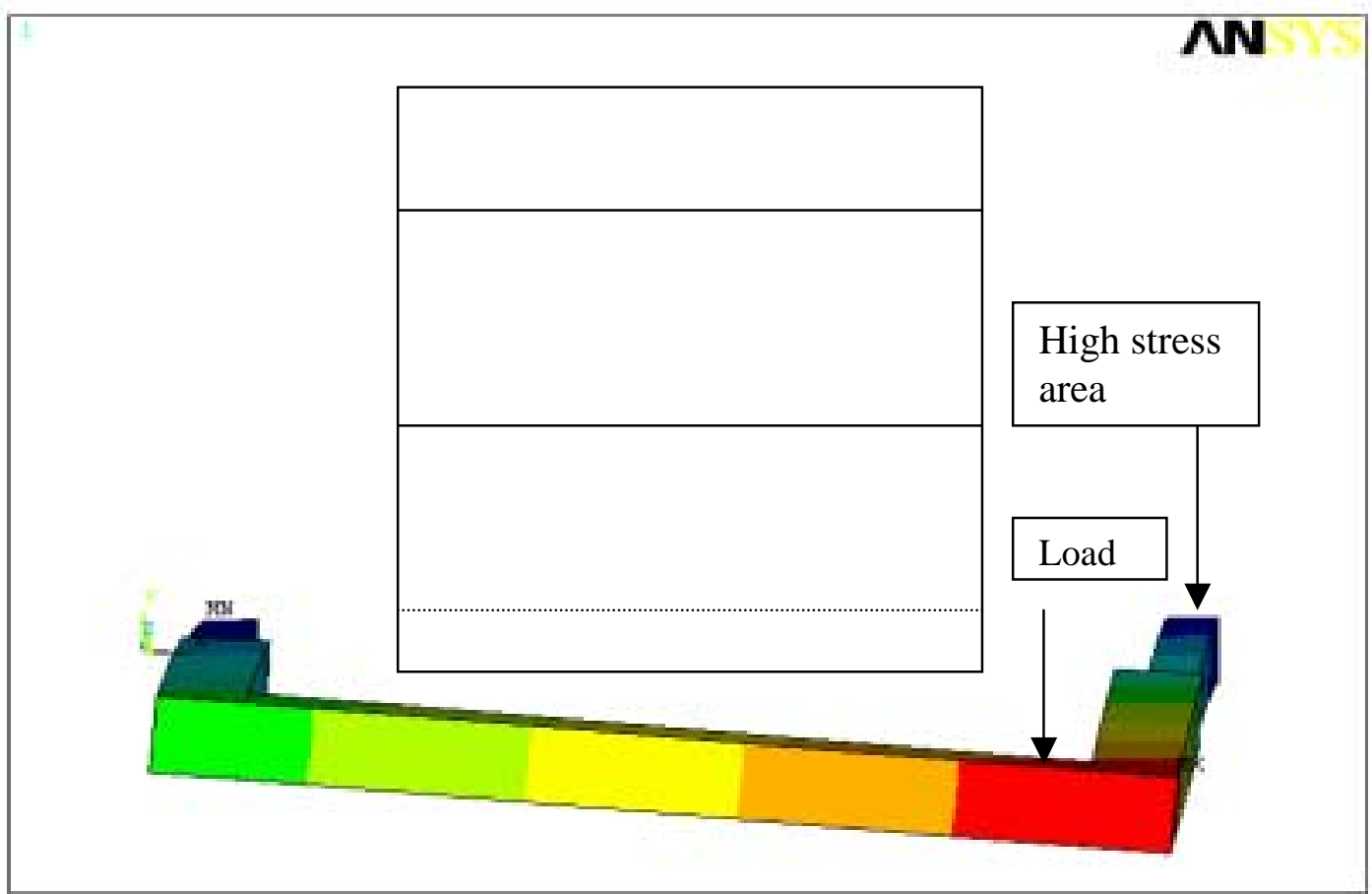

Figure 6.6: Top View of AutoROPS Deflection for the Second Longitudinal Test

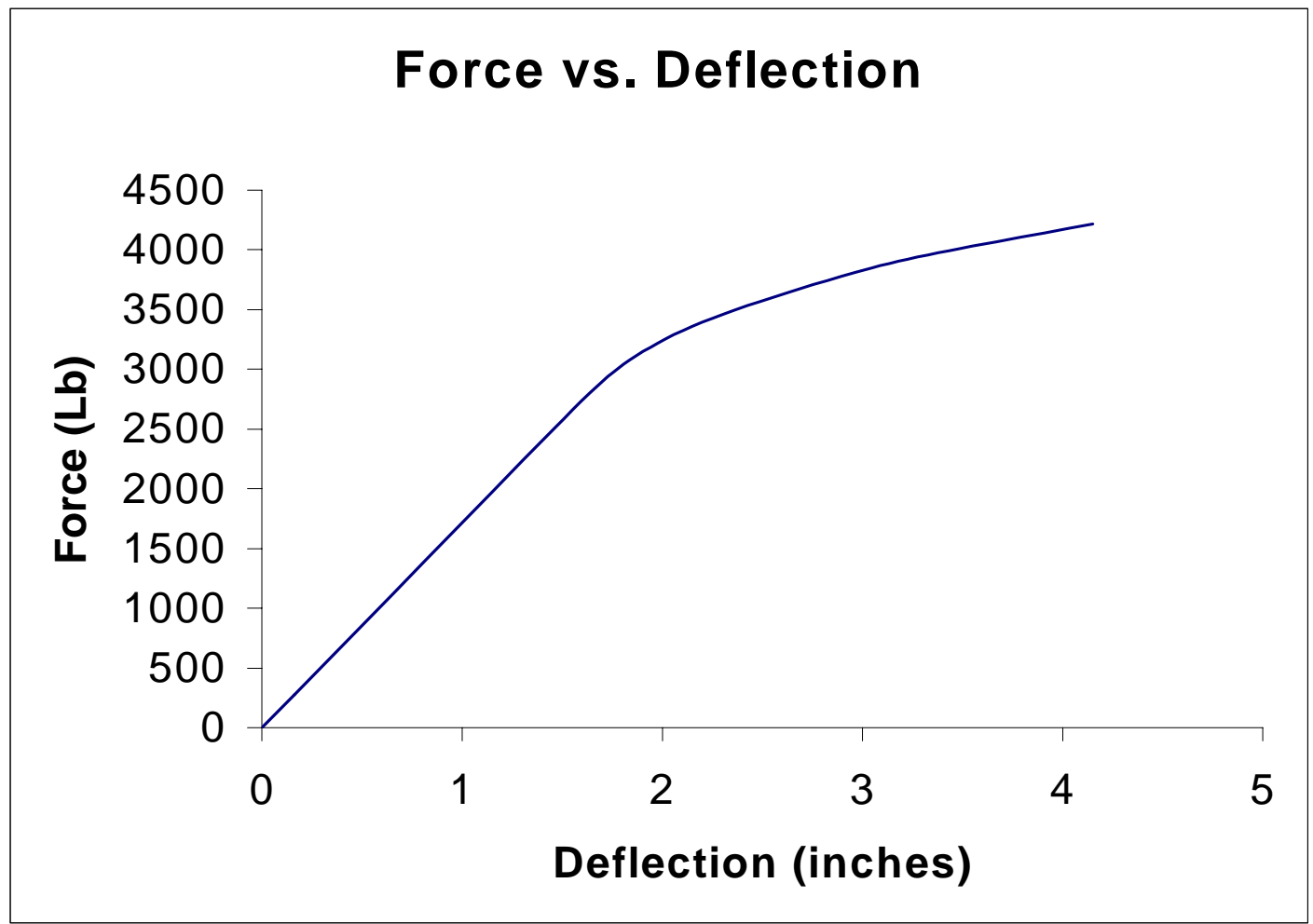

Figure 6.7: Energy Under Force Deflection Curve for the Second Longitudinal Test 


\subsection{The Base}

To insure the safety and the efficiency, the base was carefully studied for the third generation AutoROPS. The base must withstand all stresses being applied as a result from the loads applied on the posts. Part of this study focused on the worst stress cases which were determined to be a direct result of the first longitudinal and the side transverse loading conditions.

For the first longitudinal, the maximum stresses resulted in 97,146 psi and was found in bolt number 3 (see figure 6.8).

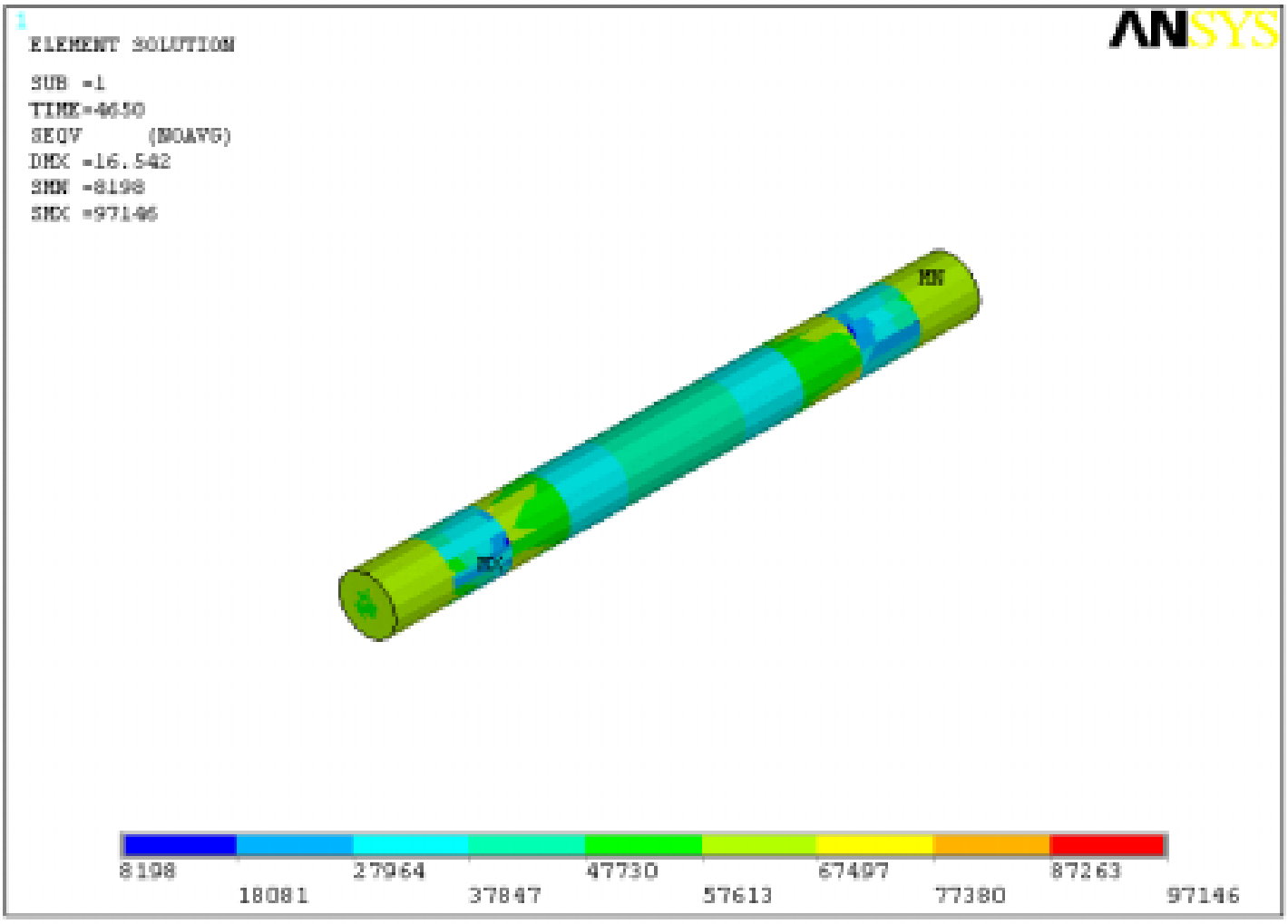

Figure 6.8: Maximum Stress in Bolt Number 3 for the First Longitudinal Test 
For the side transverse test the maximum stress was 89,826 psi, in bolt number 5. (See figure 6.9).

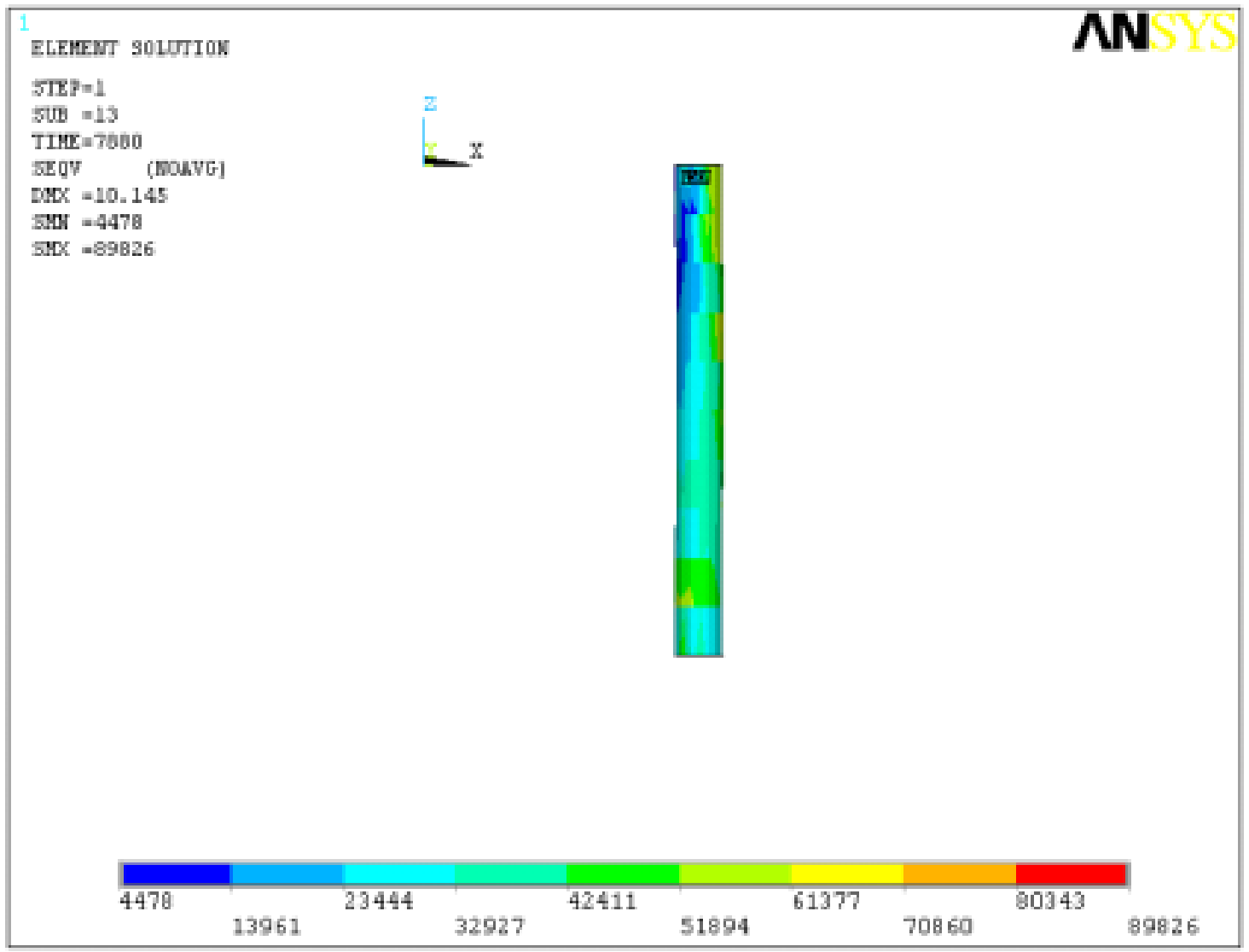

Figure 6.9: Maximum Stress on Bolts Number 5 for Side Transverse Test

The bolts were preloaded with a tension and force of $10,000 \mathrm{lb}$.

For more details about the preload and the stresses in all the bolts see appendix A. 


\section{Chapter 7}

\section{Redesigned Model of the NIOSH Third Generation}

\section{AutoROPS}

\section{1: Introduction}

The purpose behind analyzing the main model of third generation AutoROPS was to find the highest stresses. After the analysis was completed, it is needed to be determined how to redesign the AutoROPS. During this time, consideration needed to be made as to the dimensions required to fit the overlap area between the deployable outside and the fixed inside posts, and how the latching mechanisms would work while leaving enough room for the deployment of the springs in the upper part of the Auto ROPS.

\section{2: Selecting Post Dimensions}

The first step in selecting the proper post size while redesigning the AutoROPS was the basic design size. The thickness and the overlap volume of the redesign posts are similar to the main AutoROPS model but the difference was in the post height between them. The redesigned model has an upper post of 39 inches and lower post of 29 inches in order to allow 10 inches of room for the spring to fit inside the upper post and above the lower post (see figure 
7.1, 7.2). The total number of elements in the redesigned model of the third generation Auto ROPS is 27,048 elements.
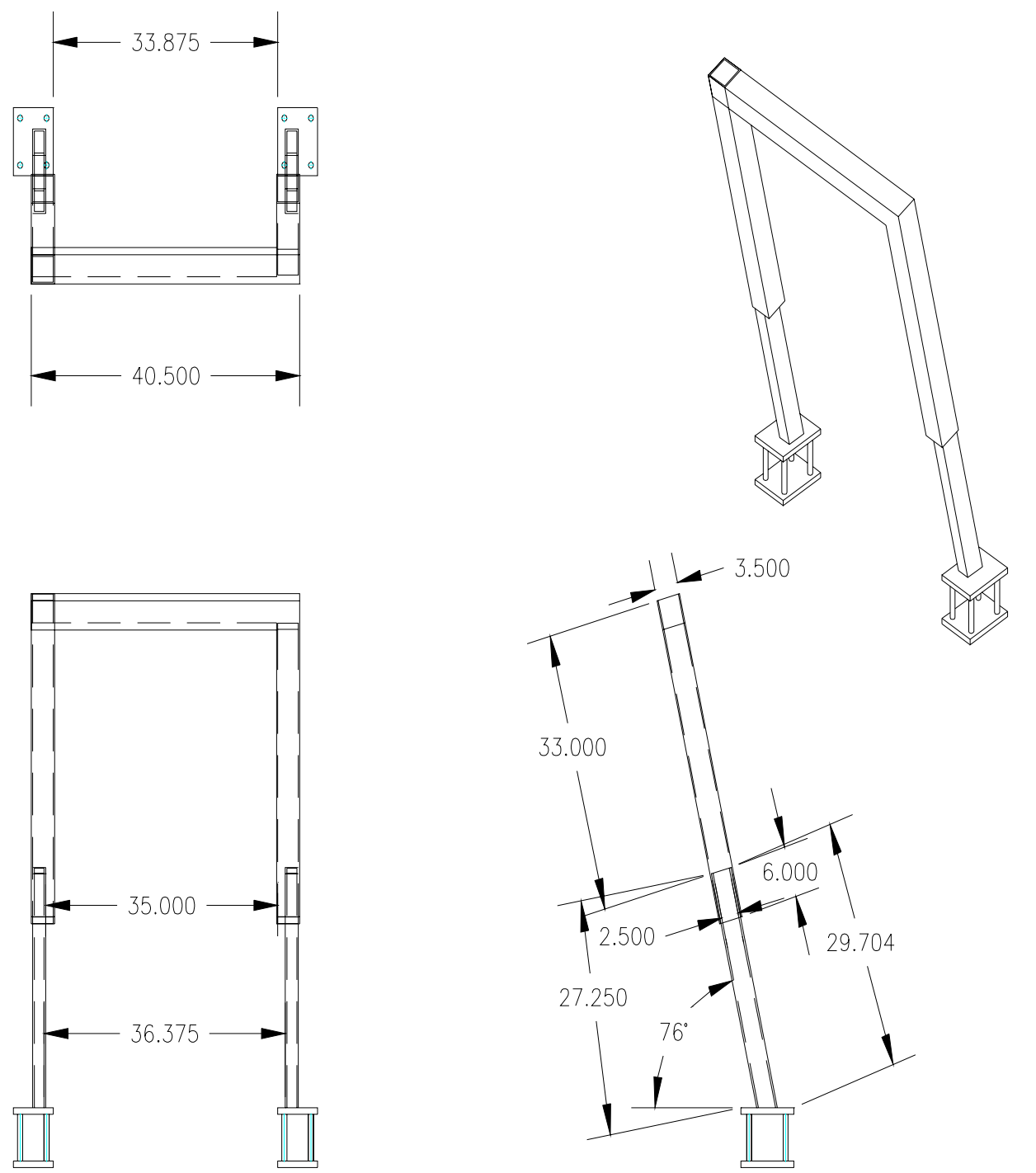

Figure 7.1: Dimensions for the Redesigned Third Generation AutoROPS 


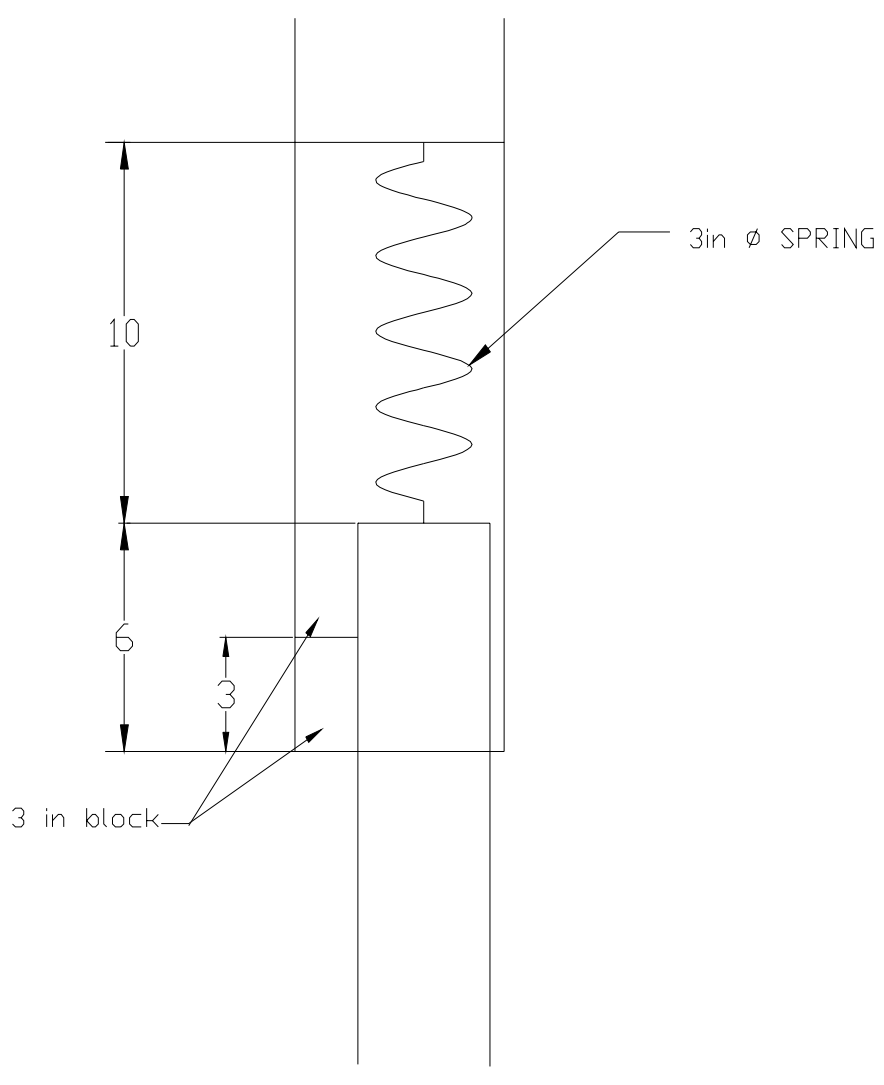

Figure 7.2: Overlap Dimensions for the Redesigned Third Generation AutoROPS 


\section{3: First Longitudinal Test Results}

The load on the first longitudinal test was gradually increased until it reaches the maximum required load of $4,630 \mathrm{lb}$., with the maximum deflection being 11.72 inches. The AutoROPS did withstand the applied load and absorbed a total energy of 46,203 in-lb. (See Figure 7.3, 7.4).

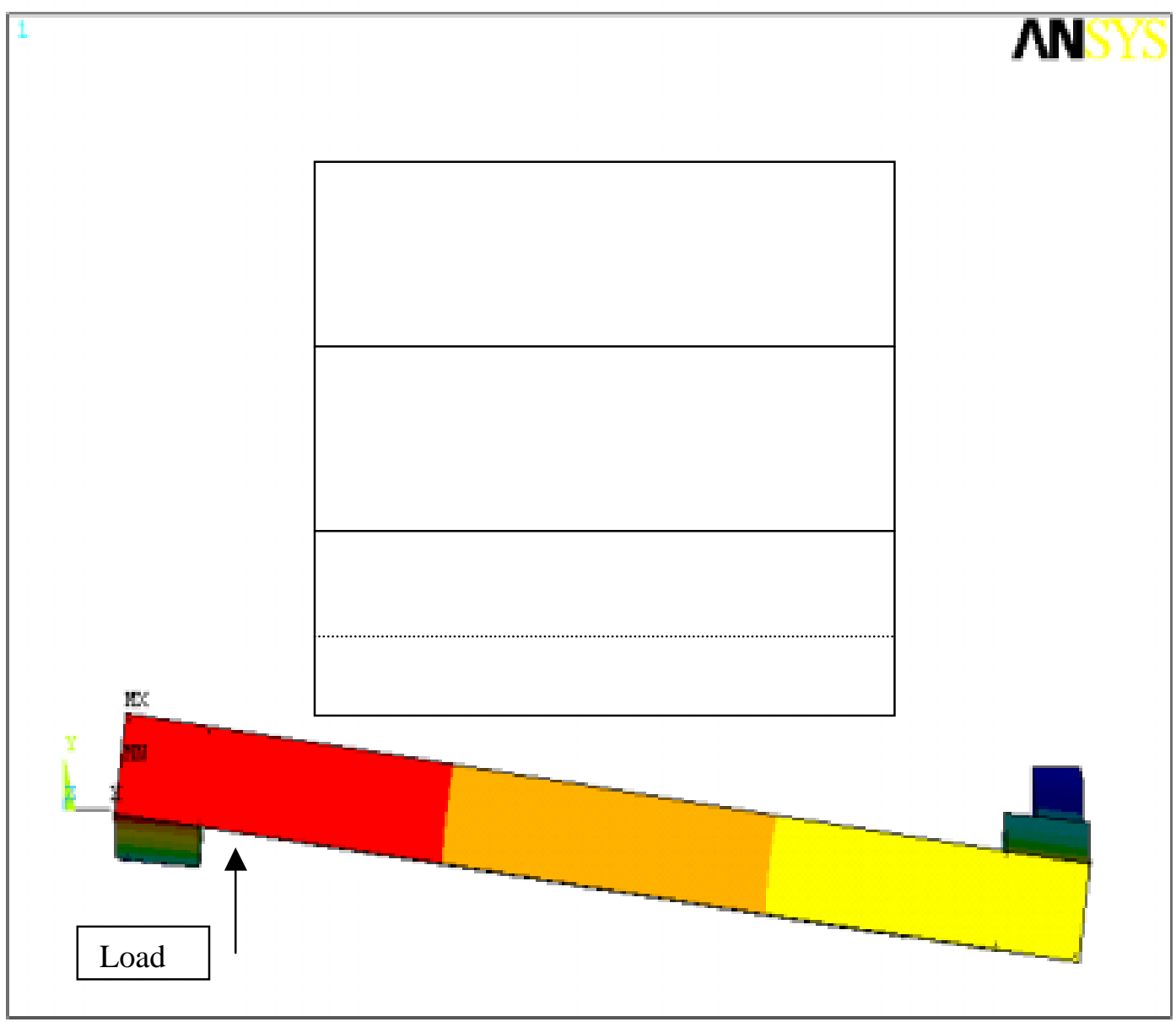

Figure 7.3: Top View for the Redesigned First Longitudinal Test 


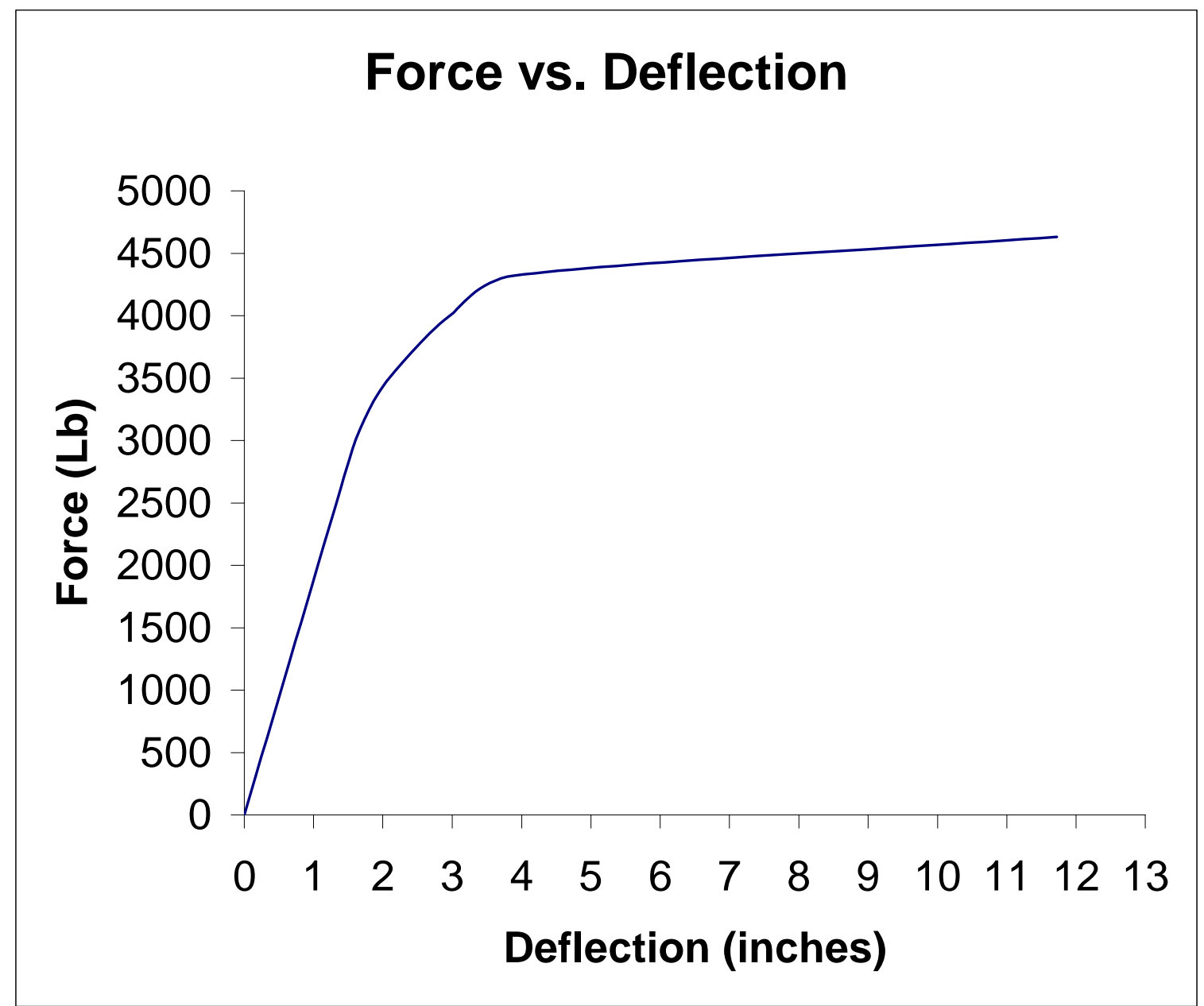

Figure 7.4: Force Deflection Curve for the Redesigned First Longitudinal Test

Stresses are the primary aspects studied in this design. The maximum stress of 64,044 psi was found at the lowest 10 inches the inside fixed post height of the AutoROPS.

(For detailed energy calculation see appendix - C Table C-4) 


\subsection{Vertical Crush Test}

The vertical load was the next load to be applied on the AutoROPS based on the SAE J-2195 sequence requirements. No latching mechanisms were considered in this thesis. Therefore, we assumed a perfect contact in the overlap area. The results needed are deflection and the energy being absorbed by the AutoROPS.

The force applied was $16,700 \mathrm{lb}$. The AutoROPS had relatively low deflection during this test. As shown in figure 7.5, the maximum stress was 64,823 psi and deflection was 0.78 inches.

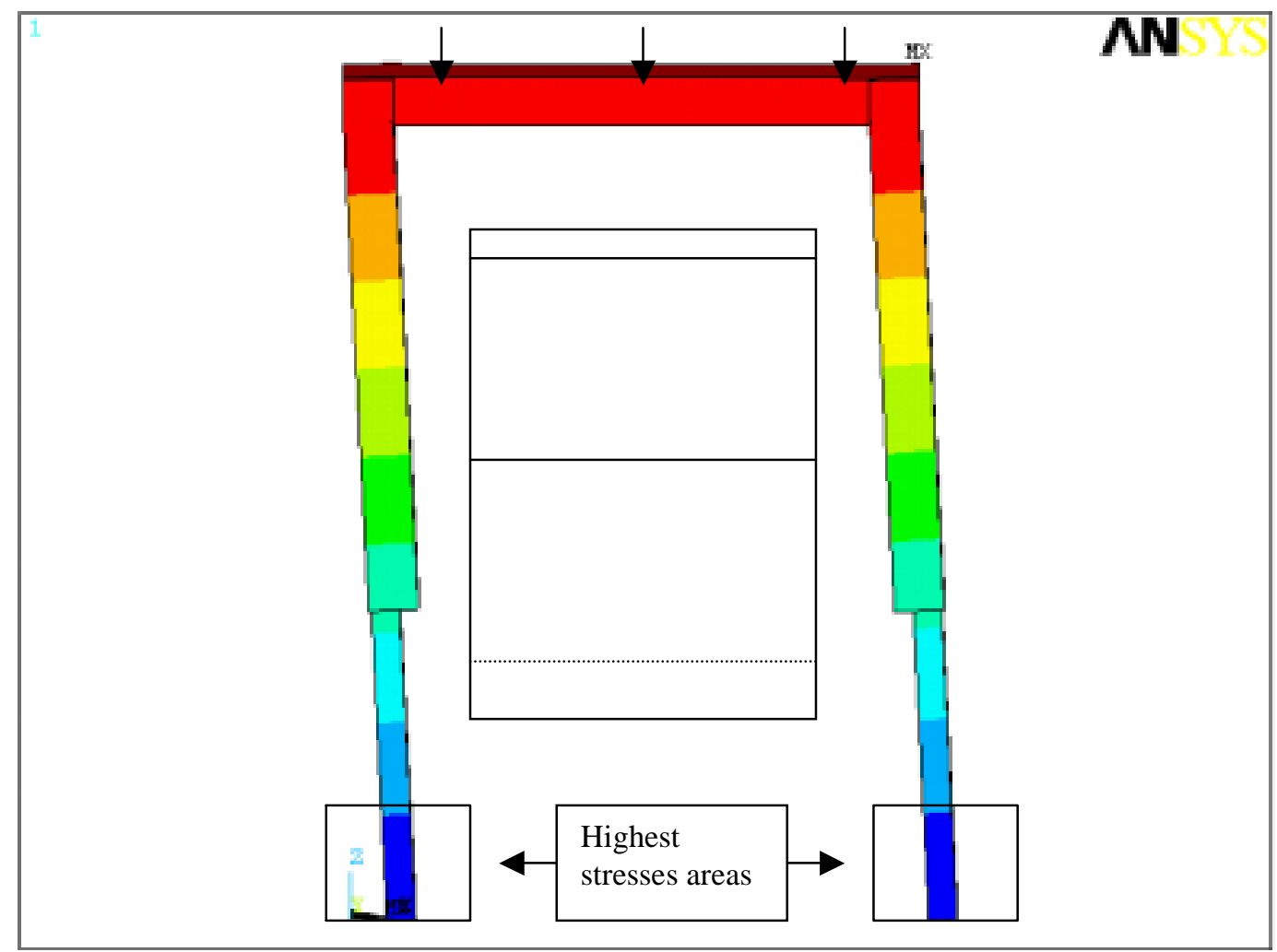

Figure 7.5: Deflection for the Vertical Crush Test 


\section{5: Side Transverse Test}

A force of $8,450 \mathrm{lb}$ was applied on the side of the AutoROPS. It deformed 7.8 inches and absorbed a total energy of 57, 962 in-lb. (See figure 7.6). The maximum stress found was 64,283 psi at the lowest part of the internal fixed post.

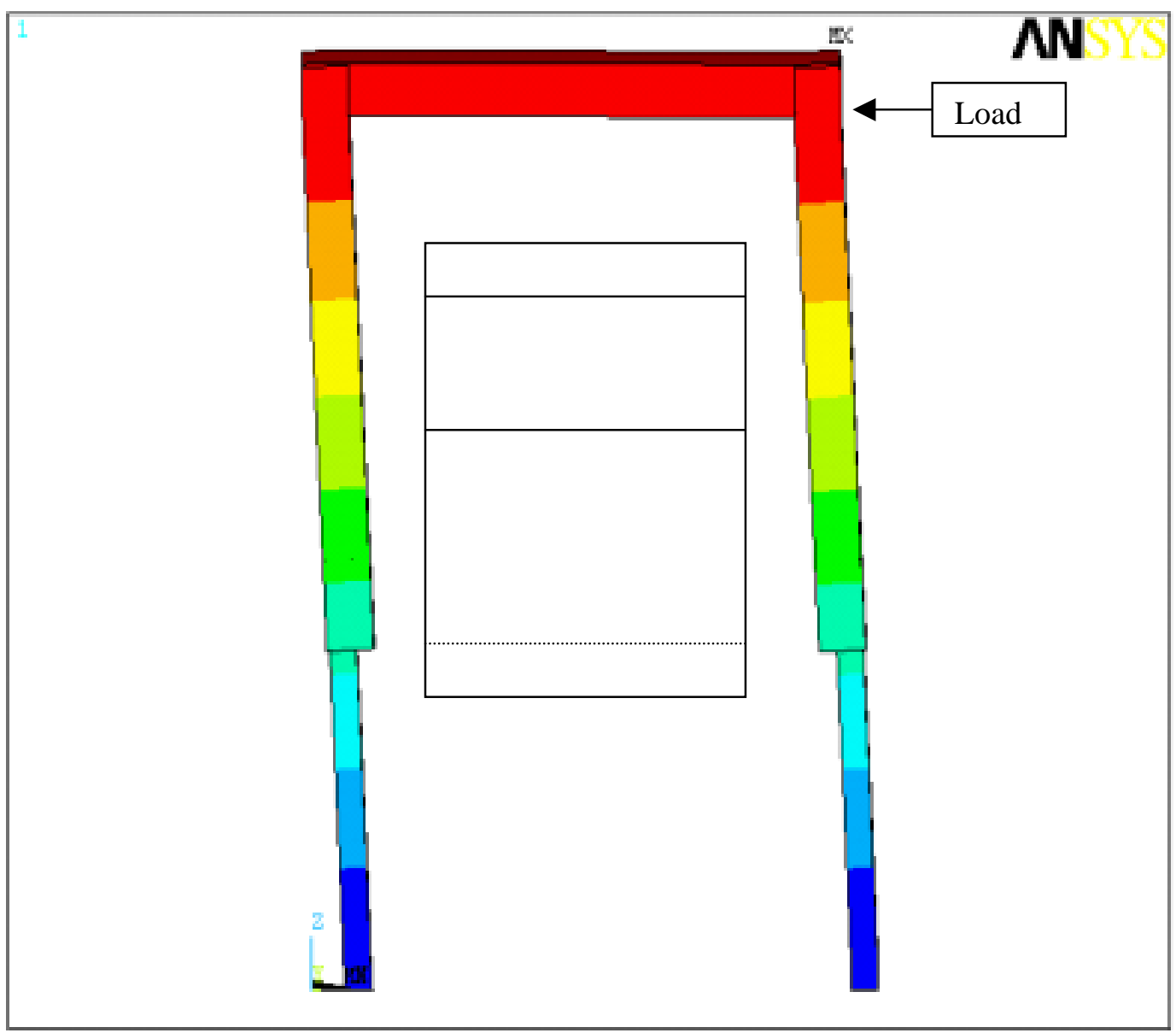

Figure 7.6: Rear View for the Side Transverse Test 


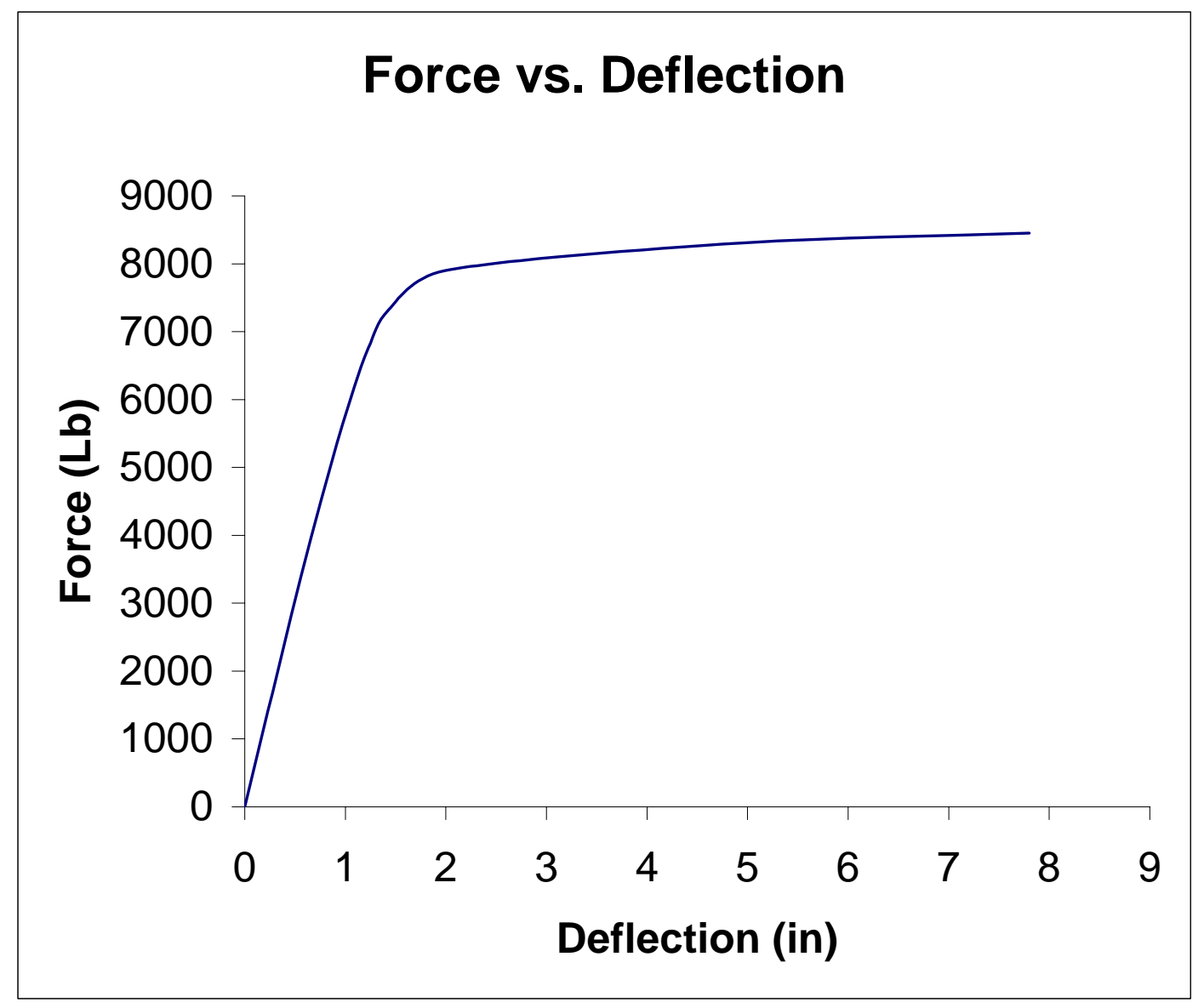

Figure 7.7: Force Deflection Curve for the Side Transverse Test

The deflected AutoROPS did not intrude into the clearance zone.

The AutoROPS is mounted at an angle tilted 14 degrees away from the clearance zone (see figure 7.1).

(For detailed energy calculation see appendix - C Table C-5) 


\section{6: Second Longitudinal Test}

The maximum force applied on the second longitudinal test was 4,250 lb., thus causing the AutoROPS to deform 4.0 inches. The AutoROPS absorbed 11,581 in-lb of energy (see figure 7.8,7.9).

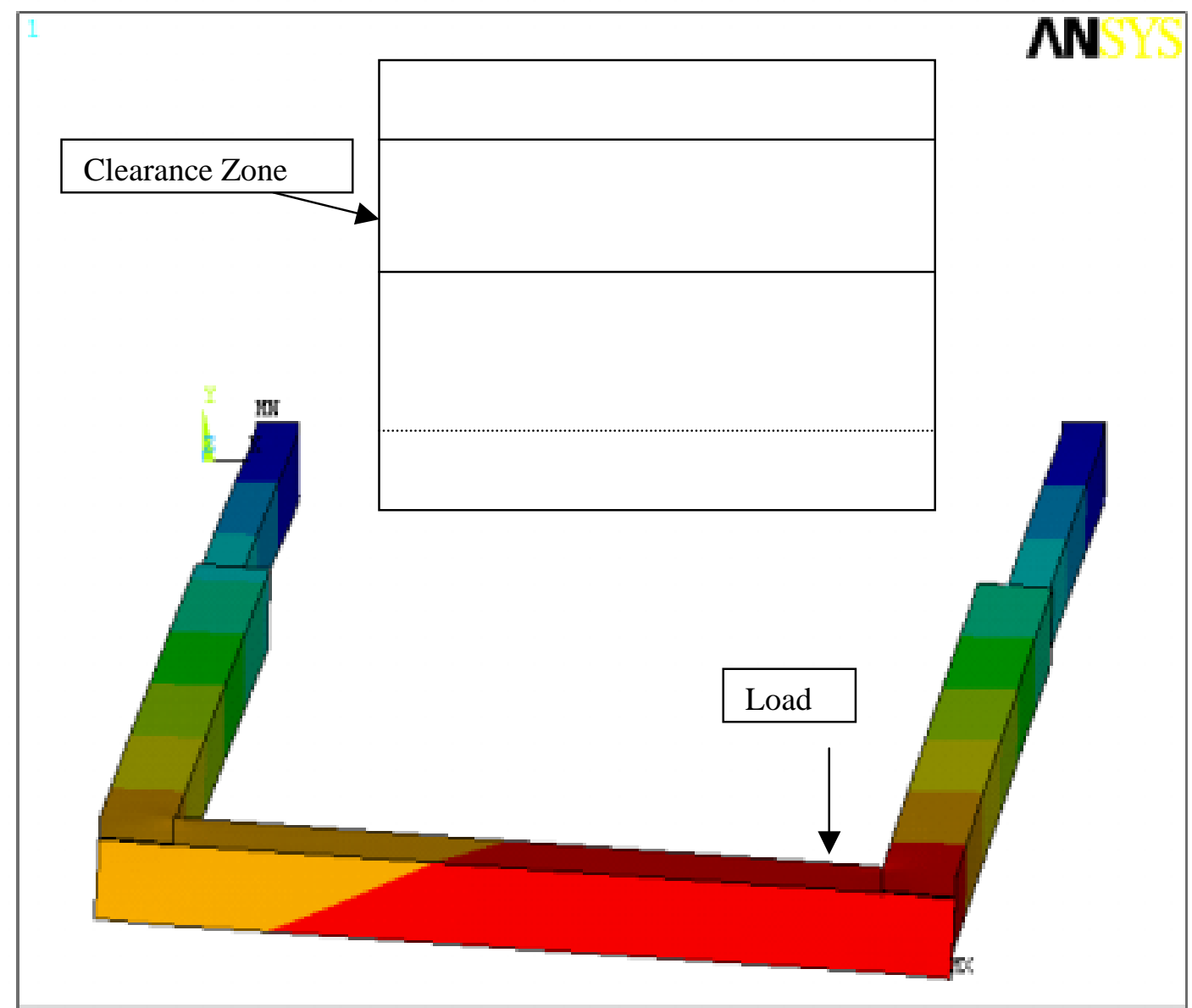

Figure 7.8: Top View of the Deflection for the Second Longitudinal Test 


\section{Force vs. Deflection Curve}

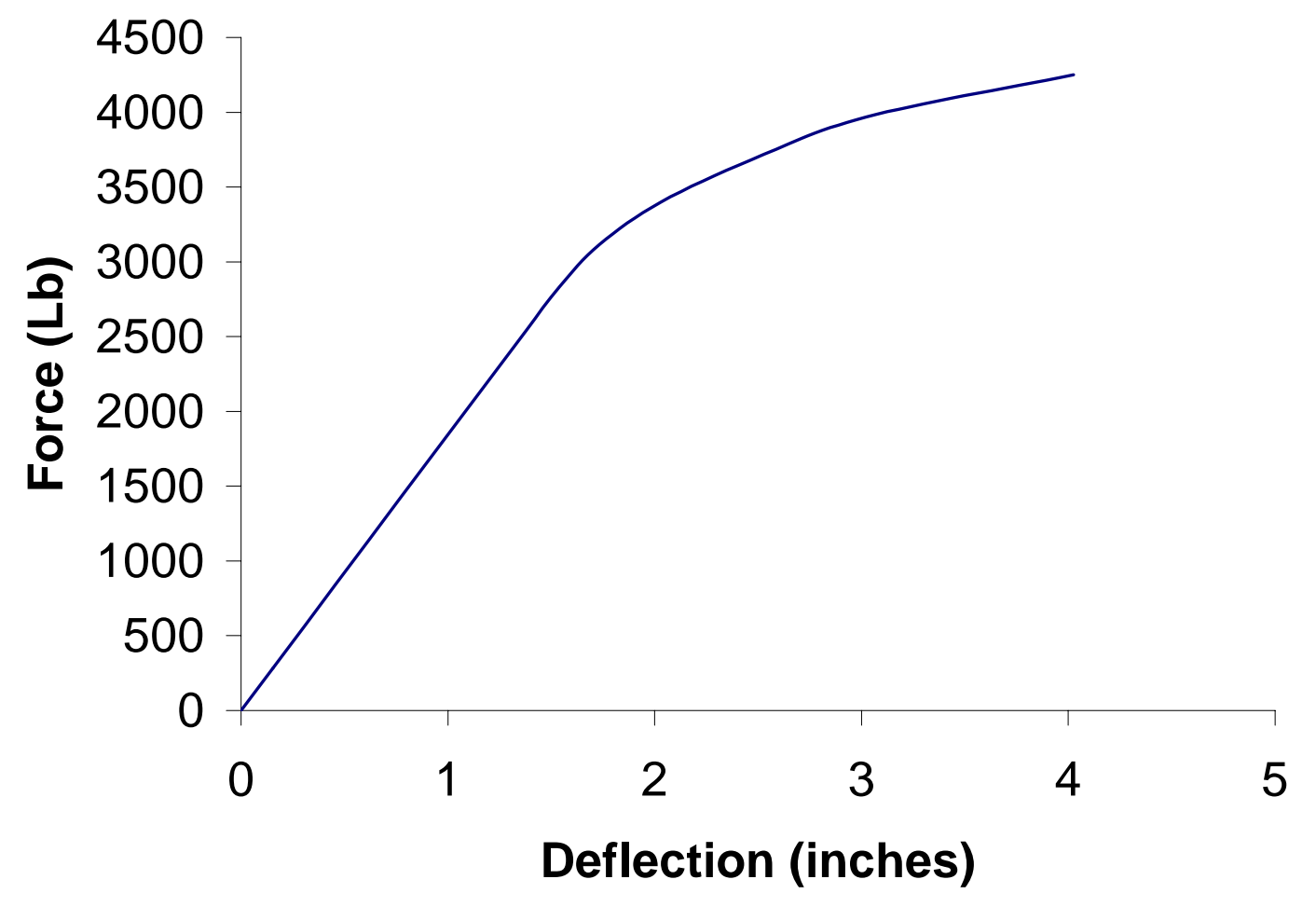

Figure 7.9: Force Deflection Curve for Second Longitudinal Test

Again all of the energy being absorbed by the AutoROPS was calculated using Trapezoidal rules and Excel spreadsheet. (For a detailed program on how the energy was calculated in this test see appendix C Table C-6). 


\section{Chapter 8}

\section{Comparable Experimental Results}

\section{1: Introduction}

Any theoretical study must be comparable to an experimental result for verification, but the question here is "How can the comparable range be found?" The best answer for that is to have some experimental results as a background, and compare the similar model to those results. Since no experimental tests have yet been performed on the third generations AutoROPS, we had to find experimental data to relate to the third generation AutoROPS. An experimental study was conducted by on designing Cost-effective Rollover Protective Structures (CROPS) is close in shape and boundary conditions to the third generation AutoROPS, therefore the results of that study was taken as reference to the third generation AutoROPS theoretical study.

Two CROPS prototypes were built from common structural materials conforming to popular consensus standards. The prototype designs have used standard steel pipe and rectangular tubing (similar to the one used in third generation AutoROPS). The first prototype is made out of 2 " $\times 3$ " $\times 1 / 4$ " while the second prototype made from $2 " x 4 " x 1 / 4 "$ rectangular tubing and same materials (see figure 8.1 ). The 
aim of the CROPS is to increase ROPS usage on tractors by providing farmers with lower cost ROPS. (Harris, McKenzie, et.al,.)

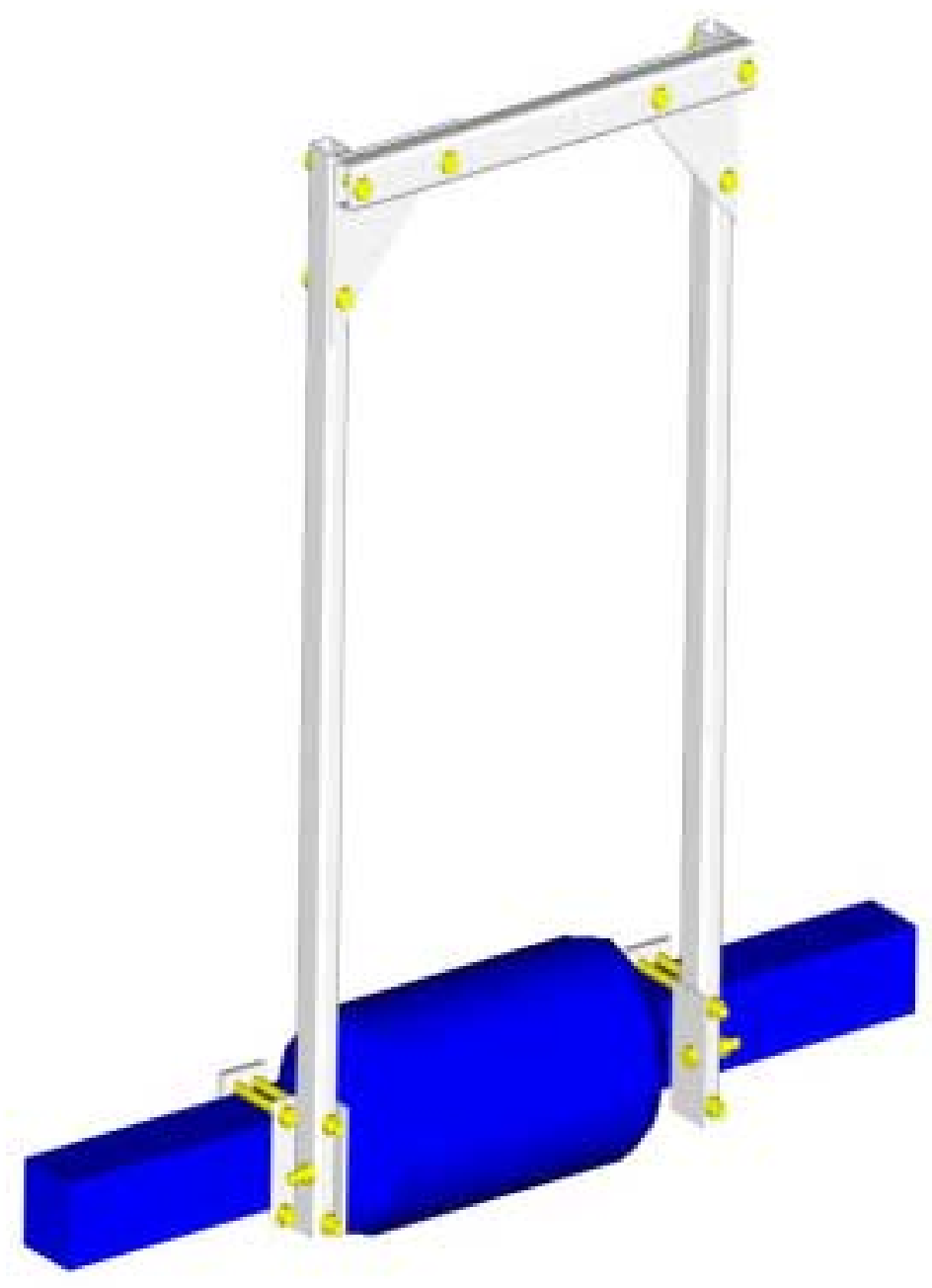

Figure 8.1: Prototype 1, Rectangular Tubing Similar to the Third Generation AutoROPS Used to Build the CROPS

For the first longitudinal tests of the CROPS, the maximum load applied was 4,030 lb. and the maximum deflection was $13.0 \mathrm{in}$. The 
maximum energy absorbed is $39,830 \mathrm{in}-\mathrm{lb}$. This test did fall short of meeting the energy criterion, which is $46,193 \mathrm{in}-\mathrm{lb}$, (see figure 8.2 , 8.3).

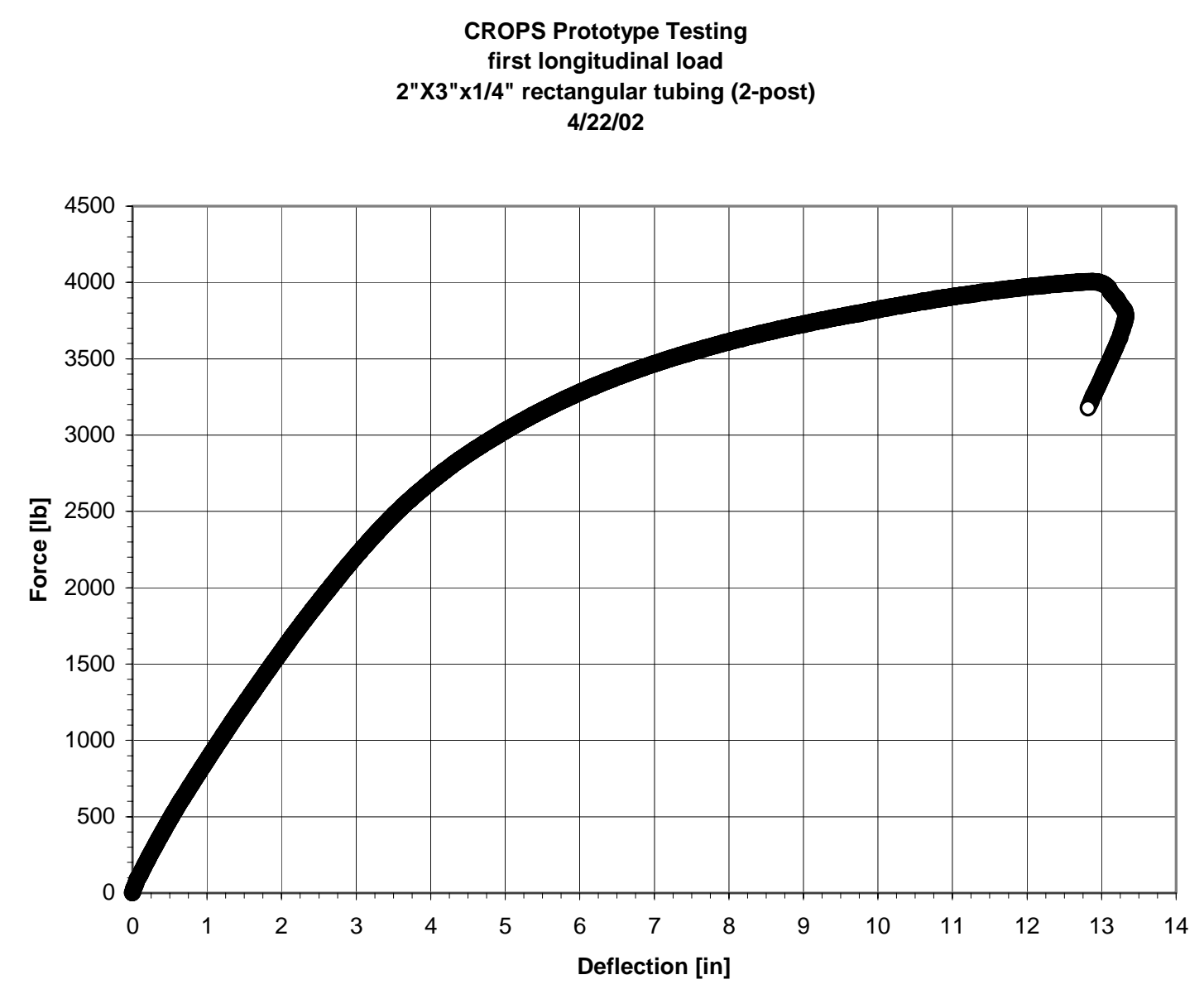

Figure 8.2: Longitudinal Load Test, Force vs. Deflection Curve for Prototype 1 
CROPS Prototype Testing

first longitudinal load

2"x3"x1/4" rectangular tubing (2-post)

4/22/02

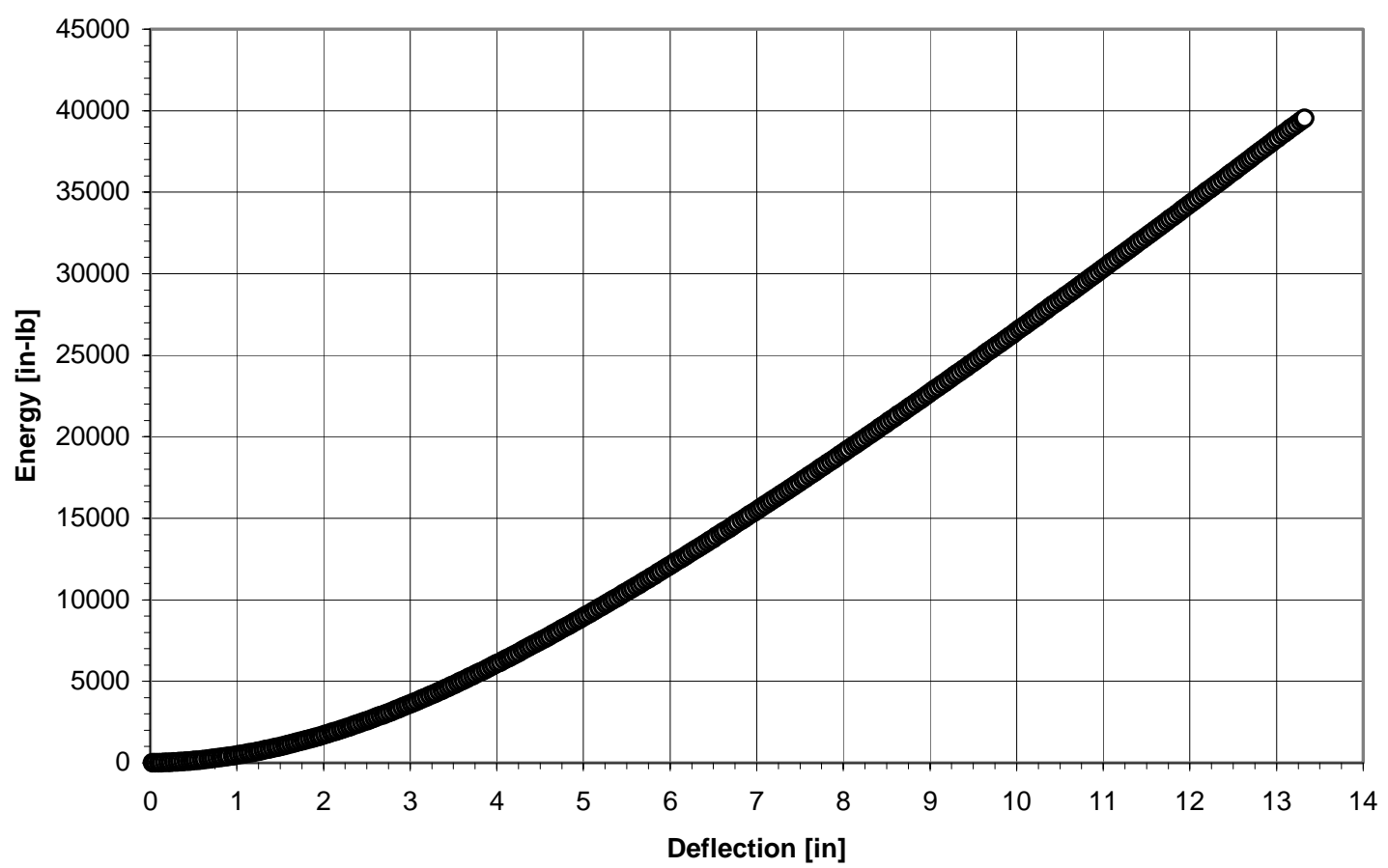

Figure 8.3: Energy Curve for First Longitudinal Test

Prototype 1 came very close to passing the energy criterion of the first longitudinal load based on the SAE J-2194. Consequently, only minor changes were required in the design to meet all requirements of the longitudinal loading test. The vertical posts were changed from a 2"x3"x1/4" cross-section to 2"x4"x1/4". Longer bolts were then needed to secure the vertical posts to the axle housing angles, and for attaching the upper diagonal reinforcing corner plates and crossbar to the vertical posts. Force and energy vs. deflection results are shown in figures 8.4 and 8.5 (Harris, McKenzie, et.al). 
CROPS Prototype Testing

2"x4"x1/4" rectangular tubing (2-post)

First longitudinal test $-4 / 30 / 02$

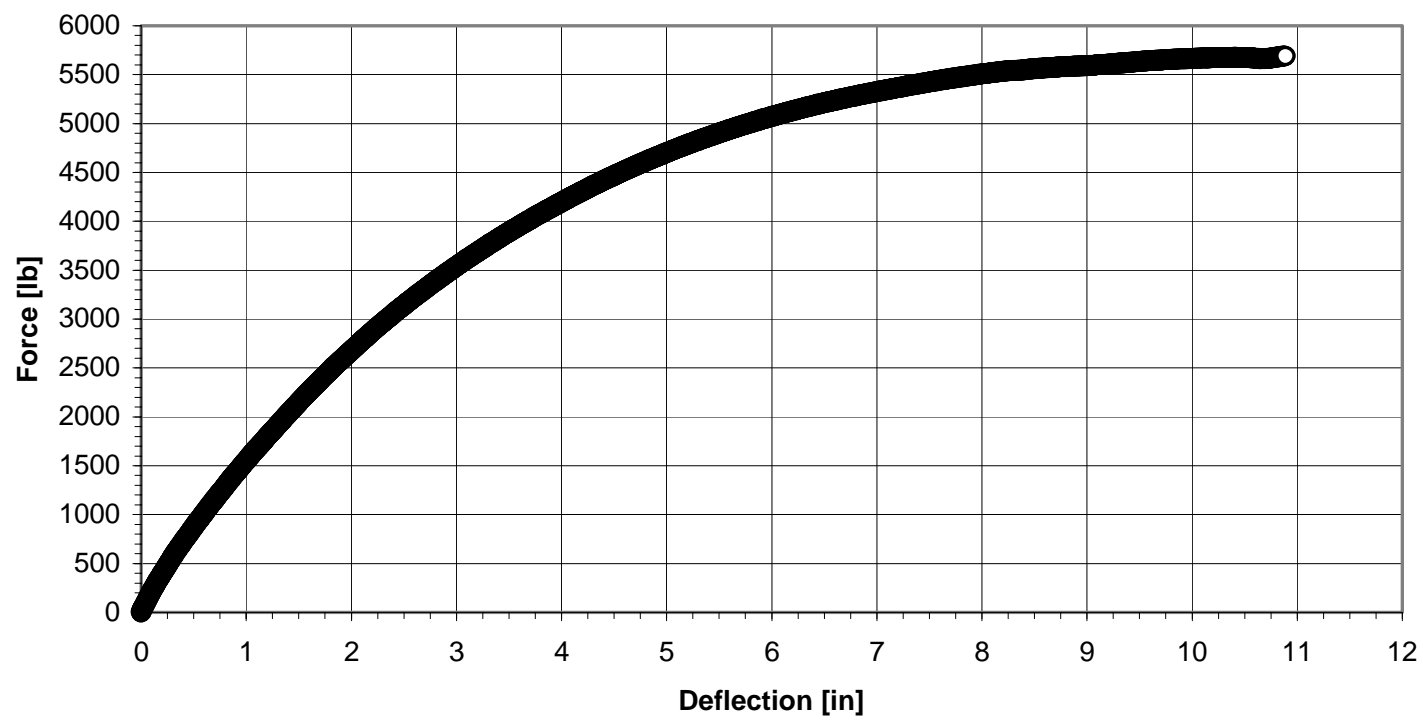

Figure 8.4: First Longitudinal Test, Force vs. Deflection Curve of Prototype 2

CROPS Prototype Testing

2"x4"x1/4" rectangular tubing (2-post)

First longitudinal test $-4 / 30 / 02$

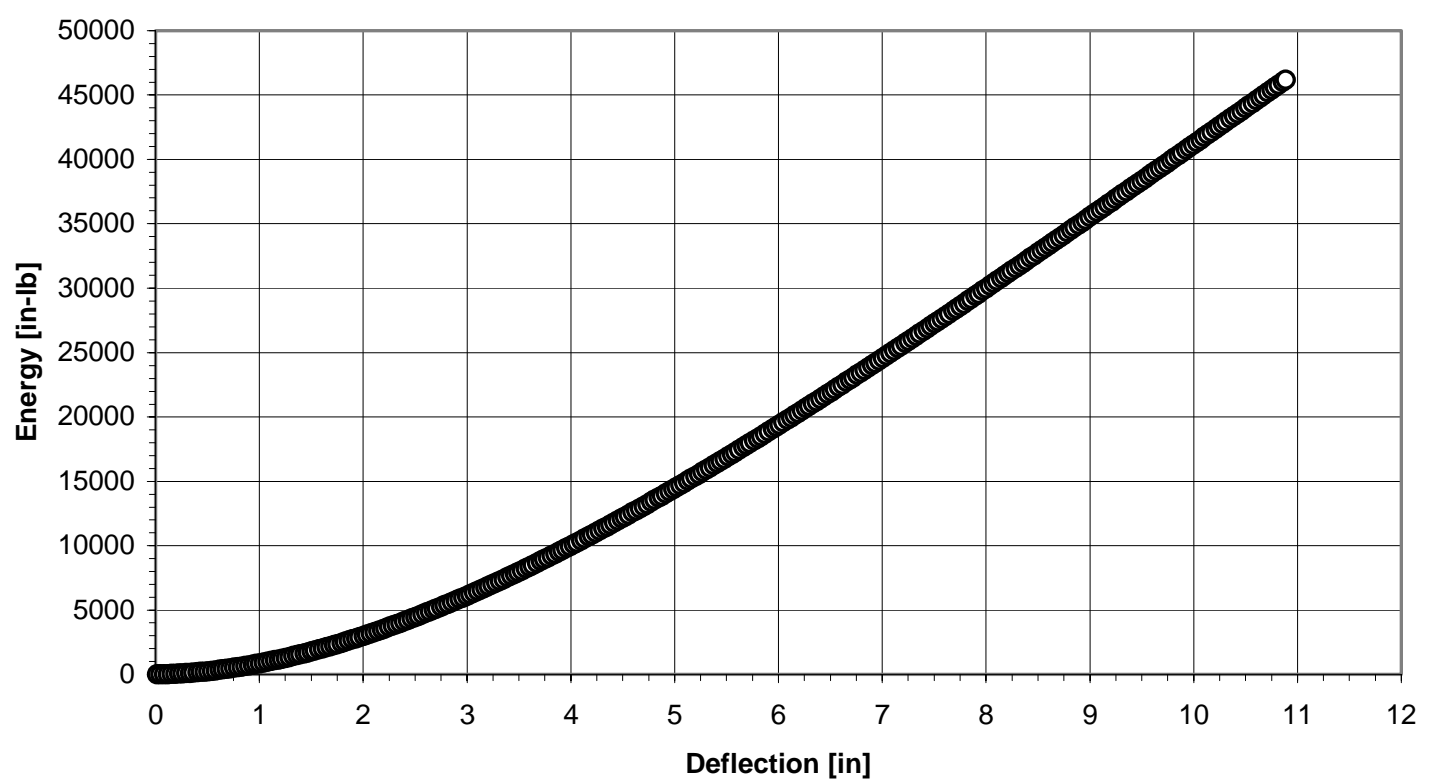

Figure 8.5: First Longitudinal Test, Energy vs. Deflection Curve of Prototype 2 
Figure 8.7 shows the deformed ROPS shaped at the end of this testing with a string indicating the ground plane for assessment of exposure criteria as required by SAE J-2194. This is similar to the test set up for prototype 1 and for the third generation AutoROPS (Harris, McKenzie, et.al).

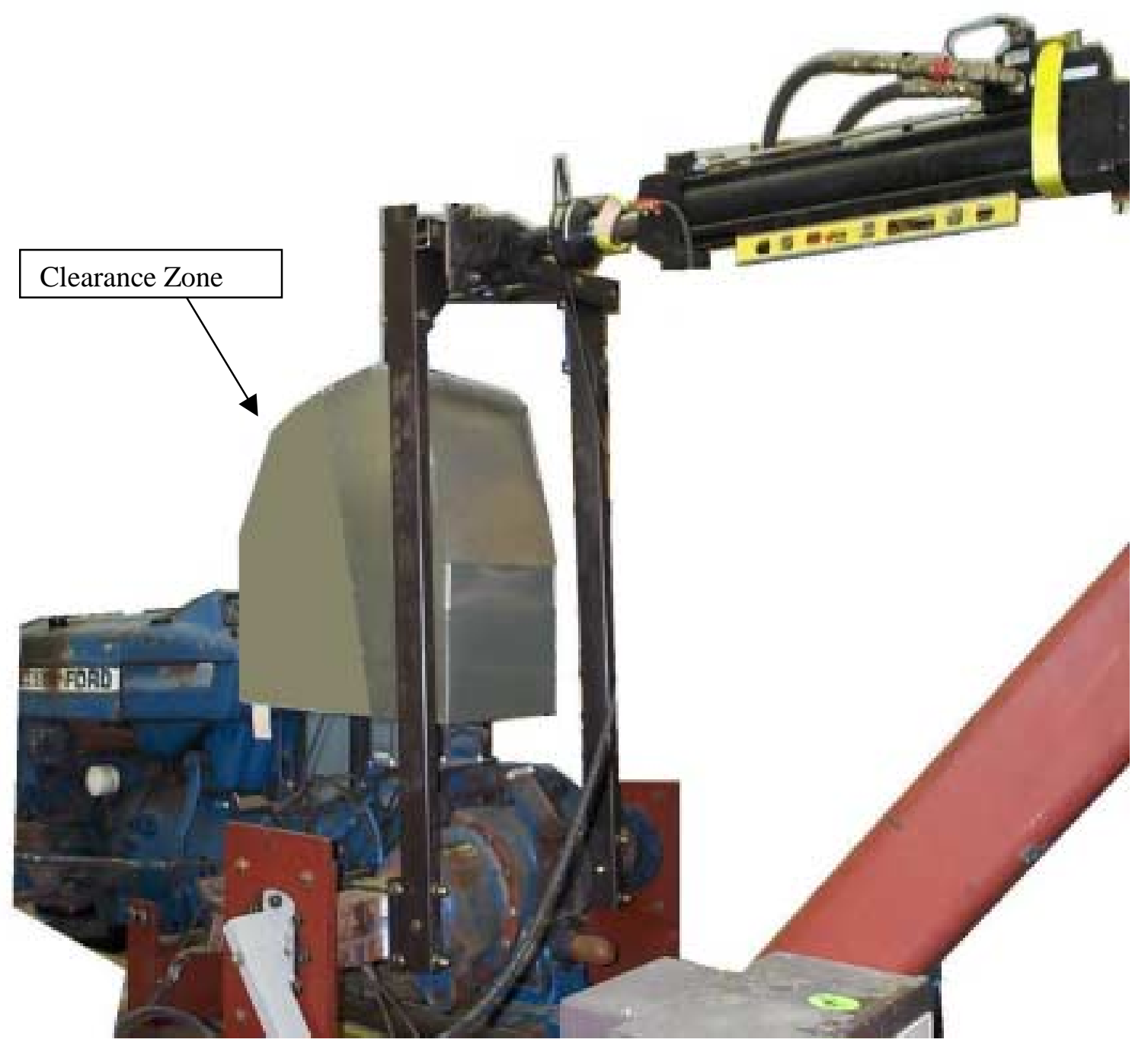

Figure 8.6: First Longitudinal Test Set Up for Prototype 2 


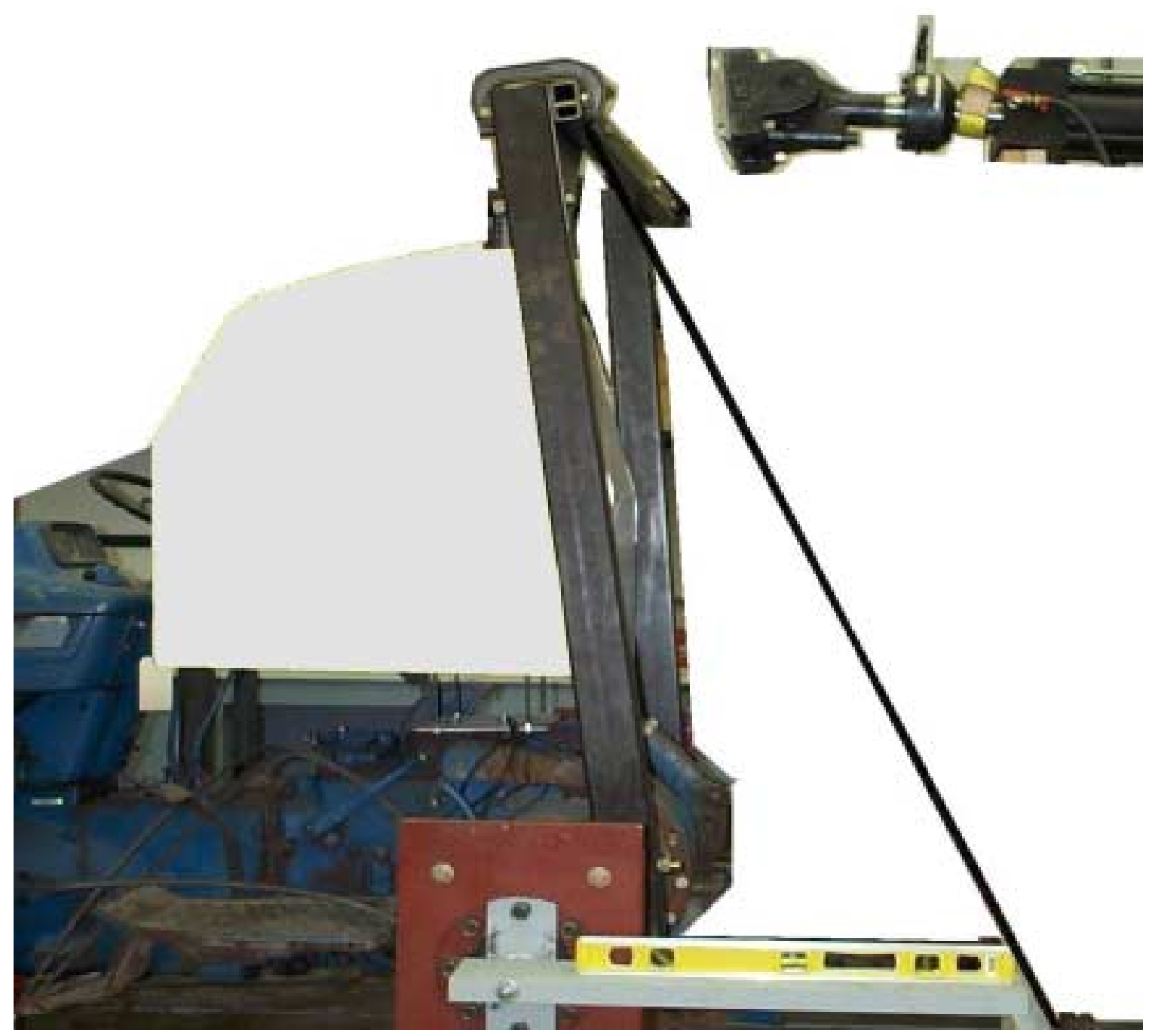

Figure 8.7: The Deformed Shape for Prototype 2 After the First Longitudinal Load

As shown in Figure 8.7, longitudinal loading was terminated after the prototype met the energy criterion of 46, 193 in-lb. This criterion was met an applied load of 5,621 lb. and a deflection of $11 \mathrm{in}$. This CROPS prototype did not enter the clearance zone at any point during the longitudinal loading. The final position of the prototype after loading the ground plane representation is shown in Figure 8.7. 
The next test in the static sequence of SAE J-2194 is a vertical crush test. The references mass in this study for the tractor is equal to $8220 \mathrm{lb}$. The load applied was16, $763 \mathrm{lb}$. Figure 8.8 shows the test setup for the vertical crush load.

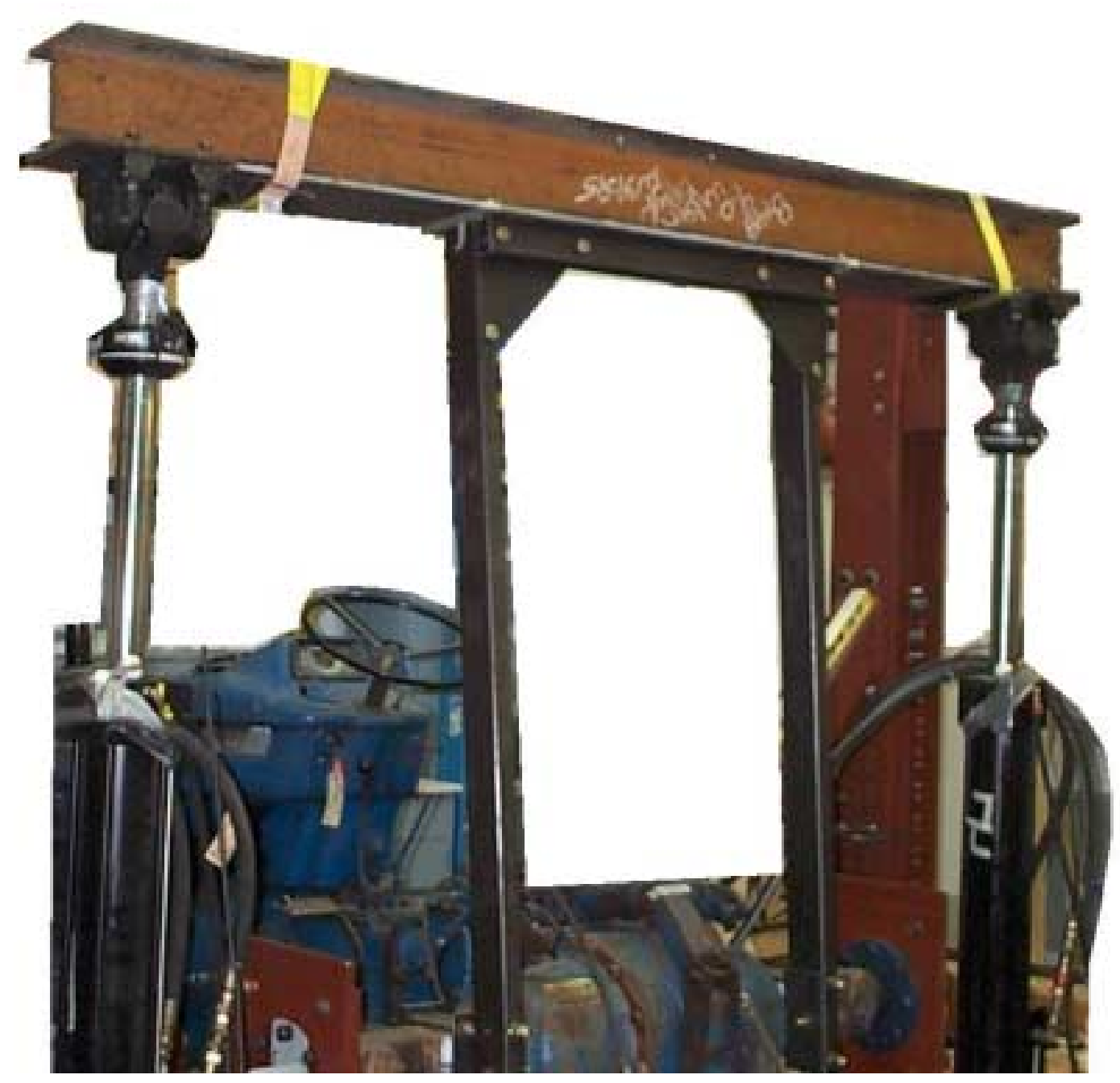

Figure 8.8: Vertical Crush Test set Up for Prototype 2

The maximum resultant load from the two actuators in this test was $15,810 \mathrm{lb}$., and did not reach the load criterion calculated for a 
reference mass of $8220 \mathrm{lb}$. The resultant load did not reach the criterion due to uneven loading between the two actuators and the manner in which the load rate was controlled. The test was run under load control with an equivalent ramp command being sent to each actuator. When the first actuator reached the end level for the ramp (in this case $74,560 / 2=37,280 \mathrm{~N}(16,763 / 2=8382 \mathrm{lb})$.$) , a hold signal was$ generated regardless of the position of the other actuator. In this vertical crush test, actuator 2 reached $8,320 \mathrm{lb}$. and a hold signal was generated. By reaching a resultant load of $15,810 \mathrm{lb}$., this was an acceptable crush test for a reference mass of $7,753 \mathrm{lb}$. The next test in the static test sequence of SAE J-2194 was the transverse load test. The reference mass was chosen for this study $8,220 \mathrm{lb}$. This resulted in an energy requirement of $57,744 \mathrm{in}-\mathrm{lb}$. Figure 8.9 shows the setup for the transverse load test. 


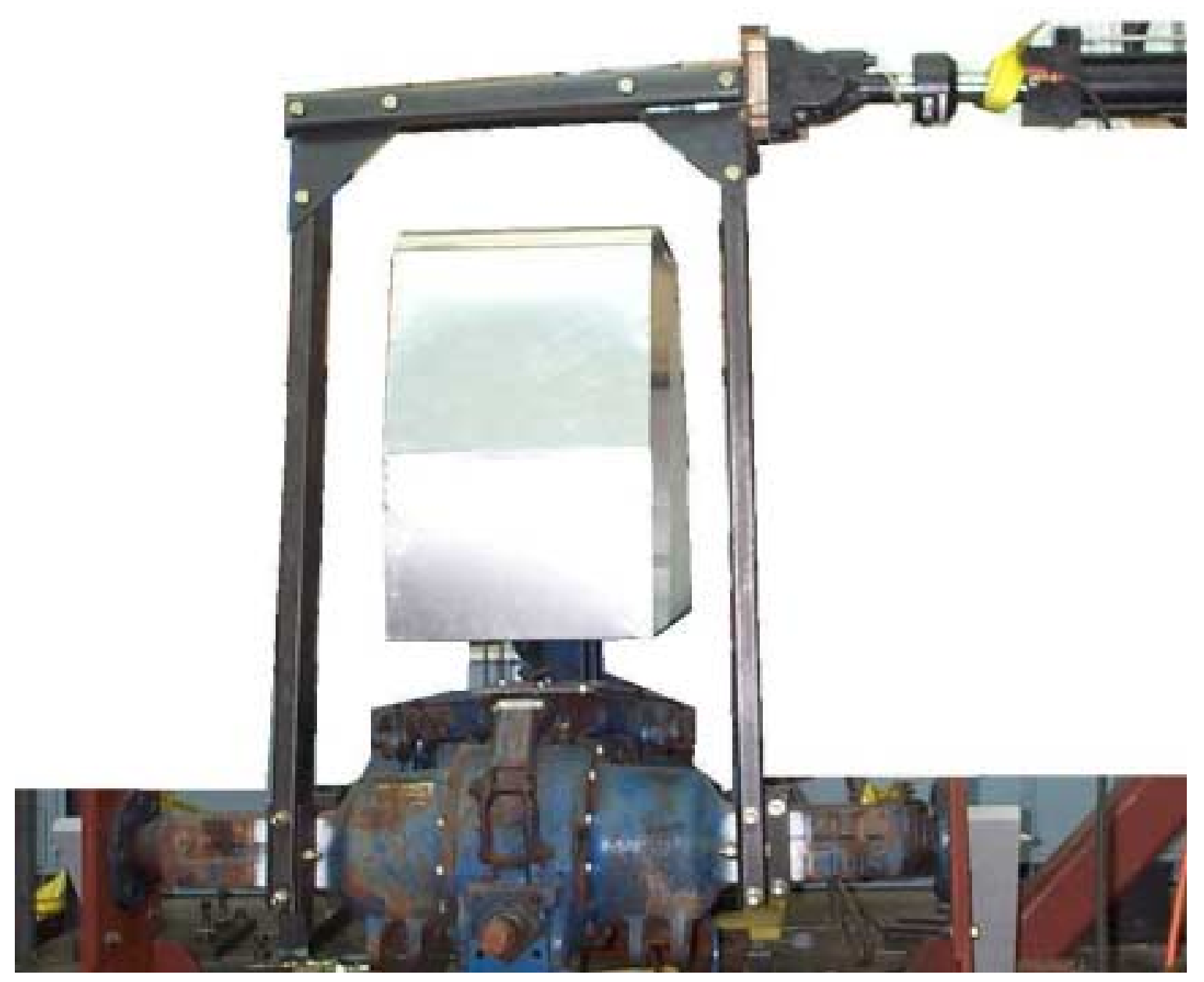

Figure 8.9: Transverse Test Set Up for Prototype 2

Figure 8.10 and 8.11 below demonstrate the force vs. deflection and energy vs. deflection curves for the transverse test that was performed on prototype 2 . 
CROPS Prototype Testing

2"x4"x1/4" rectangular tubing (2-post)

Transverse test $-5 / 16 / 02$

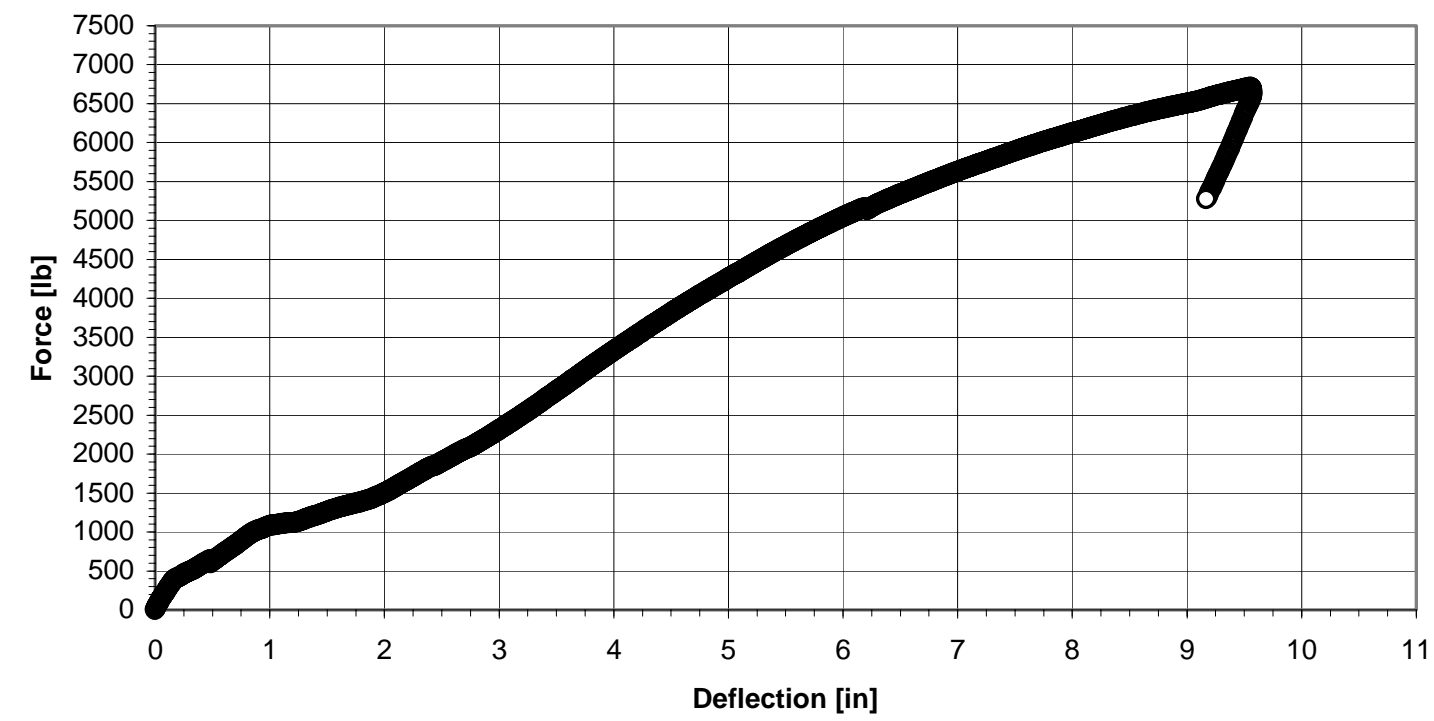

Figure 8.10: Transverse Load Test, Force vs. Deflection Curve for Prototype 2

CROPS Prototype Testing

2"x4"x1/4" rectangular tubing (2-post)

Transverse test $-5 / 16 / 02$

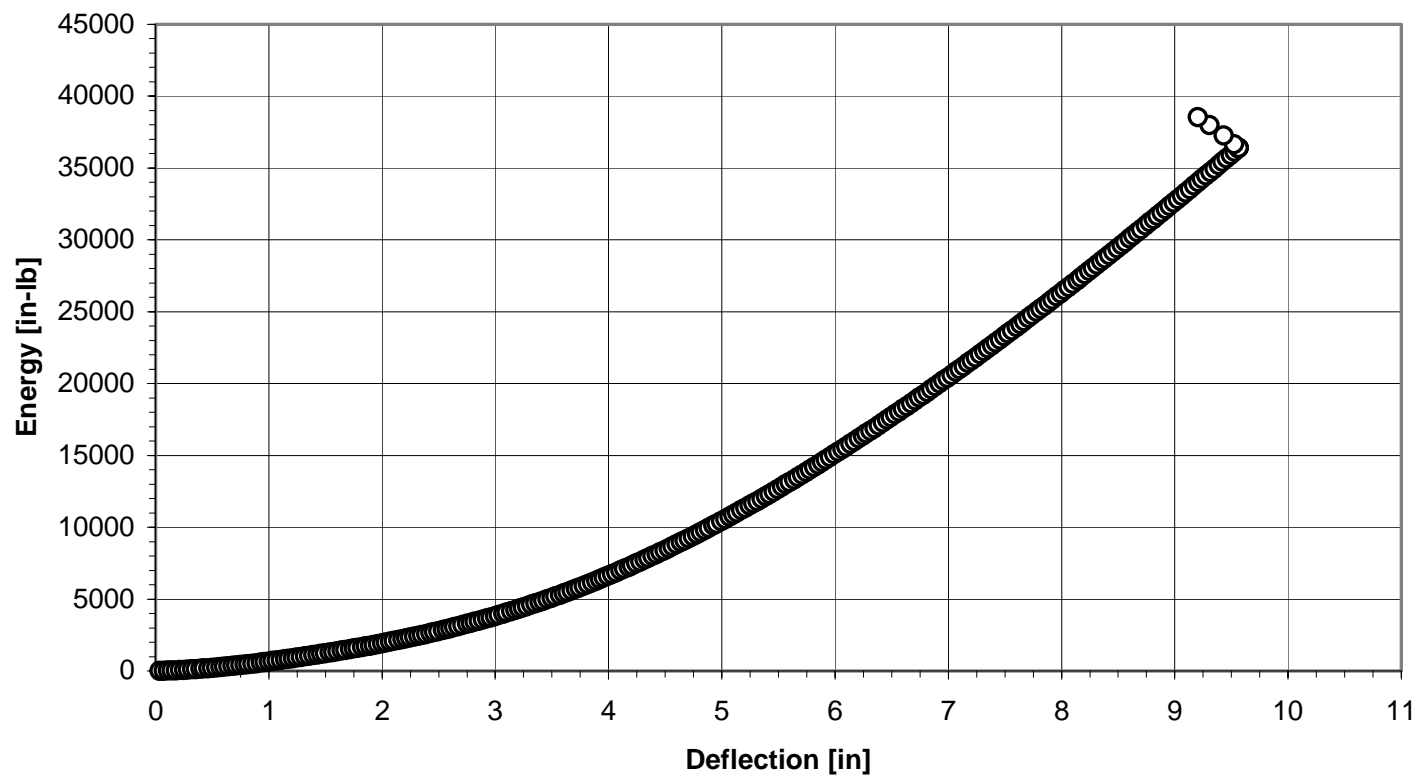

Figure 8.11: Transverse Load Test, Energy vs. Deflection Curve for Prototype 2 
During the transverse test, a vertical post from prototype 2 touched the clearance zone. When contact occurred, the transverse test was terminated and as a result, prototype 2 did not pass this test for a reference mass of $8220 \mathrm{lb}$. $35,935 \mathrm{in}-\mathrm{lb}$. of energy had been absorbed at the conclusion of this test. Working backward from an energy criterion of $1.75^{*} \mathrm{~m}_{\mathrm{t}}$, as was done in the vertical crush test, it can be shown that the transverse test was successfully completed when $m_{t}=5184 \mathrm{lb}$, see figure 8.12 (Harris, McKenzie, et.al).

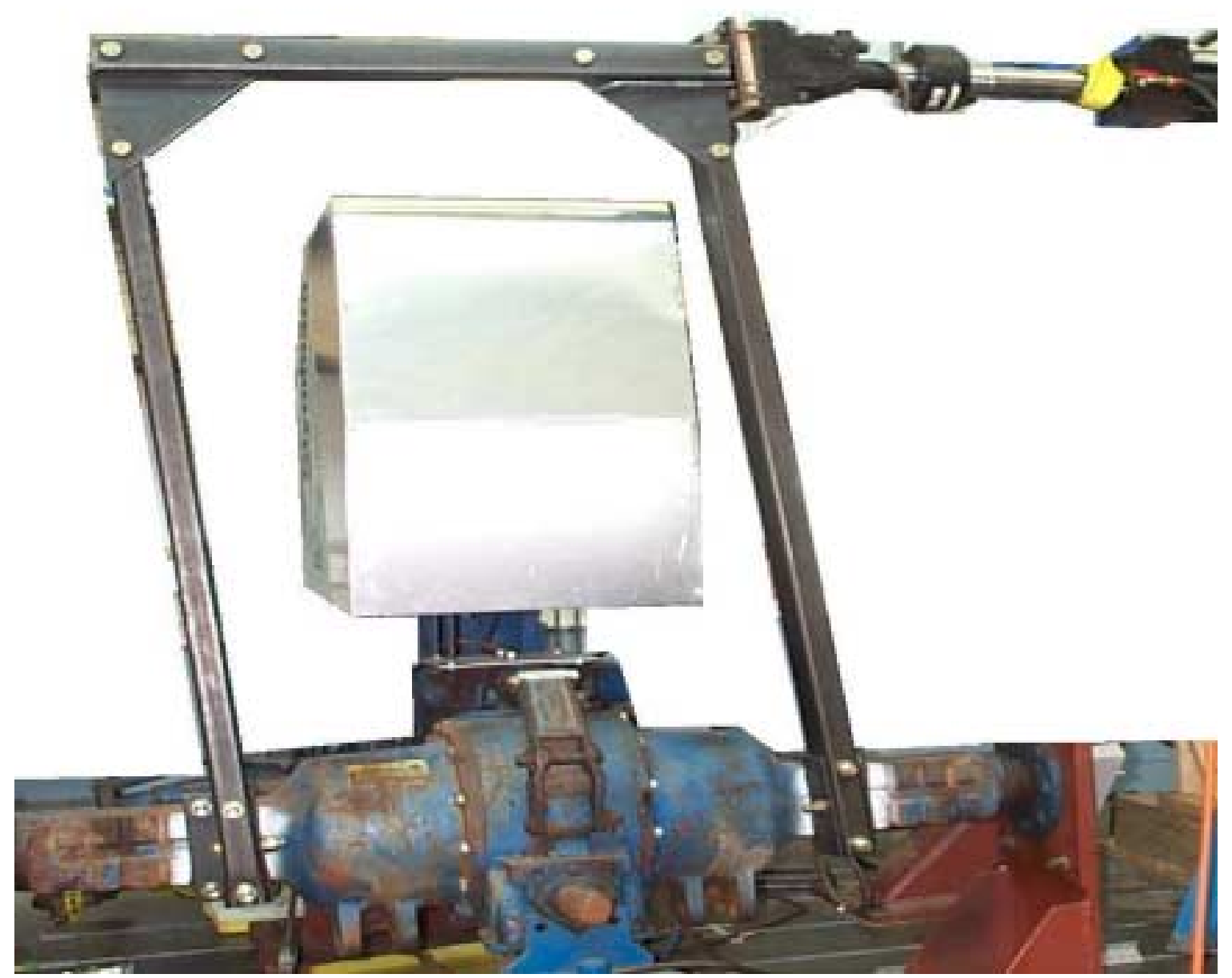

Figure 8.12: Prototype 2 After the Transverse Loading 


\section{2: Data Comparison Between Analytical Studies Conducted on}

NIOSH Third Generation AutoROPS and Prototype One and

\section{Two Experimental Data}

This section summarizes the research on the $\mathrm{NIOSH}$ project investigating of cost-effective ROPS (CROPS). Two CROPS Prototypes have been fabricated and tested to meet the in SAE J-2194 requirements. The results of the previous experimental test can be related to the theoretical study of the generation AutoROPS. The results should be close to the experimental data and the differences between the prototypes need to be taken into consideration. The first longitudinal test was required to fall in a range between the results of the first longitudinal test of prototype one and prototype two. The side transverse did intrude into the clearance zone, therefore they did not have successful test data, but the data can be useful for at least a rough estimation. Table 8.1 has detailed the energy and load comparison between all of the experimental and theoretical tests. The table also lists mass references for all of the tests in order to have a clear and accurate comparison. Prototype one had only the first longitudinal test because the prototype did not pass that test. Due to this failure, there is no need to continue testing this prototype. 
Table 8.1: Energy and Load Comparison Table for Experimental

Prototypes and Third Generation AutoROPS

\begin{tabular}{|c|c|c|c|c|c|c|c|c|}
\hline & \multicolumn{3}{|c|}{ First Longitudinal } & \multicolumn{3}{|c|}{ Side Transverse } & \multicolumn{2}{|c|}{$\begin{array}{l}\text { Reference } \\
\text { Mass }\end{array}$} \\
\hline & Energy & Load & Deflection & Energy & Load & Deflection & F.L.T & S.T.T \\
\hline Prototype 1 & $\begin{array}{l}39,830 \\
\text { in-lb }\end{array}$ & $4,030 \mathrm{lb}$ & 13.0 in & NA & NA & NA & $8220 \mathrm{lb}$ & NA \\
\hline Prototype 2 & $\begin{array}{l}46193 \\
\text { in-lb }\end{array}$ & $5621 \mathrm{lb}$ & $11.0 \mathrm{in}$ & $35935 \mathrm{in}-\mathrm{lb}$ & $6850 \mathrm{lb}$ & 9.6 in & $8220 \mathrm{lb}$ & $5172 \mathrm{lb}$ \\
\hline $\begin{array}{l}\text { NIOSH Main } \\
3^{\text {rd }} \\
\text { AutoROPS }\end{array}$ & $\begin{array}{l}46266 \\
\text { in-lb }\end{array}$ & $\begin{array}{l}4650 \\
\mathrm{lb}\end{array}$ & 11.74 in & $\begin{array}{l}57847 \\
\text { in-lb }\end{array}$ & $\begin{array}{l}7900 \\
\mathrm{lb}\end{array}$ & 8.34 in & $8220 \mathrm{lb}$ & $8220 \mathrm{lb}$ \\
\hline $\begin{array}{l}\text { Redesigned } \\
\text { NIOSH } 3^{\text {rd }} \\
\text { AutoROPS }\end{array}$ & $\begin{array}{l}46203 \\
\text { in-lb }\end{array}$ & $4630 \mathrm{lb}$ & 11.72 in & $\begin{array}{l}57962 \\
\text { in-lb }\end{array}$ & $8450 \mathrm{lb}$ & $7.8 \mathrm{in}$ & $8220 \mathrm{lb}$ & $8220 \mathrm{lb}$ \\
\hline
\end{tabular}

The second longitudinal test for CROPS prototypes has not been completed yet; therefore, no results were available for that test to be compared with this study. All of the experimental data was conducted at the NIOSH Hi-bay Lab. 


\section{Chapter 9}

\section{Conclusions and Recommendations}

\section{1: Conclusion}

Much of the research up to this date has dealt with costly experimental testing. This study shows the benefits of using Finite Element Analysis studies to estimate the results of a design and cut down the cost and time of the design cycle.

This first part of this research has been a continuation of earlier research conducted on the second generation AutoROPS. This was conducted in coordinated effort between West Virginia University's Mechanical and Aerospace Engineering Department and NIOSH. The first part was focused on using finite element analysis to analyze the stresses on the base. The results were positive. It was determined that the base will take the entire load being applied to it. Maximum stress of 38,593 psi was found on bolt number 5 , which is below the minimum proof yield stress of $120,000 \mathrm{psi}$ for the grade 8 bolt. The base is overdesigned and did show factor of safety 3.1 during all the sequence loads as required by the $\mathrm{J}-2194$ standard. 
The second part was on a new model design called "NIOSH third generation AutoROPS". The focus for the second part was on using finite element analysis to predict the behavior of that third generation AutoROPS, and for finding the overlap size between the deployable and fixed posts.

All of the loads were applied in sequence on the main model of the third generation AutoROPS, and the results met the expectations of SAE J-2194 standard. The AutoROPS absorbed all of the required energies and did not intrude into the clearance zone. The size of the overlap between the deployable and fixed post is one of the important results in this part of the study. This is because the post has to be large enough to hold the latching mechanisms inside and still be able to hold the two posts together during any type of load being applied. The overlap was determined to be 6 inches. The base was also studied carefully and did withstand all of the reaction caused by the applied loads on the posts. The maximum load was 97,146 psi, and that is less than the minimum approved load for grade 8 bolts which is 120, 000 psi.

For the redesigned third generation AutoROPS, the study used posts with different heights. The AutoROPS did take all the applied 
sequence loaded on it. Since the fixed inside post is shorter that the one in the main model of third generation AutoROPS, the post did withstand a higher load in all of the cases, with the exception of the first longitudinal test. The redesigned model of the third generation AutoROPS met the required energy absorption. The redesigned version withstood 4,630 lbs., while the main third generation version withstood 4,650 lbs. The redesigned version has 10 inches of overlap room between the posts, which meets the design criteria and gives room for the spring to fit. This design also allows the deployable post to retract all the way down to the base of AutoROPS and to have a height of 39 inches only. The first design had a height of 44 inches.

After comparing the third generation theoretical results to the CROPS experimental tests, they fall within the expected range. The results were similar to each other; therefore, can be used as a reference in comparing the studies since no experimental prototypes designs have been built and tested. 


\subsubsection{General Safety Tips}

Since the AutoROPS does not guarantee the safety of the tractor operator by itself, it is necessary to be familiar with the safety instructions. Also, having other safety tools available on the tractor is always useful. These precautions should be taken before operating the tractor.

AutoROPS cannot be expected to protect a tractor operator in the event of a rollover without a seatbelt to hold the operator in the protected clearance zone. Employers should provide safety training to his workers, including information regarding potential hazards and safe operation of equipment. Farming often involves working with potentially dangerous equipment so in order to ensure a safe environment, it is important that employers provide training to employees about hazardous situations that could occur during the course of work. Instructions for operating equipment safely, such as downshifting and reducing speed when descending a hill, can help workers to avoid injury.

Never try to construct your own AutoROPS - There are too many variables in mounting and metal strength to design a rollover protection system that is guaranteed to protect you. An approved rollover 
protective structure is designed to crush down slightly to absorb some of the impact of a tractor rollover.

\section{2: Recommendation for Future Work}

The need for a better analytical study in designing the AutoROPS becomes very important after realizing that the standard is basically a pass or fail criteria. This study looked at simulating the SAE J-2194 static load standard.

First and foremost, the deployable AutoROPS is a novel idea to protect the tractor operator and to meet his need of having a lowclearance. Since the third generation AutoROPS is a new design, there are other criteria that need to be studied. An example would be: The latching mechanisms and how it can be fitted in the overlap area between the two posts. Another important subject that needs to be looked at is the deployment time required for the outside deployable posts to be deployed and still meet the necessary standards. Also, aspects of the spring criteria such as size, diameter and the release strength needed to be determined. Last but not least, the material properties like the strength and weight, and the cost of building the prototype need to be researched further. 
In closing, studies have shown that AutoROPS do the intended job of saving human lives, and also minimizes the injuries in the case of a tractor rollover. Although the AutoROPS has proven effective in this research, it is necessary to continue research on future improvements of the AutoROPS. The possibility of saving even more lives makes the continued research worth looking at. 


\section{Appendix A}

Stresses on the Base Bolts for Third Generation AutoROPS 




Figure A-1: Preload Maximum Stress on the Bolts



Figure A-2: Maximum Stress on Bolt Number 5 in the First Longitudinal Test 


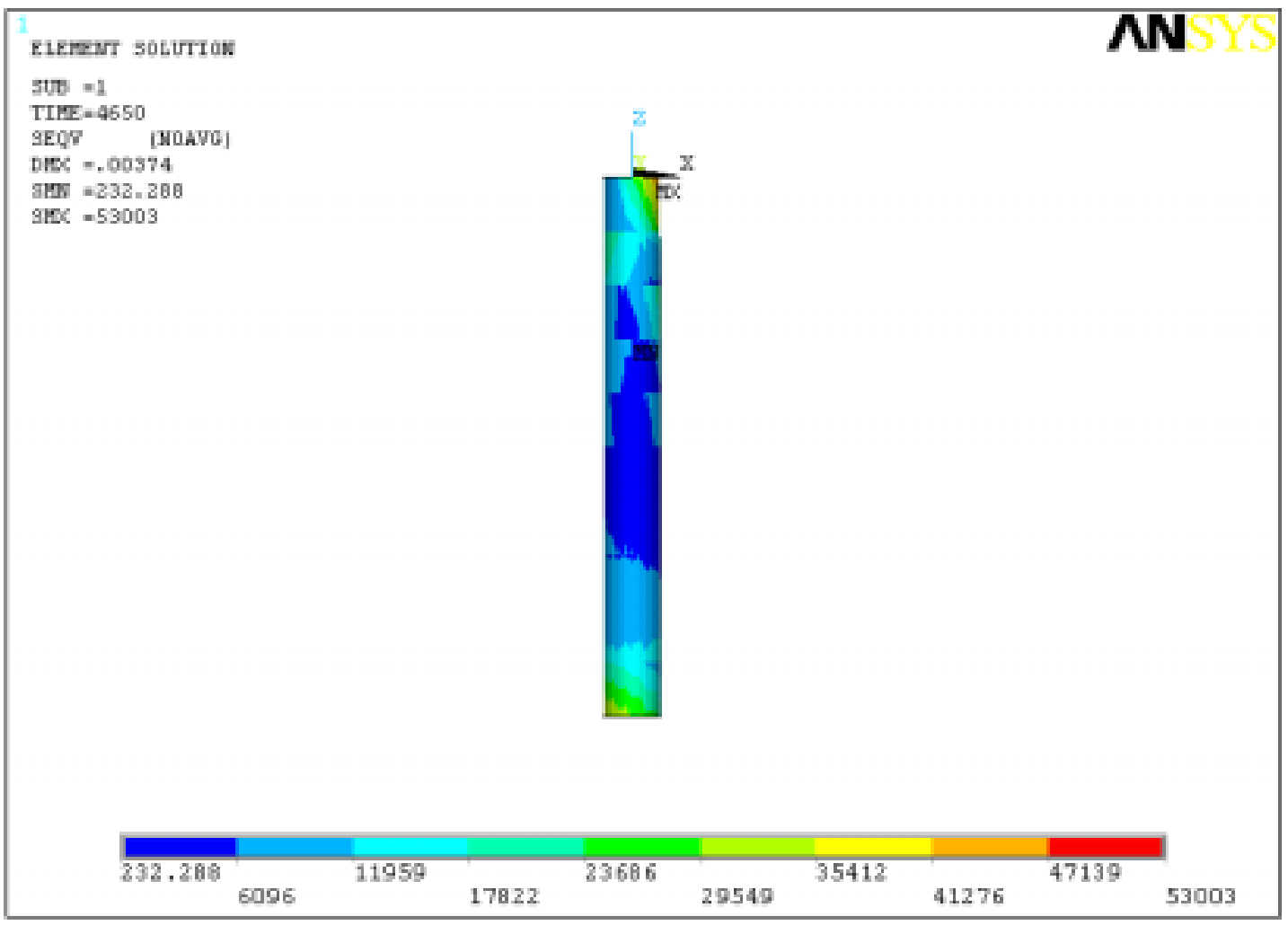

Figure A-3: Maximum Stress on Bolt Number 7 for the First Longitudinal Test

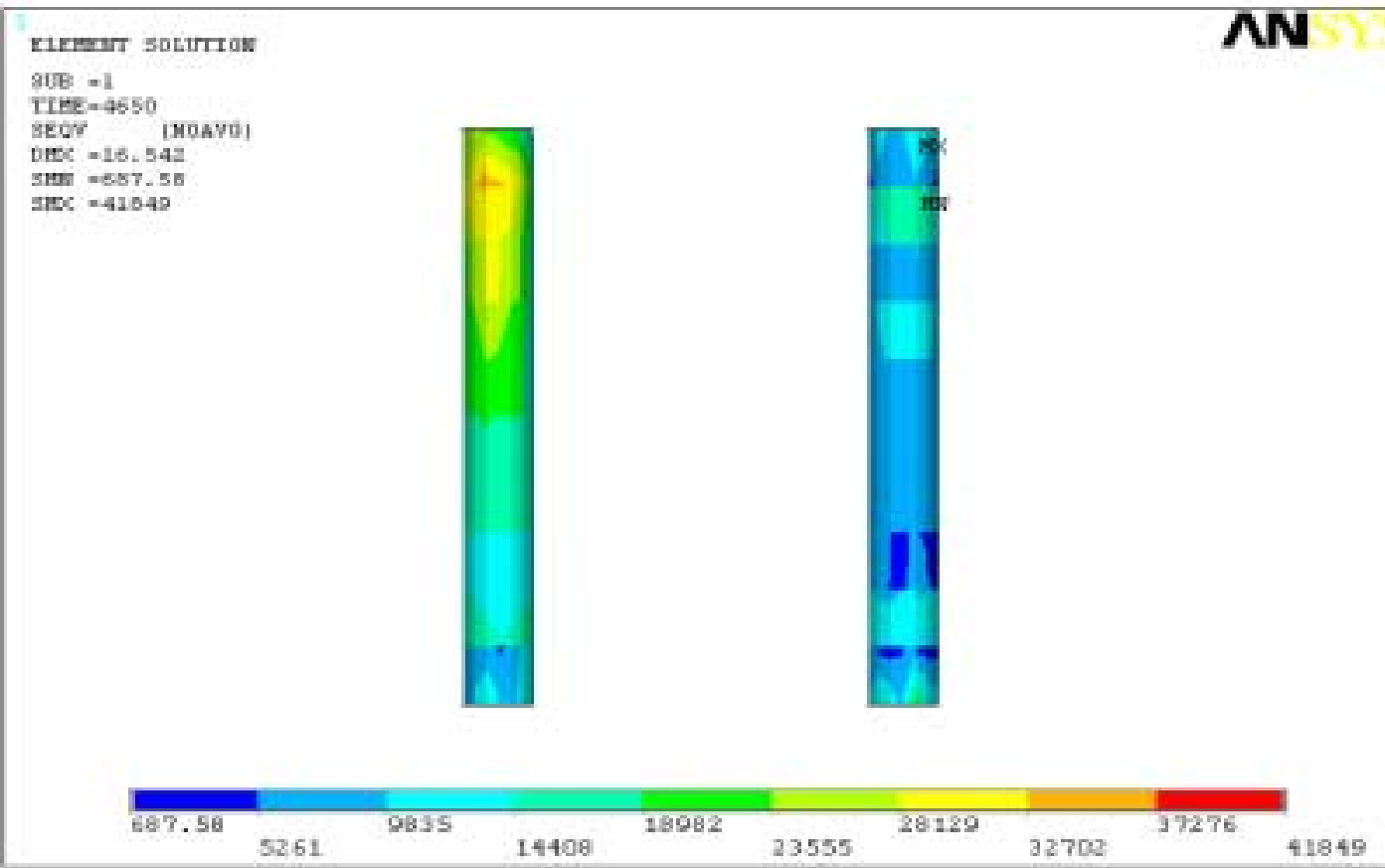

Figure A-4: Stresses on Bolts 2 and 4 for the First Longitudinal Test 


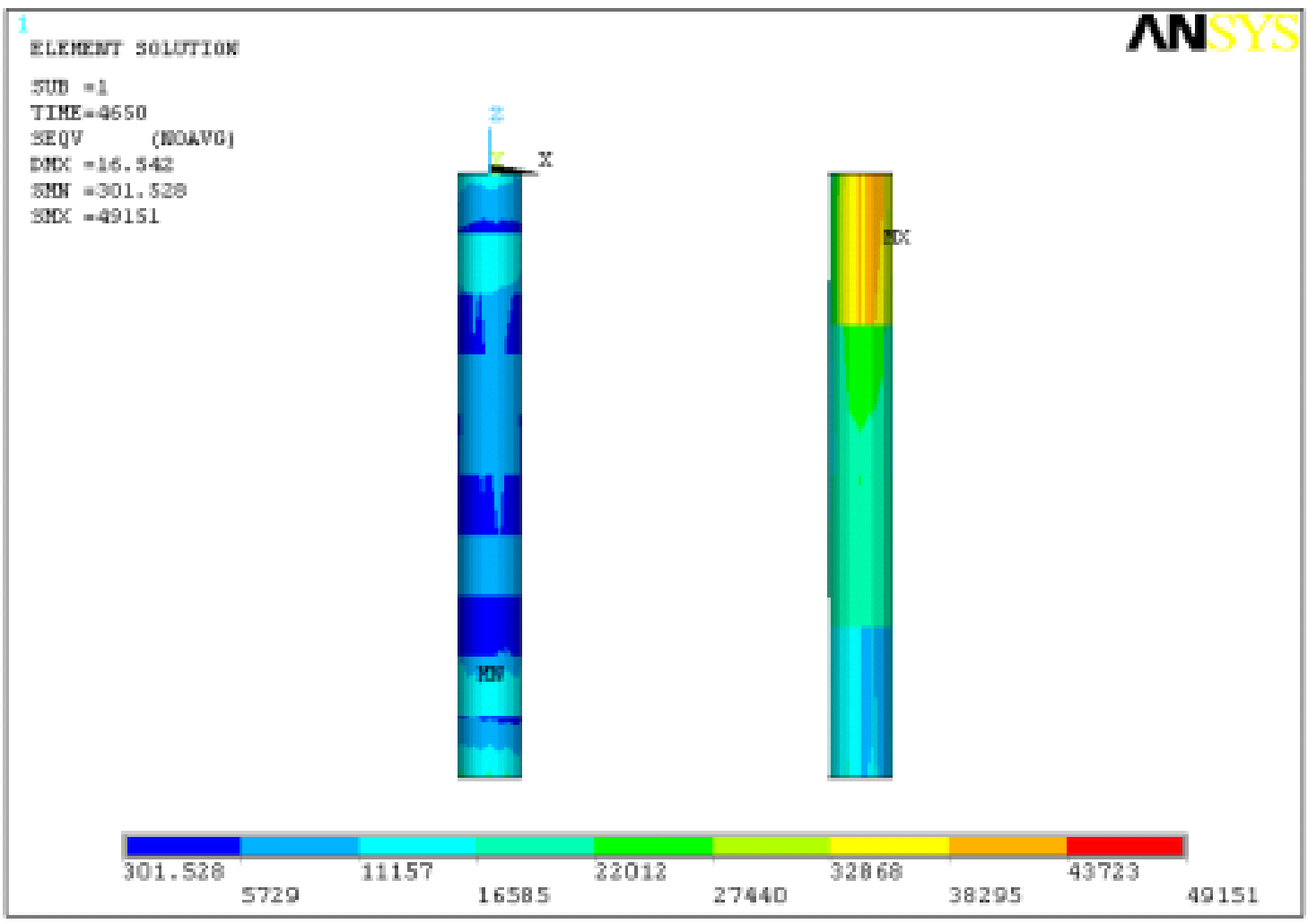

Figure A-5: Stresses on Bolts 6 and 8 for the First Longitudinal Test

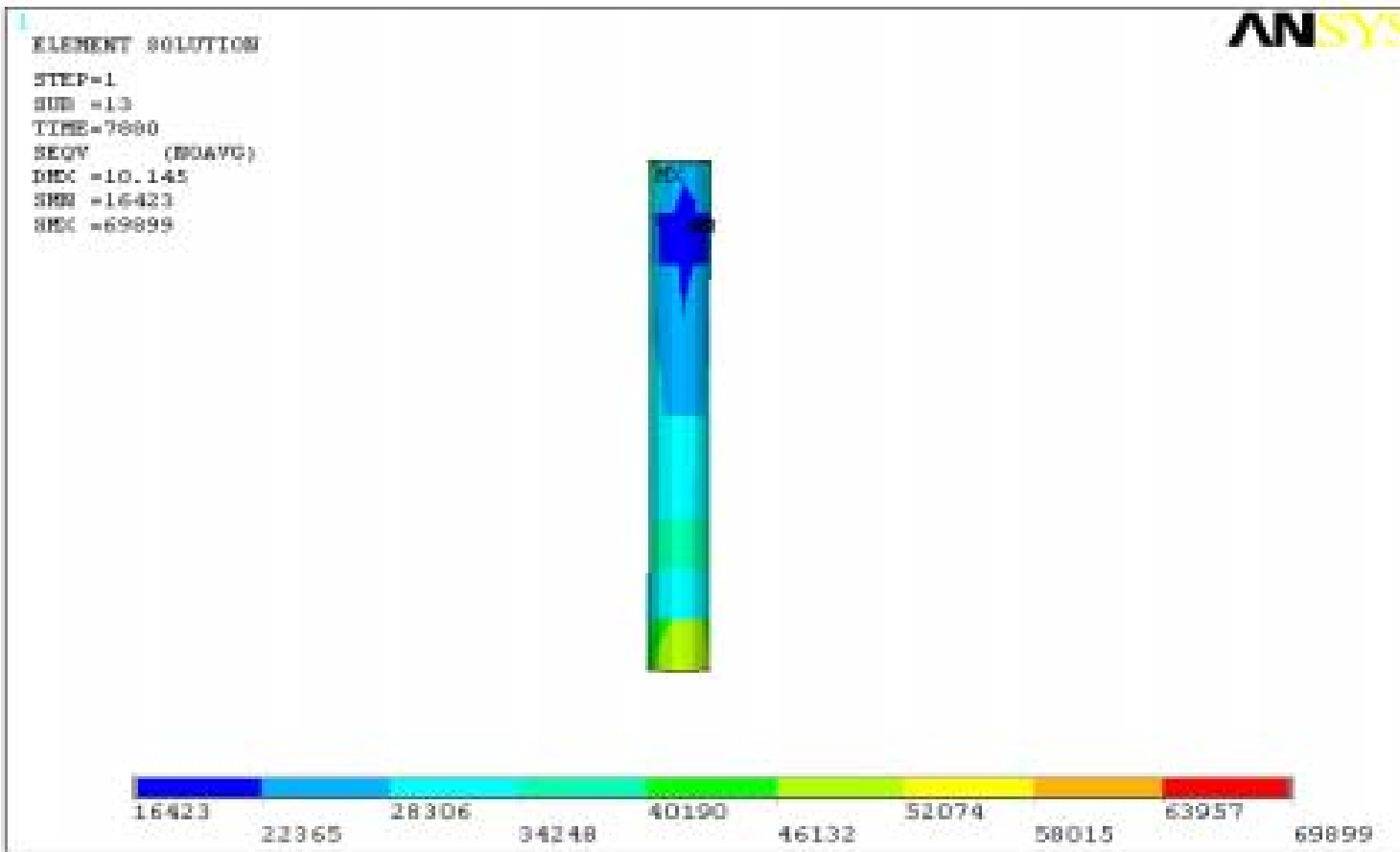

Figure A-6: Stresses on Bolt Number 1 for the Side Transverse Test 


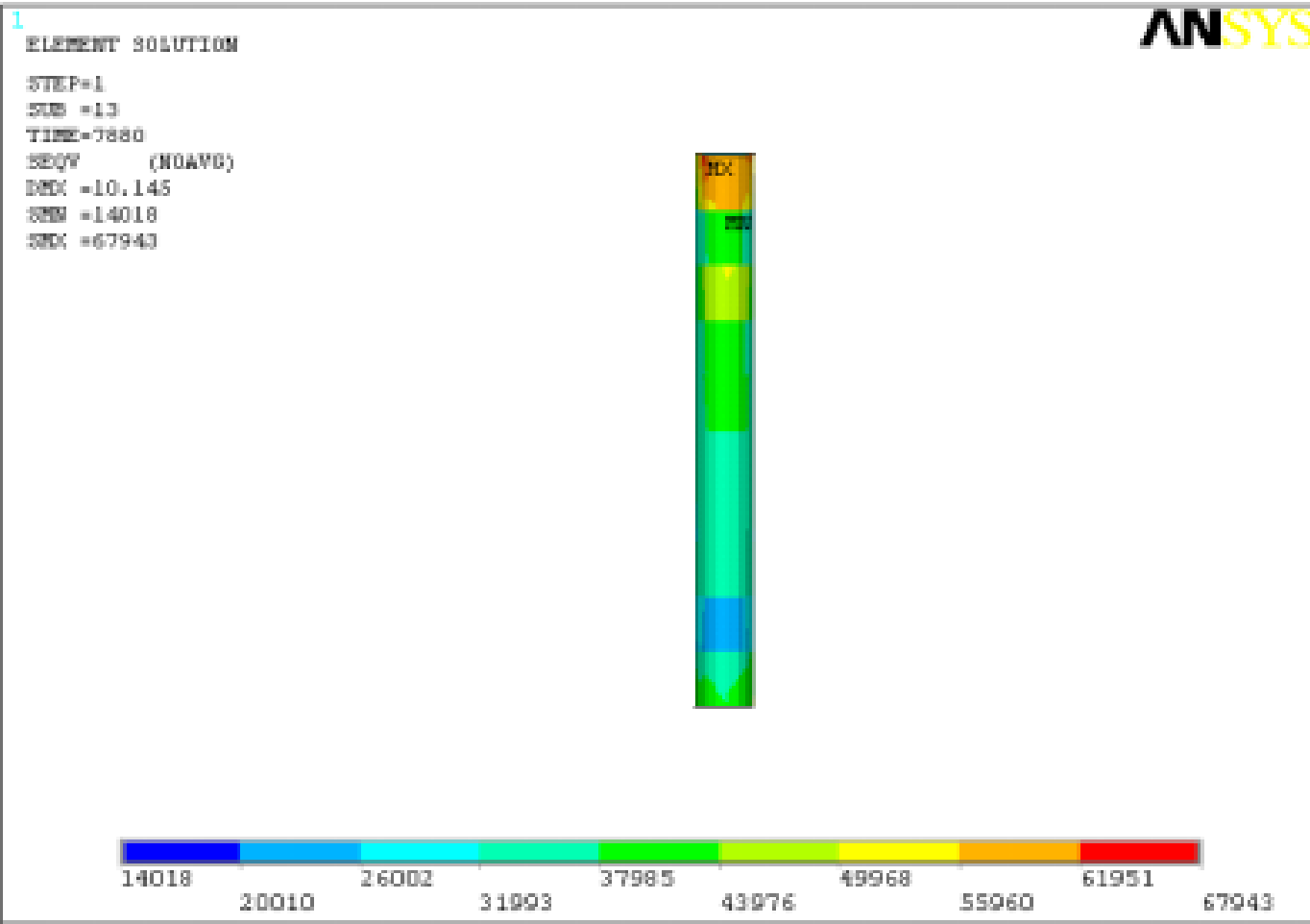

Figure A-7: Stresses on Bolt Number 2 for the Side Transverse Test

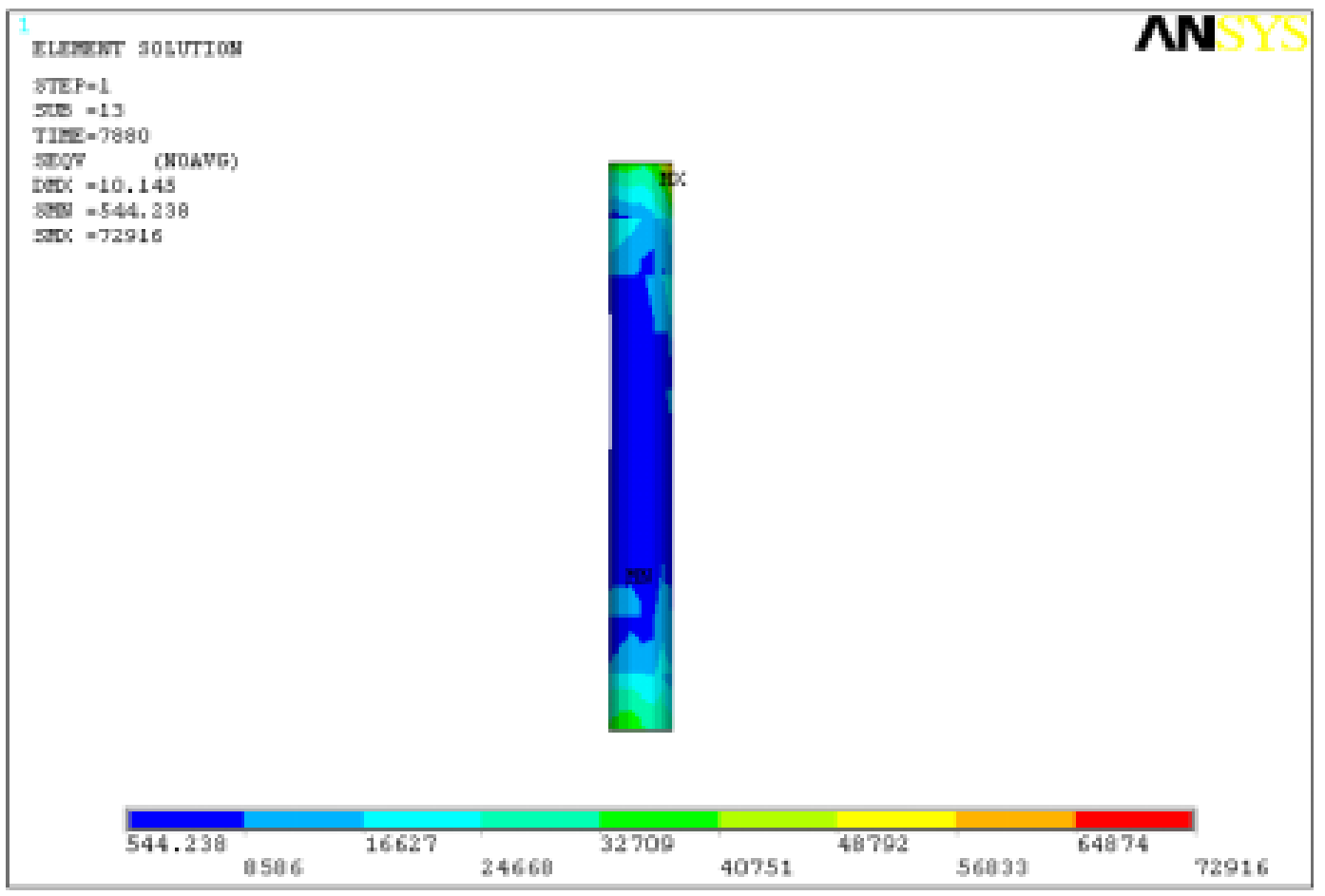

Figure A-8: Stresses on Bolt Number 3 for the Side Transverse Test 


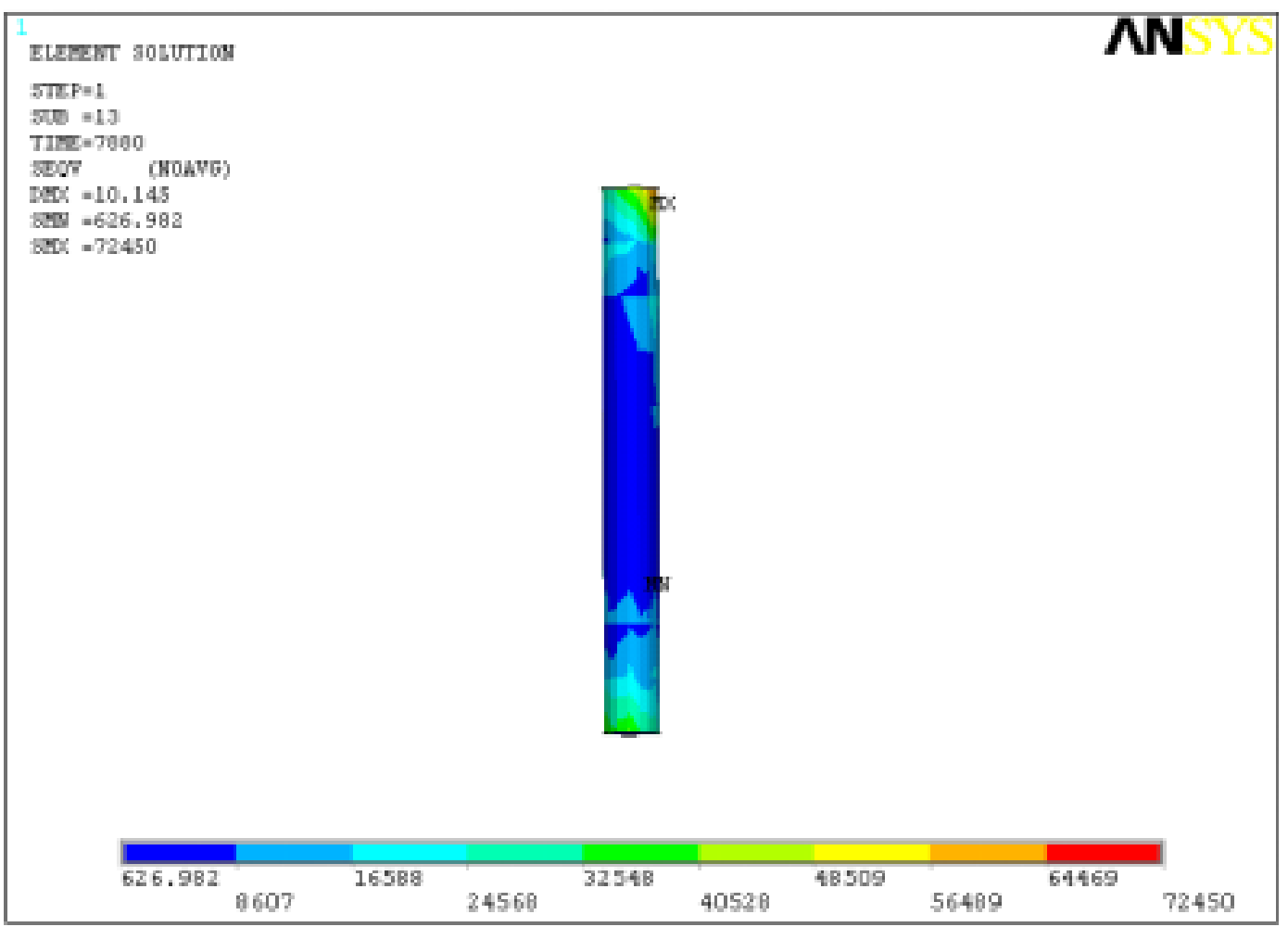

Figure A-9: Stresses on Bolt Number 4 for the Side Transverse Test

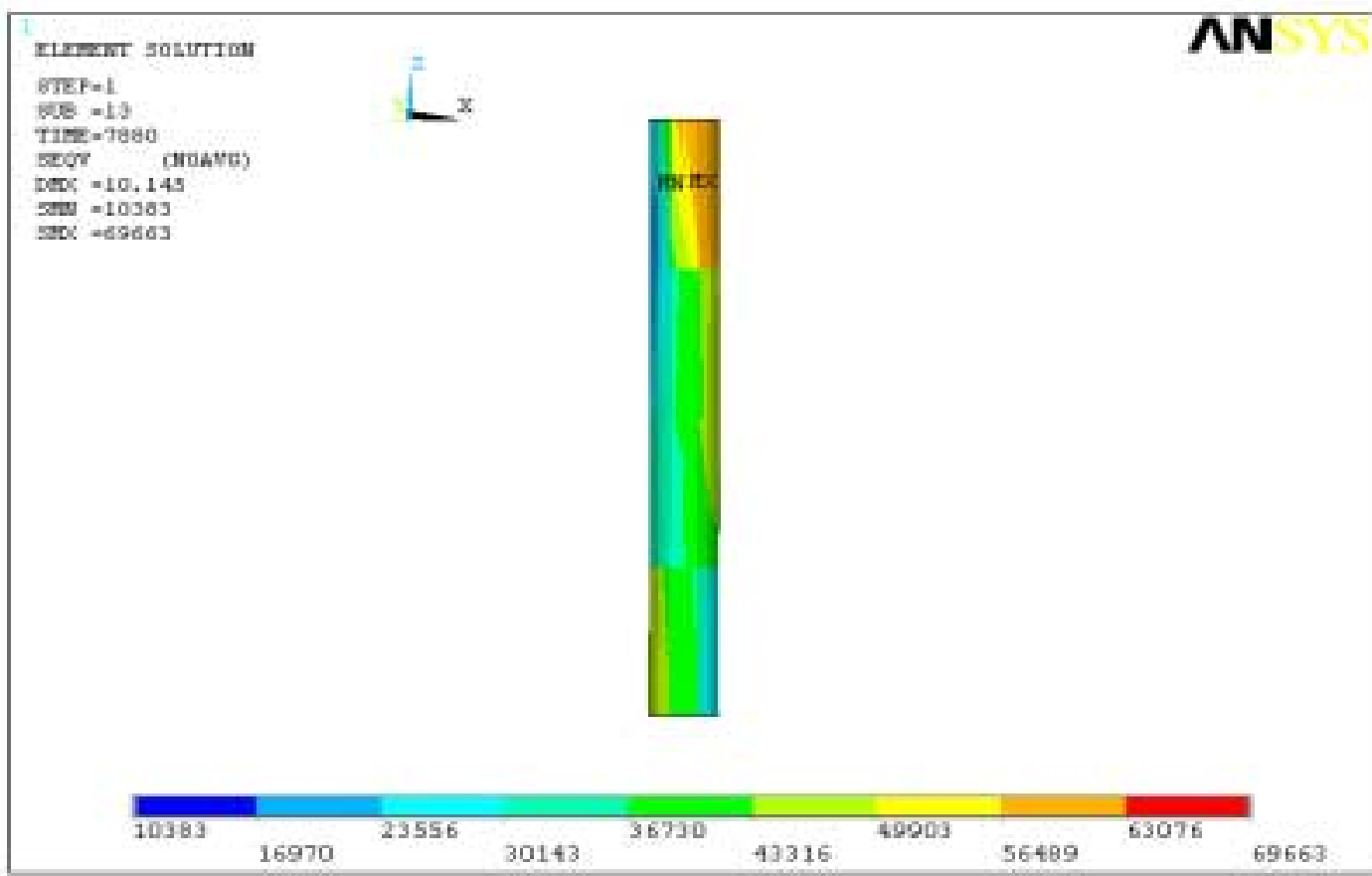

Figure A-10: Stresses on Bolt Number 6 for the Side Transverse Test 


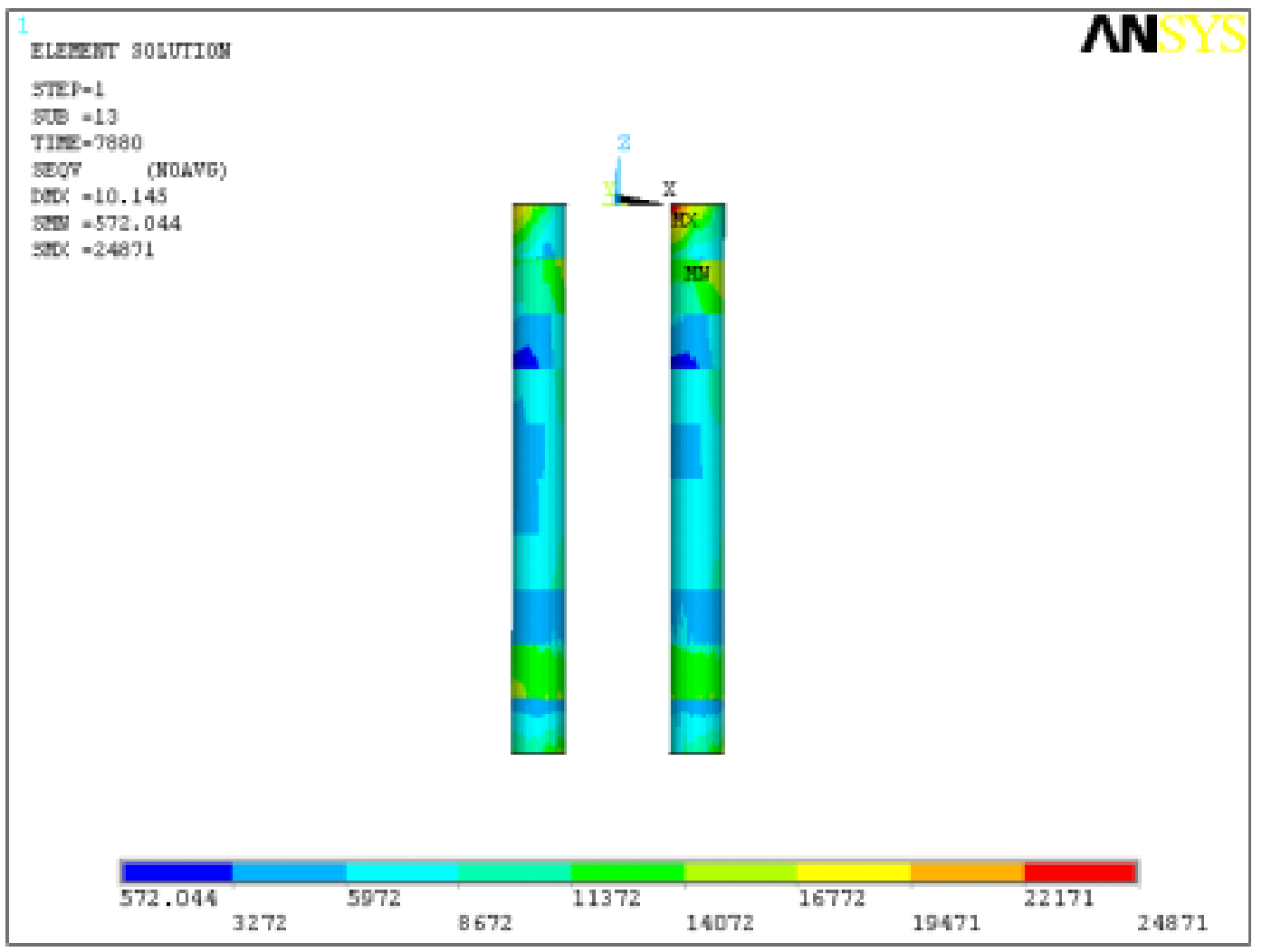

Figure A-11: Stresses on Bolts Number 7 and 8 for the Side Transverse Test 


\section{Appendix B}

Dimensions and Experimental Results for the First Generation AutoROPS 




Figure B-1: Lay out for Second Generation AutoROPS

Table B-1: Dimensions for the Second Generation AutoROPS

\begin{tabular}{|c|c|c|}
\hline $\begin{array}{c}\text { Sym } \\
\text { bol }\end{array}$ & Identity & $\begin{array}{c}\text { Dimension(s) } \\
\text { [Inches }]\end{array}$ \\
\hline HP & Horizontal Tube/Pipe & $\begin{array}{c}\text { Inner Radius }=1.3 \\
\text { Outer Radius }=1.5 \\
\text { Total Length }=53.25\end{array}$ \\
\hline HPC & Horizontal Tube/Pipe & Clearance $=2$ \\
& Clearance & Overhang $=1.625$ \\
\hline UTO & Upper Tube Overhang & Inner Radius $=2.375$ \\
\hline UT & Upper Tube & Outer Radius $=2.625$ \\
& & Total Length $=37.5$ \\
\hline LTC & Lower Tube Cap & Inner Radius $=2.75$ \\
& & Outer Radius $=3.25$ \\
& & Total Height $=3$ \\
\hline P & Piston & Inner Radius $=2.375$ \\
& & Outer Radius $=2.625$ \\
& & Inside Height $=5.25$ \\
& & Outside Height $=4.75$ \\
\hline LM & Latching Mechanism (Pins) & Radius $=0.375$ \\
& & Length $=1.25$ \\
\hline LT & Lower Tube & Inner Radius $=3.25$ \\
& & Outer Radius $=3.50$ \\
& & Total Length $=34$ \\
\hline
\end{tabular}


AutoROPS Prototype A

static testing-first longitudinal load



Figure B-2: Force Deflection Data for First Longitudinal Loading

AutoROPS Prototype A

static testing - transverse load

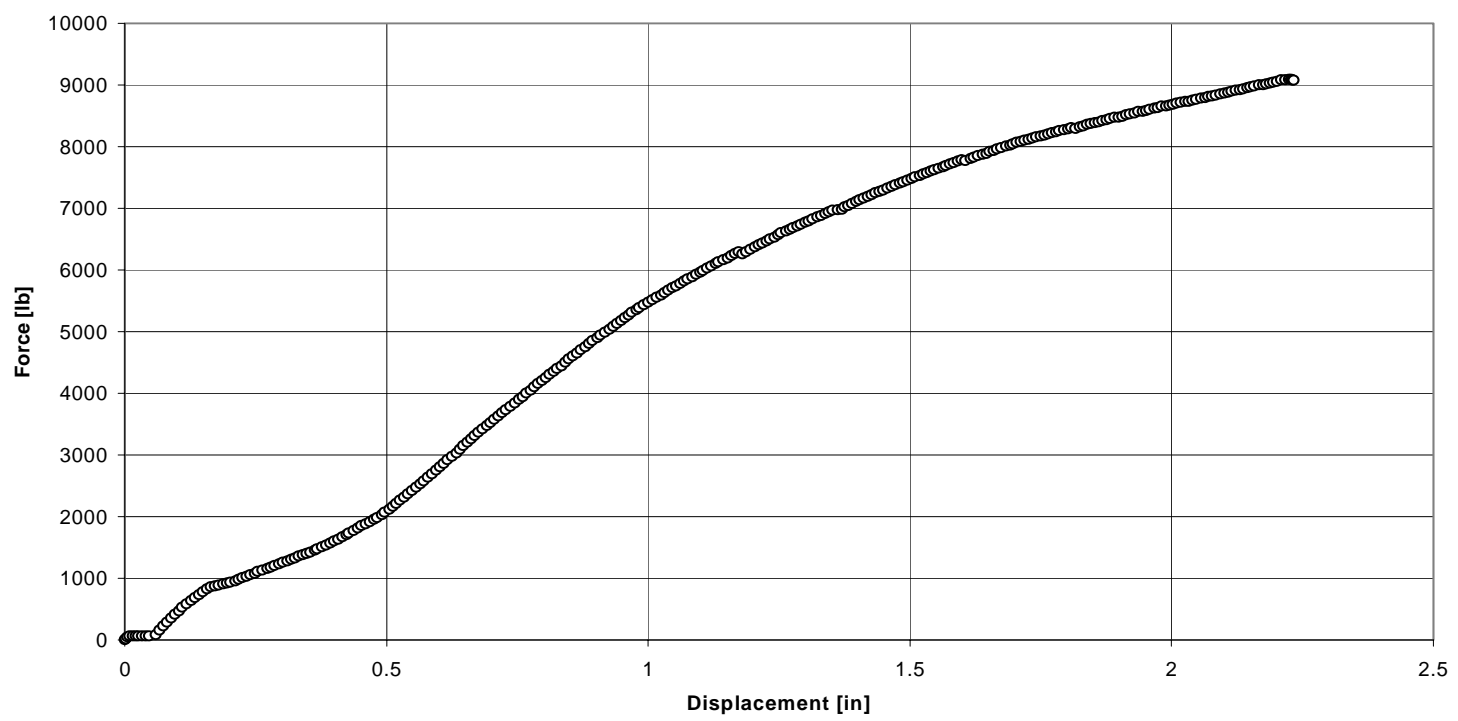

Figure B-3: Force Deflection Data for Transverse Loading 
AutoROPS Prototype A

static testing - second longitudinal load

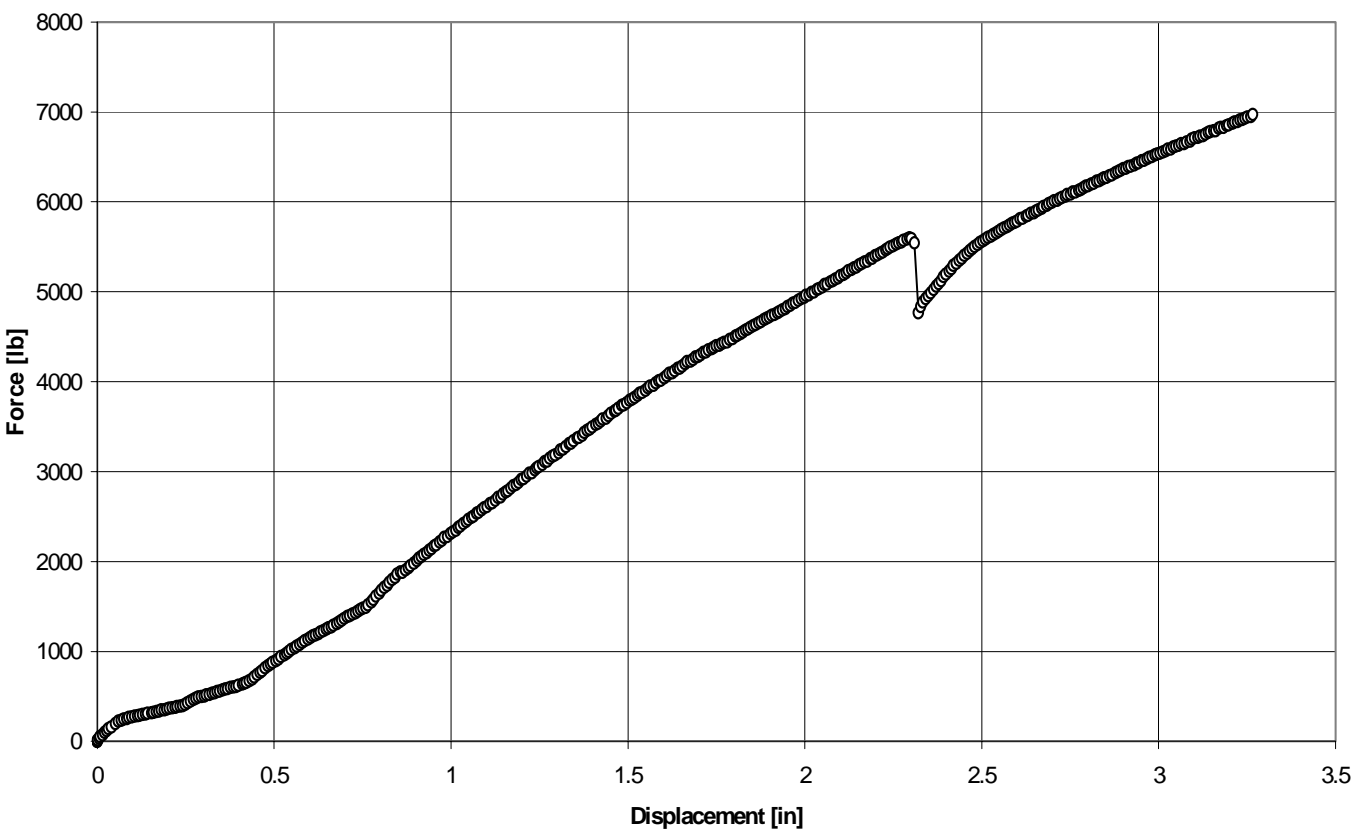

Figure B-4: Force Deflection Data for Second Longitudinal Loading 
Appendix C

\section{Detailed Energy Data}


Trapezoidal rules methods are obtained by integrating $f$ function under the stress deflection curve (Kreyszing). The simplest way to do that is dividing the interval of the integration $a \leq X \leq b$ into $n$ subintervals of equal length $h=(\mathrm{b}-\mathrm{a}) / \mathrm{n}$ to get the $\boldsymbol{f}$, then approximating the area under the curve by sum by using Trapezoid rule function as which is:

$J=\int_{a}^{b} f(x) d x \approx h\left[0.5 f(a)+f\left(x_{1}\right)+f\left(x_{2}\right)+\ldots \ldots+f\left(x_{n-1}\right)+0.5 f(b)\right]$

\section{Table C-1: Energy Table for First Longitudinal Test}

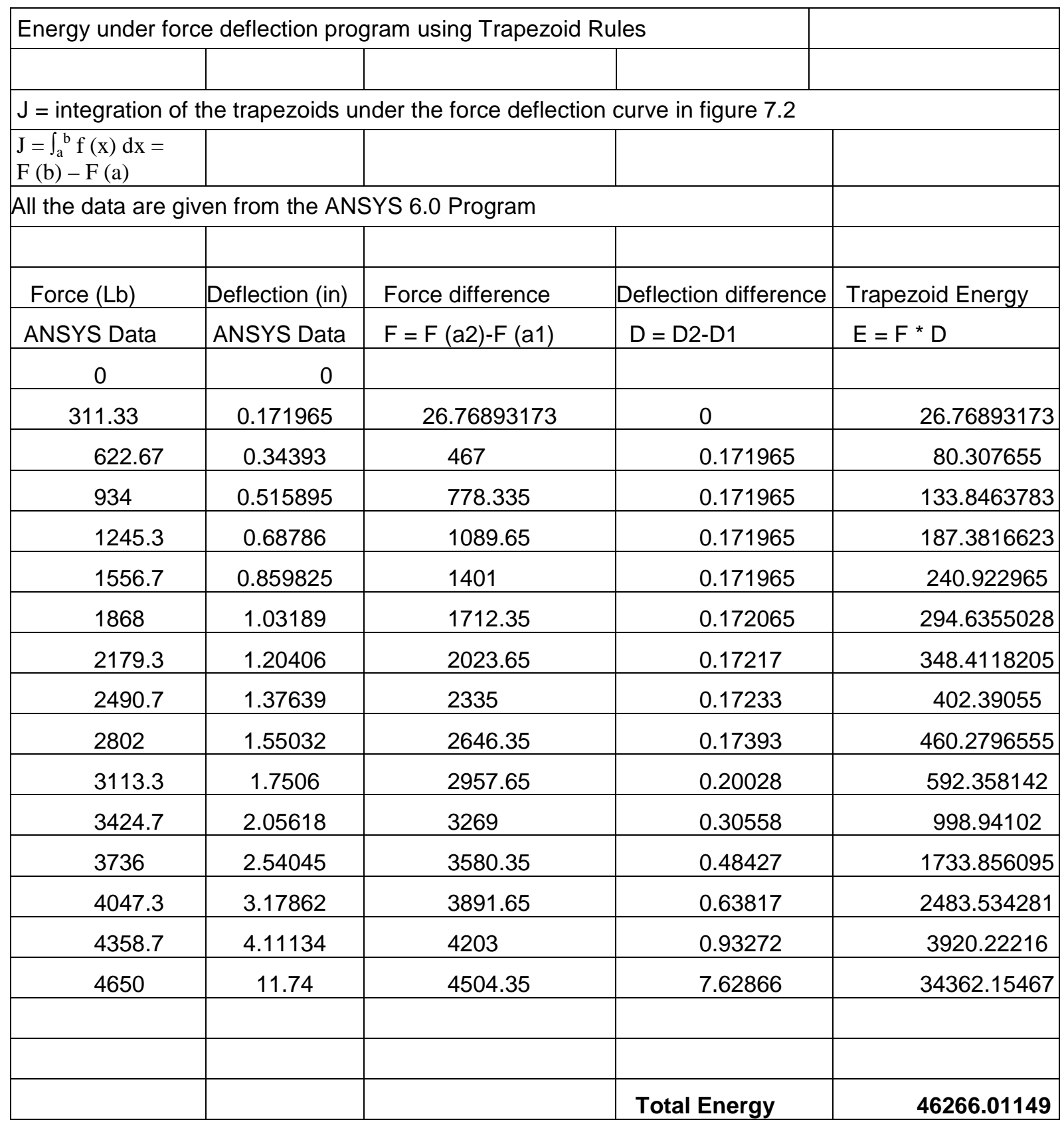




\section{Table C-2: Energy Table for Side Transverse Test}

\begin{tabular}{|c|c|c|c|c|}
\hline \multicolumn{4}{|c|}{ Energy under force deflection program using Trapezoid Rules } & \\
\hline \multicolumn{5}{|c|}{$\mathrm{J}=$ integration of the trapezoids under the force deflection curve in figure 7.5} \\
\hline \multicolumn{2}{|c|}{$\mathrm{J}=\int_{\mathrm{a}}^{\mathrm{b}} \mathrm{f}(\mathrm{x}) \mathrm{dx}=\mathrm{F}(\mathrm{b})-\mathrm{F}(\mathrm{a})$} & & & \\
\hline \multicolumn{4}{|c|}{ All the data are given from the ANSYS 6.0 Program } & \\
\hline Force (Lb) & Deflection (in) & Force difference & Deflection difference & Trapezoid Energy \\
\hline ANSYS Data & ANSYS Data & $\mathrm{F}=\mathrm{F}(\mathrm{a} 2)-\mathrm{F}(\mathrm{a} 1)$ & $D=D 2-D 1$ & $E=F * D$ \\
\hline 0 & 0 & & & \\
\hline 315.96 & 5.33E-02 & 8.426937564 & 0 & 8.426937564 \\
\hline 631.92 & 0.106684 & 473.94 & 0.0533422 & 25.28100227 \\
\hline 947.88 & 0.160026 & 789.9 & 0.053342 & 42.1348458 \\
\hline 1263.8 & 0.213367 & 1105.84 & 0.053341 & 58.98661144 \\
\hline 1579.8 & 0.266791 & 1421.8 & 0.053424 & 75.9582432 \\
\hline 1895.8 & 0.32047 & 1737.8 & 0.053679 & 93.2833662 \\
\hline 2211.7 & 0.374842 & 2053.75 & 0.054372 & 111.666495 \\
\hline 2527.7 & 0.430585 & 2369.7 & 0.055743 & 132.0941871 \\
\hline 2843.6 & 0.488743 & 2685.65 & 0.058158 & 156.1920327 \\
\hline 3159.6 & 0.549539 & 3001.6 & 0.060796 & 182.4852736 \\
\hline 3475.6 & 0.613204 & 3317.6 & 0.063665 & 211.215004 \\
\hline 3791.5 & 0.67982 & 3633.55 & 0.066616 & 242.0525668 \\
\hline 4107.5 & 0.750672 & 3949.5 & 0.070852 & 279.829974 \\
\hline 4423.4 & 0.826483 & 4265.45 & 0.075811 & 323.36803 \\
\hline 4739.4 & 0.907218 & 4581.4 & 0.080735 & 369.879329 \\
\hline 5055.4 & 0.994485 & 4897.4 & 0.087267 & 427.3814058 \\
\hline 5371.3 & 1.08867 & 5213.35 & 0.094185 & 491.0193698 \\
\hline 5687.3 & 1.19191 & 5529.3 & 0.10324 & 570.844932 \\
\hline 6003.2 & 1.30497 & 5845.25 & 0.11306 & 660.863965 \\
\hline 6319.2 & 1.43242 & 6161.2 & 0.12745 & 785.24494 \\
\hline 6635.2 & 1.58369 & 6477.2 & 0.15127 & 979.806044 \\
\hline 6951.1 & 1.81104 & 6793.15 & 0.22735 & 1544.422653 \\
\hline 7267.1 & 2.35928 & 7109.1 & 0.54824 & 3897.492984 \\
\hline 7583 & 4.04574 & 7425.05 & 1.68646 & 12522.04982 \\
\hline 7737.3 & 5.71238 & 7660.15 & 1.66664 & 12766.7124 \\
\hline 7818.1 & 6.8883 & 7777.7 & 1.17592 & 9145.952984 \\
\hline \multirow[t]{2}{*}{7910} & 8.38 & 7864.05 & 1.4917 & 11730.80339 \\
\hline & & & Total Energy & 57835.44878 \\
\hline
\end{tabular}




\section{Table C-3: Energy Table for Second Longitudinal Test}

\begin{tabular}{|c|c|c|c|c|}
\hline \multicolumn{4}{|c|}{ Energy under force deflection program using Trapezoids Rules } & \\
\hline \multicolumn{5}{|c|}{$\mathrm{J}=$ integration of the trapezoids under the force deflection curve in figure 7.7} \\
\hline \multicolumn{2}{|c|}{$\mathrm{J}=\int_{\mathrm{a}}^{\mathrm{b}} \mathrm{f}(\mathrm{x}) \mathrm{dx}=\mathrm{F}(\mathrm{b})-\mathrm{F}(\mathrm{a})$} & & & \\
\hline \multicolumn{4}{|c|}{ All the data are given from the ANSYS 6.0 Program } & \\
\hline Force (Lb) & Deflection (in) & Force difference & Deflection difference & Trapezoid Energy \\
\hline Data & Data & $\mathrm{F}=\mathrm{F}(\mathrm{a} 2)-\mathrm{F}(\mathrm{a} 1)$ & $\mathrm{D}=\mathrm{D} 2-\mathrm{D} 1$ & $E=F * D$ \\
\hline 0 & 0 & & & \\
\hline 280 & 0.163138 & 22.83932 & 0 & 22.83932 \\
\hline 560 & 0.326277 & 420 & 0.163139 & 68.51838 \\
\hline 840 & 0.489415 & 700 & 0.163138 & 114.1966 \\
\hline 1120 & 0.652554 & 980 & 0.163139 & 159.87622 \\
\hline 1400 & 0.815692 & 1260 & 0.163138 & 205.55388 \\
\hline 1680 & 0.978844 & 1540 & 0.163152 & 251.25408 \\
\hline 1960 & 1.14212 & 1820 & 0.163276 & 297.16232 \\
\hline 2240 & 1.30549 & 2100 & 0.16337 & 343.077 \\
\hline 2520 & 1.46924 & 2380 & 0.16375 & 389.725 \\
\hline 2800 & 1.6365 & 2660 & 0.16726 & 444.9116 \\
\hline 3080 & 1.83952 & 2940 & 0.20302 & 596.8788 \\
\hline 3360 & 2.14854 & 3220 & 0.30902 & 995.0444 \\
\hline 3640 & 2.61898 & 3500 & 0.47044 & 1646.54 \\
\hline 3920 & 3.22478 & 3780 & 0.6058 & 2289.924 \\
\hline \multirow[t]{2}{*}{4215} & 4.1501 & 4067.5 & 0.92532 & 3763.7391 \\
\hline & & & Total Energy & 11589.2407 \\
\hline
\end{tabular}




\section{Table C-4: Energy Table for Redesigned First Longitudinal Test}

\begin{tabular}{|c|c|c|c|c|}
\hline \multicolumn{4}{|c|}{ Energy under force deflection program using Trapezoid Rules } & \\
\hline \multicolumn{5}{|c|}{$\mathrm{J}=$ integration of the trapezoids under the force deflection curve in figure 8.2} \\
\hline \multicolumn{5}{|l|}{$\begin{array}{l}J=\int_{a}^{b} f(x) d x= \\
F(b)-F(a)\end{array}$} \\
\hline \multicolumn{5}{|c|}{ All the data are given from the ANSYS 6.0 Program } \\
\hline Force (Lb) & Deflection (in) & Force difference & Deflection difference & Trapezoid Energy \\
\hline ANSYS Data & ANSYS Data & $\mathrm{F}=\mathrm{F}(\mathrm{a} 2)-\mathrm{F}(\mathrm{a} 1)$ & $\mathrm{D}=\mathrm{D} 2-\mathrm{D} 1$ & $E=F{ }^{*} D$ \\
\hline 0 & 0 & & & \\
\hline 308.67 & 0.164077 & 25.3228238 & 0 & 25.3228238 \\
\hline 617.33 & 0.328154 & 463 & 0.164077 & 75.967651 \\
\hline 926 & 0.49221 & 771.665 & 0.164077 & 126.6124782 \\
\hline 1234.7 & 0.656308 & 1080.35 & 0.164077 & 177.260587 \\
\hline 1543.3 & 0.820385 & 1389 & 0.164077 & 227.902953 \\
\hline 1852 & 0.984462 & 1697.65 & 0.164077 & 278.5453191 \\
\hline 2160.7 & 1.14858 & 2006.35 & 0.164118 & 329.2781493 \\
\hline 2469.3 & 1.31288 & 2315 & 0.1643 & 380.3545 \\
\hline 2778 & 1.47846 & 2623.65 & 0.16558 & 434.423967 \\
\hline 3086.7 & 1.66797 & 2932.35 & 0.18951 & 555.7096485 \\
\hline 3395.3 & 1.95611 & 3241 & 0.28814 & 933.86174 \\
\hline 3704 & 2.40527 & 3549.65 & 0.44916 & 1594.360794 \\
\hline 4012.7 & 2.99406 & 3858.35 & 0.58879 & 2271.757897 \\
\hline 4321.3 & 3.89329 & 4167 & 0.89923 & 3747.09141 \\
\hline \multirow[t]{2}{*}{4630} & 11.7235 & 4475.65 & 7.83021 & 35045.27939 \\
\hline & & & Total Energy & 46203.7293 \\
\hline
\end{tabular}




\section{Table C-5: Energy Table for Redesigned Side Transverse Test}

\begin{tabular}{|c|c|c|c|c|}
\hline Energy under forc & deflection prog & ram using Trapez & zoid Rules & \\
\hline $\mathrm{J}=$ integration of & e trapezoids un & der the force defl & lection curve in figure 8 & \\
\hline $\begin{array}{l}J=\int_{a}^{b} f(x) d x= \\
F(b)-F(a)\end{array}$ & & & & \\
\hline All the data are gi & en from the $A N$ & SYS 6.0 Program & & \\
\hline Force (Lb) & Deflection (in) & Force difference & Deflection difference & Trapezoid Energy \\
\hline ANSYS Data & ANSYS Data & $\mathrm{D}=\mathrm{D} 2-\mathrm{D} 1$ & $\mathrm{D}=\mathrm{D} 2-\mathrm{D} 1$ & $E=F * D$ \\
\hline 0 & 0 & & & \\
\hline 564 & $9.25 \mathrm{E}-02$ & 26.09396 & 0 & 26.0939676 \\
\hline 1128 & 0.185064 & 846 & 0.0925322 & 78.2822412 \\
\hline 1692 & 0.277595 & 1410 & 0.092531 & 130.46871 \\
\hline 2256 & 0.370206 & 1974 & 0.092611 & 182.814114 \\
\hline 2820 & 0.463424 & 2538 & 0.093218 & 236.587284 \\
\hline 3384 & 0.558001 & 3102 & 0.094577 & 293.377854 \\
\hline 3948 & 0.655488 & 3666 & 0.097487 & 357.387342 \\
\hline 4512 & 0.756802 & 4230 & 0.101314 & 428.55822 \\
\hline 5076 & 0.862748 & 4794 & 0.105946 & 507.905124 \\
\hline 5640 & 0.97419 & 5358 & 0.111442 & 597.106236 \\
\hline 6204 & 1.09356 & 5922 & 0.11937 & 706.90914 \\
\hline 6768 & 1.22977 & 6486 & 0.13621 & 883.45806 \\
\hline 7332 & 1.43395 & 7050 & 0.20418 & 1439.469 \\
\hline 7896 & 1.98921 & 7614 & 0.55526 & 4227.74964 \\
\hline 8306.3 & 4.9383 & 8101.15 & 2.94909 & 23891.02045 \\
\hline 8450 & 7.8 & 8378.15 & 2.8617 & 23975.75186 \\
\hline & & & Total Energy & 57962.93924 \\
\hline
\end{tabular}


Table C-6: Energy Table for Redesigned Second Longitudinal Test.

\begin{tabular}{|c|c|c|c|c|}
\hline Energy under for & deflection progra & am using Trapezo & id Rules & \\
\hline $\mathrm{J}=$ integration of & trapezoids und & ler the force defle & ction curve in figure 8.7 & \\
\hline $\begin{array}{l}J=\int_{a}^{b} f(x) d x= \\
F(b)-F(a)\end{array}$ & & & & \\
\hline All the data are $g$ & from the ANS & YS 6.0 Program & & \\
\hline Force (Lb) & Deflection (in) & Force difference & Deflection difference & Trapezoid Energy \\
\hline ANSYS Data & ANSYS Data & $\mathrm{D}=\mathrm{D} 2-\mathrm{D} 1$ & $\mathrm{D}=\mathrm{D} 2-\mathrm{D} 1$ & $E=F * D$ \\
\hline 0 & 0 & & & \\
\hline 283.33 & 0.153607 & 21.7607 & 0 & 21.76073566 \\
\hline 566.67 & 0.307213 & 425 & 0.153606 & 65.28255 \\
\hline 850 & 0.46082 & 708.335 & 0.153607 & 108.8052143 \\
\hline 1133.3 & 0.614426 & 991.65 & 0.153606 & 152.3233899 \\
\hline 1416.7 & 0.768033 & 1275 & 0.153607 & 195.848925 \\
\hline 1700 & 0.921639 & 1558.35 & 0.153606 & 239.3719101 \\
\hline 1983.3 & 1.07526 & 1841.65 & 0.153621 & 282.9161147 \\
\hline 2266.7 & 1.22895 & 2125 & 0.15369 & 326.59125 \\
\hline 2550 & 1.383 & 2408.35 & 0.15405 & 371.0063175 \\
\hline 2833.3 & 1.54019 & 2691.65 & 0.15719 & 423.1004635 \\
\hline 3116.7 & 1.7339 & 2975 & 0.19371 & 576.28725 \\
\hline 3400 & 2.02899 & 3258.35 & 0.29509 & 961.5065015 \\
\hline 3683.3 & 2.46717 & 3541.65 & 0.43818 & 1551.880197 \\
\hline 3966.7 & 3.02164 & 3825 & 0.55447 & 2120.84775 \\
\hline 4250 & 4.04 & 4108.35 & 1.01836 & 4183.77936 \\
\hline & & & Total Energy & 11581.30788 \\
\hline
\end{tabular}




\section{BIBLIOGRAPHY}

Brewer, Clay D. " Solid Modeling generation and Nonlinear Finite Element Analysis Of Two Post Roll-Over Protective Structure (ROPS) in Accordance with SAE J2194 Static Loading Standard", MS Thesis, West Virginia University, Dept. Of Mechanical and Aerospace Engineering 1996.

Gillispie, Adam. "Optimization of Rollover Protective Structure (ROPS) Using Nonlinear Finite Element Analysis", M.S. Thesis, West Virginia University, Dept. Of Mechanical and Aerospace Engineering 2000.

ASAE Standards " Roll-Over Protective Structures (ROPS) for Wheeled Agricultural Tractor", J2194, December 1997.

Bathe, Klaus-Jurgen, "Finite Element Procedures", Prentice-Hall, Inc. New Jersey, 1996.

Adam and Askenazi. " Building better Products with Finite Element Analysis", Onward Press, Santa Fe, NM, 1999.

Staab, J.E. "Development of ROPS Criteria for construction and Industrial Vehicles". SAE Transactions, PP. 2399-2411, 1971.

Kreyszing, Erwin, "Advanced Engineering Mathematics", seventh edition, Wiley, New York, 1993.

Howard, Steven H. "A Study of Impact Using 80-dermometer Rubber". M.S. Thesis, West Virginia University, Dept. Of Mechanical and Aerospace Engineering 1998.

Harris, James R. "Finite Element Modeling of Rollover Protective Structures for Analysis of Standard ASAES 519", M.S. Thesis, West Virginia University, Dept. Of Mechanical and Aerospace Engineering 1995.

Harris, James R. E.A. McKenzie, Jr., et.al. "Designing Cost Effective Rollover Protective Structures (CROPS) at NIOSH". Paper, Not published yet. 2002 . 